\title{
Investigation of growth dynamics of carbon nanotubes
}

\author{
Marianna V. Kharlamova
}

\author{
Review \\ Address: \\ Faculty of Physics, University of Vienna, Strudlhofgasse 4, 1090 \\ Vienna, Austria \\ Email: \\ Marianna V. Kharlamova - mv.kharlamova@gmail.com \\ Keywords: \\ activation energy; carbon nanotube; growth dynamics; growth rate; \\ synthesis
}

\author{
Beilstein J. Nanotechnol. 2017, 8, 826-856. \\ doi:10.3762/bjnano.8.85 \\ Received: 16 December 2016 \\ Accepted: 23 March 2017 \\ Published: 11 April 2017 \\ Associate Editor: P. Leiderer \\ (c) 2017 Kharlamova; licensee Beilstein-Institut. \\ License and terms: see end of document.
}

\begin{abstract}
The synthesis of single-walled carbon nanotubes (SWCNTs) with defined properties is required for both fundamental investigations and practical applications. The revealing and thorough understanding of the growth mechanism of SWCNTs is the key to the synthesis of nanotubes with required properties. This paper reviews the current status of the research on the investigation of growth dynamics of carbon nanotubes. The review starts with the consideration of the peculiarities of the growth mechanism of carbon nanotubes. The physical and chemical states of the catalyst during the nanotube growth are discussed. The chirality selective growth of nanotubes is described. The main part of the review is dedicated to the analysis and systematization of the reported results on the investigation of growth dynamics of nanotubes. The studies on the revealing of the dependence of the growth rate of nanotubes on the synthesis parameters are reviewed. The correlation between the lifetime of catalyst and growth rate of nanotubes is discussed. The reports on the calculation of the activation energy of the nanotube growth are summarized. Finally, the growth properties of inner tubes inside SWCNTs are considered.
\end{abstract}

\section{Review \\ Introduction}

Single-walled carbon nanotubes (SWCNTs) discovered in 1993 $[1,2]$ possess extraordinary physical, chemical and mechanical properties [3]. They are unique nanoscale objects, because their electronic structure (metallic or semiconducting) is solely dependent on the atomic structure [3,4]. Since the discovery of SWCNTs, attempts of many researchers have been aimed at developing the methods of their efficient synthesis. During last years, significant progress was made in this field. The arc-discharge, laser ablation and chemical vapor deposition (CVD) methods were optimized for the synthesis of SWCNTs in a high yield [5,6]. Synthesis parameters can be varied in a broad range, which leads to the production of SWCNTs with defined morphology and high purity. Although selective synthesis of SWCNTs with certain conductivity type and structure was attempted [7,8], typical as-synthesized samples consist of a mixture of metallic and semiconducting SWCNTs [6]. This causes inhomogeneity of their properties. 
The synthesis of SWCNTs with defined properties is required for both fundamental investigations and practical applications. Despite the fact that the use of SWCNTs in the fields of nanoelectronics [9-12], thin-film flexible electronics [13,14] and bioelectronics [15] was already demonstrated, many applications of SWCNTs were not yet realized. The revealing and thorough understanding of the growth mechanism of SWCNTs is the key to the synthesis of nanotubes with required properties.

The aim of this manuscript is to deliver a comprehensive review of the current status of the research on the investigation of growth dynamics of carbon nanotubes. In the first part of the review, the peculiarities of the growth mechanism of carbon nanotubes are discussed. The well-accepted growth models of nanotubes are highlighted. Among them are the vapor-liquid-solid and vapor-solid-solid models, the tip- and base-growth models as well as the tangential and perpendicular growth modes. The physical and chemical states of the catalyst during the nanotube growth are considered. The chirality selective growth of nanotubes is described. The main part of the review is dedicated to the analysis and systematization of reported results on the investigation of growth dynamics of nanotubes. The models suggested for the description of growth dynamics of nanotubes are presented. The studies on the revealing of the dependence of the growth rate of nanotubes on the synthesis parameters (the pressure of carbon precursor, size and chemical nature of catalyst particle, synthesis temperature) are reviewed. The correlation between the lifetime of catalyst and growth rate of nanotubes is discussed. The reports on the calculation of the activation energy of the nanotube growth are summarized. Finally, the growth properties of inner tubes inside SWCNTs filled with fullerene and organometallic molecules are considered.

\section{Synthesis of carbon nanotubes}

The SWCNTs can be synthesized by the arc-discharge, laser ablation and chemical vapour deposition (CVD) techniques. A detailed overview of these synthesis procedures can be found in previous reviews $[5,6,16,17]$.

The synthesis methods of SWCNTs include also the growth of tubes inside the outer SWCNTs. The inner tubes can be formed inside SWCNTs filled with molecules of fullerenes, metallocenes, acetylacetonates and other precursors, as described in detail in [18].

\section{Growth mechanism of carbon nanotubes}

Although the synthesis of nanotubes with controlled properties can be performed in the CVD process, the growth mechanism of nanotubes is not completely understood and is still debated.

\section{Nanotube growth in the CVD process}

Vapor-liquid-solid and vapor-solid-solid growth models. In the 1970s, Baker with co-authors suggested in [19-21] that the growth of carbon filaments occurred by the vapor-liquid-solid (VLS) model, which was previously developed by Wagner and Ellis to explain the growth of silicon whiskers [22]. In the growth process of Si whiskers, the initial condition was the formation of a liquid droplet of the alloy of Si with Au impurity on a Si wafer. The liquid Au-Si alloy acted as a preferred sink for the deposition of $\mathrm{Si}$ atoms from the vapor that was obtained as a result of the thermally-induced decomposition of gaseous $\mathrm{SiCl}_{4}$. As soon as the liquid alloy particle was supersaturated, the growth of the whisker started. It occurred by the precipitation of $\mathrm{Si}$ atoms from the droplet at the interface between solid $\mathrm{Si}$ and liquid alloy. As a result, the alloy droplet was displaced from the Si substrate crystal to the tip of the growing whisker [22]. Thus, the VLS model of Wagner and Ellis implied two hypotheses: (i) the particle was liquid and (ii) the diffusion of reactant atoms occurred through the bulk of the particle.

The use of the VLS model for the growth of carbon filaments and nanotubes received massive support, because the activation energies of the growth calculated by Baker with co-authors were in good agreement with the activation barriers of the bulk carbon diffusion through the corresponding metals, which was defined as the growth rate-limiting process [19-21]. However, Baker with co-authors compared the calculated activation energies with those of the bulk carbon diffusion through metals in the solid state and not in the liquid state. Therefore, their results supported only the bulk diffusion hypothesis of the VLS model and contradicted the liquid particle hypothesis. The employment of the term "VLS model" for the description of the growth mechanism on solid catalyst particles is often misleading. The considered hypothesis of the VLS model should be preferably specified [23].

The VLS model in its classical interpretation, which obeys two hypotheses of Wagner and Ellis, was used to explain the growth of carbon filaments on liquid catalysts [24-26]. Later on, the VLS model was applied to describe the growth of MWCNTs [27] and SWCNTs [28,29] on liquid-metal particles. The atomic-level description of the VLS growth process of SWCNTs was performed by molecular dynamics simulations [29-32].

There are three different steps in the VLS growth mechanism of carbon filaments and nanotubes. In the first step, atomic carbon is provided on the surface of a hot metallic particle by dissociation of adsorbed molecules. In the second step, carbon dissolves into the bulk of the catalyst particle. A liquid carbon-metal solution is formed. Carbon diffuses through the liquid particle. 
In the third step, when the carbon-metal solution becomes saturated the dissolved carbon precipitates in the form of cylindrical or tubular networks of $\mathrm{sp}^{2}$ carbon $[33,34]$.

The motor for the directed diffusion from the dissociating surface to the precipitating surface through the bulk of the catalyst particle was actively debated. Originally a temperature gradient across the catalyst particle was suggested as a driving factor for the bulk diffusion by Baker and coworkers [19]. The temperature gradient would be maintained by the exothermic catalytic decomposition of the precursor molecules and the endothermic precipitation of carbon at opposing face of the catalyst particle. However, these requirements are not met in the case of endothermic decomposition of for instance alkanes [33,35-37] and the hypothesis of a temperature gradient is further challenged for small $\mathrm{nm}$ sized particles, which can grow singlewalled carbon nanotubes. It is unlikely to play an important role in the growth of SWCNTs, because small catalytic particles have a high thermal conductivity and therefore the temperature gradient would lead to an unphysically large heat flow [30,32]. Molecular dynamics simulations performed in [30,32] showed that the carbon concentration gradient within the catalytic particle is important for the VLS growth of SWCNTs, whereas the temperature gradient is not necessary. Thermodynamic calculations conducted in [38] also indicated that the nanotube growth is mainly driven by the carbon concentration gradient in the catalytic particle.

In the late 1970 s, Oberlin with co-authors suggested an alternative mechanism to the VLS process for the description of the growth of hollow carbon filaments [39]. It implied the carbon diffusion on the surface of the metallic catalytic particle and not in its bulk. Later on, this growth mechanism was used by other authors to explain the formation process of carbon nanofibers [40-42] and nanotubes [43]. In [42], Hofmann with co-authors provided the surface diffusion model for the growth of carbon fibers on metallic catalysts on the basis of the fact that the calculated activation energies of the growth were much lower than those of the bulk carbon diffusion in the metal. They suggested that the surface carbon diffusion on the catalytic particle was also the rate-limiting step of the growth. The authors of [43] applied the surface diffusion model to explain fast growth rates of SWCNTs in the thermal CVD process at temperatures as low as $600{ }^{\circ} \mathrm{C}$. In [41], Helveg with co-authors performed the first time-resolved in situ HRTEM studies on the formation of carbon nanofibers on nickel nanoparticles and suggested the growth mechanism involving the surface diffusion. They observed the movement of atoms on the surface of the crystalline nickel cluster and change of its shape during the growth process. It was concluded that the surface transport of carbon atoms was the growth rate-limiting process. The surface diffusion mechanism of the growth of carbon nanofibers and nanotubes on metallic catalysts was also revealed by theoretical methods $[41,42,44]$. In [44], Raty with co-authors reported ab initio molecular dynamics simulations of the formation of SWCNTs on metallic nanoparticles. They showed that the SWCNT growth on $\approx 1 \mathrm{~nm}$ Fe particles occurred without the diffusion of carbon atoms into the bulk of the catalyst. The carbon diffusion on the surface of the particle was much faster than the bulk diffusion.

Because the surface diffusion mechanism is observed for the growth of carbon nanofibers and nanotubes on solid catalysts, it is often called the vapor-solid-solid (VSS) mechanism, by the analogy to the VLS mechanism. Particularly, this term is used in several reviews $[33,34,45]$. The authors of [33] describe the VSS mechanism by three steps, including the dissociation of gaseous carbon precursor on the surface of the catalytic particle, the surface diffusion of carbon atoms on the solid particle and the precipitation of carbon in the form of nanotubes. The similarity of the terms "VLS" and "VSS" and different types of the carbon diffusion involved in these growth mechanisms may be misleading. Moreover, there is no special term for the growth mechanism that includes the bulk carbon diffusion through the solid catalytic particle. Preferably, one should clearly mention the type of carbon diffusion while using the term "VSS model" for the growth of nanotubes.

The formation of nanotubes on nonmetallic catalysts has peculiarities as compared to the growth on metals [46-49]. Catalytic nanoparticles of diamond [47], zirconia [48] and silica [46,49] have negligibly small bulk solubility of carbon, and it is therefore unlikely that the bulk carbon diffusion contributes to the nanotube growth. It was reported that the formation of SWCNTs on solid nonmetallic catalysts is promoted by the surface diffusion of carbon, suggesting the VSS growth mechanism [46-49].

Figure 1 compares the classical VLS mechanism of the SWCNT growth on the metallic catalytic particle and the VSS mechanism of the growth on the $\mathrm{SiO}_{2}$ nanoparticle [46].

Physical state of catalyst. The diameter of metallic catalytic particles for the production of nanotubes varies from one to tens of nanometers. Decreasing the diameter of the metallic particles to the nanometer scale leads to an increase in the ratio of surface atoms to internal atoms [50]. The surface atoms are electronically and coordinatively unsaturated. This leads to changed physical and chemical properties of nanoparticles in comparison to the bulk metal, for example, lower melting temperature and higher carbon solubility [50]. 
(a)

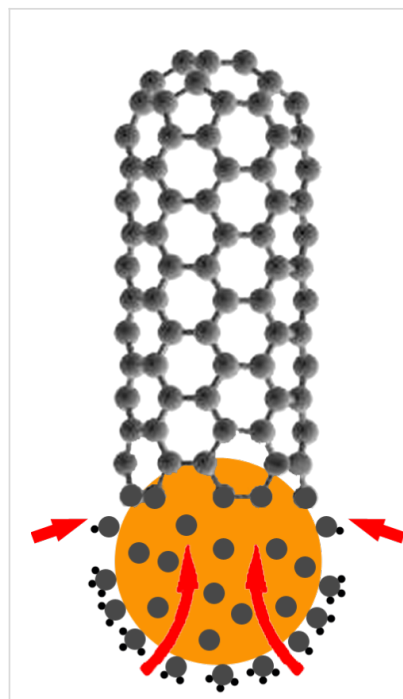

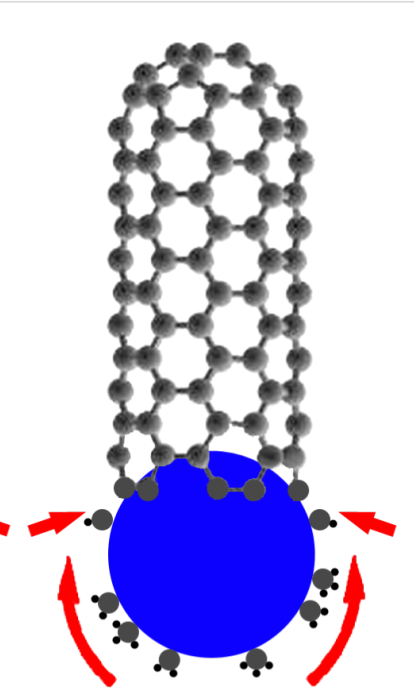

(b)
Figure 1: The comparison of the VLS mechanism of the SWCNT growth on the metallic catalytic particle (a) and the VSS mechanism of the growth on the $\mathrm{SiO}_{2}$ nanoparticle (b). In the VLS growth model (a), a gaseous carbon precursor adsorbs and dissociates on the surface of the metallic catalytic particle (orange ball). The obtained carbon atoms (grey balls) get dissolved into the metal and diffuse through the bulk of the liquid particle (as shown by large red arrows). After reaching the supersaturation, the dissolved carbon precipitates at the rear side of the particle to form a nanotube (as shown by small red arrows). In the VSS growth model (b), after the dissociation of a carbon precursor, carbon atoms diffuse on the surface of the solid catalytic particle (blue ball) and precipitate in the form of a nanotube. Figure is redrawn with modifications from [46]

The melting temperature of metallic catalytic particles is lowered by two effects. Firstly, the melting temperature of the particle $\left(T_{\mathrm{p}}\right)$ with the radius $r$ is decreased by the Gibbs-Thomson effect by the equation:

$$
T_{\mathrm{p}}=T_{0}-\frac{2 T_{0}}{\Delta H_{\text {fusion }} \rho_{\mathrm{s}} r}\left(\sigma_{\mathrm{sl}}+\left(1-\frac{\rho_{\mathrm{s}}}{\rho_{1}}\right) \sigma_{1}\right)
$$

where $T_{0}$ is the bulk melting temperature of a metal, $\Delta H_{\text {fusion }}$ is the latent heat of fusion, $\rho_{\mathrm{s}}$ and $\rho_{1}$ are the densities of solid and liquid metal, respectively, $\sigma_{\mathrm{sl}}$ is the solid-liquid interfacial energy and $\sigma_{1}$ is the surface energy of the liquid [50,51] Figure 2 demonstrates the melting temperature of iron, nickel, gold and silver particles as a function of the diameter [50]. It is seen in Figure 2 that the melting temperature is decreased from the bulk value for particles with a diameter below $100 \mathrm{~nm}$, and a noticeable decrease is observed below $10 \mathrm{~nm}$. On the basis of this calculation, the authors of [50] conclude that the catalytic particles with diameter of $1-3 \mathrm{~nm}$ should be in a liquid form at typical synthesis conditions of nanotubes.

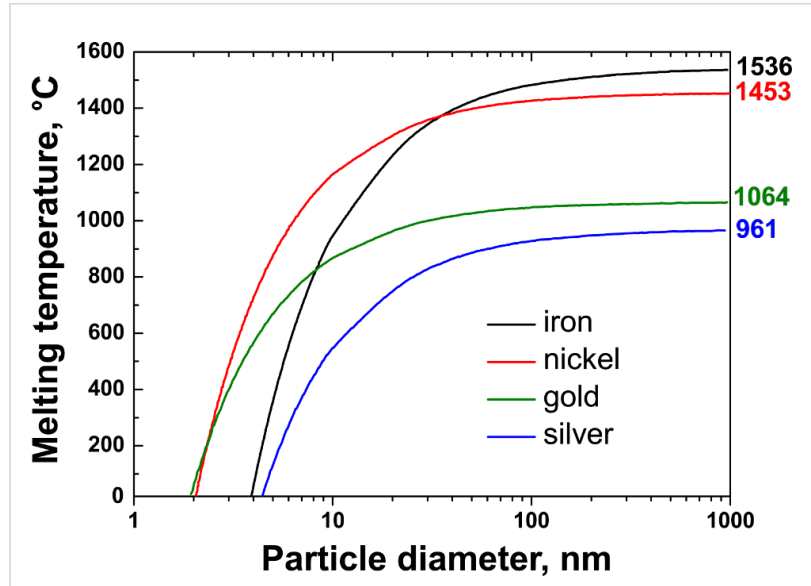

Figure 2: The melting temperature of iron, nickel, gold and silver particles as a function of the diameter. The data are replotted from [50].

Secondly, the melting point of catalytic particles is decreased by forming a eutectic with carbon [52]. In [52], it was calculated that melting points of iron particles with diameters of 1-2 nm, which catalyze the SWCNT growth, can be reduced by up to $700-800{ }^{\circ} \mathrm{C}$, down to $550{ }^{\circ} \mathrm{C}$. This trend was confirmed by molecular dynamics simulations [53-55]. There are also experimental reports on the presence of catalytic particles in the liquid state during the growth of MWCNTs [27] and SWCNTs [56].

The authors of [52] suggest that for the bulk CVD such as in the injection methods for growing SWCNTs that use temperatures in the order of $1000{ }^{\circ} \mathrm{C}[57,58]$, the catalyst is likely to be in the liquid state. However, in situ TEM observations on the growth of SWCNTs and MWCNTs by the catalytic thermal decomposition of hydrocarbons on metallic and carbidic nanoparticles at temperatures up to $650{ }^{\circ} \mathrm{C}$ demonstrated that the particles remained crystalline during the growth process, although their shape was modified [41,59-62]. In particular, it was shown that crystalline Ni nanoparticles with a size down to $\approx 4-5 \mathrm{~nm}$ catalyzed the growth of nanotubes at temperatures as high as $540{ }^{\circ} \mathrm{C}$ [41] and $615^{\circ} \mathrm{C}$ [59]. The authors of [61] observed the growth of SWCNTs with a diameter as small as $1.5 \mathrm{~nm}$ on the solid $\mathrm{Fe}_{3} \mathrm{C}$ nanoparticle that exhibited structural fluctuations at $600{ }^{\circ} \mathrm{C}$. Also, they observed the growth of $\approx 15-20 \mathrm{~nm}$ diameter MWCNTs on the crystalline $\mathrm{Fe}_{3} \mathrm{C}$ nanoparticles. The TEM data testified that carbon atoms migrated through the bulk of nanoparticles during the nanotube growth.

Figure 3 presents environmental and high-resolution TEM images of various stages of SWNT growth on Ni catalytic particles [59]. The ETEM images in Figure 3a,b recorded at $615^{\circ} \mathrm{C}$ show Ni particles for which SWCNT nucleation has stopped early. On top of each catalyst particle, a small-sized carbon cap is visible. Crystalline lattice fringe contrast is seen in the Ni par- 
ticle, as marked by white lines. The authors of [59] assigned strong reflections in the fast Fourier transform (FFT) of Figure $3 b$ to $\{111\}$ planes, with the face-centered cubic (fcc) Ni lattice oriented close to the [110] axis. Figure $3 \mathrm{c}, \mathrm{d}$ show ex situ HRTEM images of SWCNTs. Figure $3 \mathrm{c}$ presents an individual hemispherically capped SWCNT at a more progressed stage of growth. It is oriented tangentially to the Ni catalyst cluster. Figure $3 \mathrm{~d}$ demonstrates low-magnification image of several synthesized nanotubes.

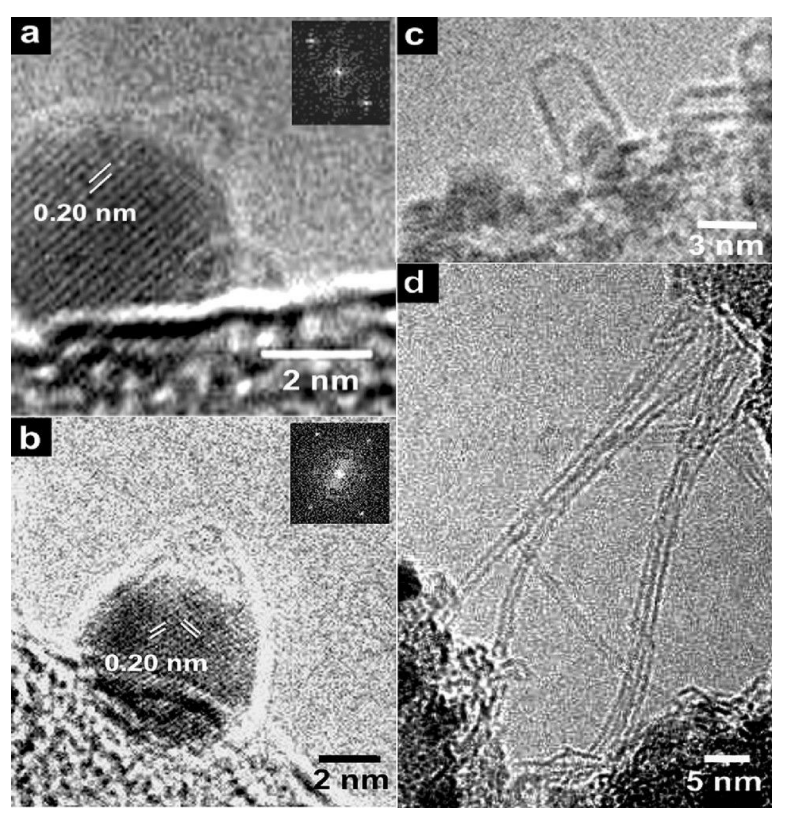

Figure 3: $(a, b)$ Environmental TEM images of Ni crystalline nanoparticles recorded at $615^{\circ} \mathrm{C}$. White lines mark crystalline lattice fringes and numbers denote spacing between neighboring fringes. The insets present FFTs of the corresponding particles. (c,d) Ex situ HRTEM micrographs obtained for the same sample. Reprinted with permission from [59], copyright 2007 American Chemical Society.

Chemical state of catalyst. The chemical state of catalyst during the nanotube growth was actively debated. The following three main questions were discussed. (i) Whether metallic catalyst particles do transform to carbide particles during the growth process? (ii) Whether sub-surface intermediate carbide is formed on the metallic particles? (iii) Whether the synthesis on purely metal carbide catalytic particles is possible?

Despite the fact that several authors reported that purely metallic particles catalyze the nanotube growth $[52,59,63,64]$, the authors of [65] performed X-ray diffraction studies (XRD) of catalytic nanoparticles of different chemical elements and showed that "typical" catalysts such as $\mathrm{Fe}, \mathrm{Ni}$ and Co underwent carburization during the induction phase of the synthesis (the period until the achievement of carbon precipitation), which disappeared after the growth process. In all cases, the metal underwent carburization before the growth of nanotubes was initiated. However, the authors of [65] mentioned that the core of nanoparticles possibly remained as pure metal. For "atypical" catalysts such as W, the carburization was observed both after induction and growth of nanotubes. On the basis of standard thermodynamic data, the authors of [65] concluded that any purely metallic catalyst should become carburized under common growth temperatures of nanotubes. Figure $4 a-d$ shows the changes in Gibbs free energy for the reaction between $\mathrm{Ni}$ and different carbon precursors $\left(\mathrm{CO}, \mathrm{CH}_{4}, \mathrm{C}_{2} \mathrm{H}_{4}\right.$ and $\mathrm{C}_{2} \mathrm{H}_{2}$ ). According to these data, nickel carbide forms under a broad range of temperatures for the reaction with $\mathrm{C}_{2} \mathrm{H}_{4}$ and $\mathrm{C}_{2} \mathrm{H}_{2}$ (Figure $4 \mathrm{a}, \mathrm{b}$ ), while temperatures higher than $800 \mathrm{~K}$ are needed for the reaction with $\mathrm{CO}$ and $\mathrm{CH}_{4}$ (Figure 4c,d). The negative changes in Gibbs free energy increase in the line with $\mathrm{CO}, \mathrm{CH}_{4}, \mathrm{C}_{2} \mathrm{H}_{4}$ and $\mathrm{C}_{2} \mathrm{H}_{2}$. This explains why $\mathrm{C}_{2} \mathrm{H}_{2}$ is one of the most reactive carbon precursors for the nanotube synthesis. The changes in Gibbs free energy for the reaction between $\mathrm{C}_{2} \mathrm{H}_{2}$ and different metallic catalysts (Ni, Co, Fe, W and $\mathrm{Mo}$ ) are presented in Figure $4 \mathrm{e}-\mathrm{i}$. The formation of metal carbides is predicted at the elevated temperatures during nanotube growth for all these metals. The largest increases in Gibbs free energy are predicted for the reactions with $\mathrm{Ni}, \mathrm{Co}$ and $\mathrm{Fe}$ [65].

The transformation of purely metallic catalysts into metal carbides with their subsequent decomposition before the nanotube growth was also observed by other authors [66-69]. This implies the decomposition of metal carbides as an elementary step of carbon nanotube synthesis [69]. In [66,67], XRD studies revealed the formation of iron oxides and carbide before the nanotube growth. Iron carbide was observed immediately before the start of the growth [67], and the process of its decomposition to $\mathrm{Fe}$ and graphite coincided with the onset of the nanotube growth [66]. In [68], time-resolved XPS studies showed the formation of chemisorbed carbon on Fe catalyst and carbidic carbon before the nanotube growth, with their further transformation to $\mathrm{sp}^{2}$ graphitic carbon network.

The question of the formation of the intermediate metastable carbidic phases during the nanotube growth was also actively debated. In the last decades, it was reported that metal nanoparticles can undergo partial carburization, i.e., the chemical transformation of metal into metal carbide, and subsequent reverse decomposition during the synthesis of carbon filaments and nanotubes by the catalytic thermal decomposition of hydrocarbons. In 1970-1980s, the growth of carbon filaments on metallic iron catalyst was actively studied by Buyanov and Chesnokov, and a carbide cycle mechanism of the growth was proposed [70-75]. According to this mechanism, a metastable carbide-like intermediate compound was formed in the subsurface layer of a catalytic particle as a result of the decomposition 

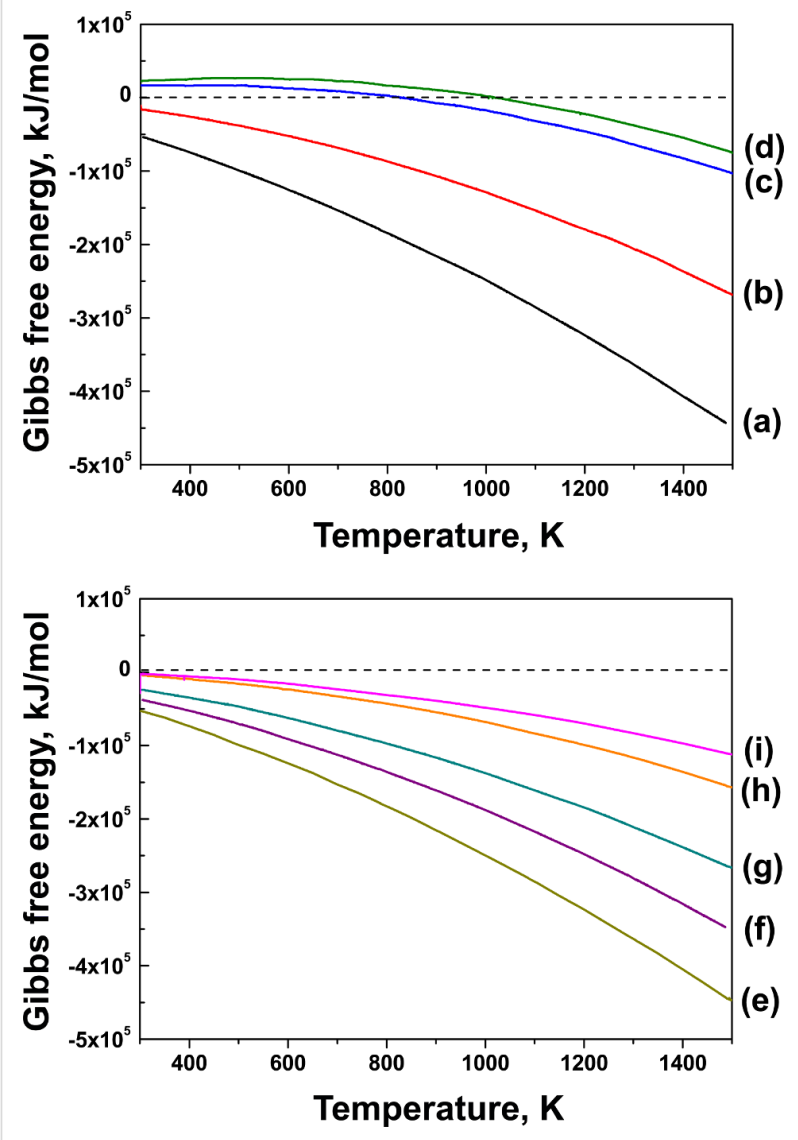

Figure 4: Calculated changes in Gibbs free energy for the reaction of $\mathrm{Ni}$ with (a) $\mathrm{C}_{2} \mathrm{H}_{2}$, (b) $\mathrm{C}_{2} \mathrm{H}_{4}$, (c) $\mathrm{CH}_{4}$ and (d) CO. Calculated changes in Gibbs free energy for the reaction of $\mathrm{C}_{2} \mathrm{H}_{2}$ with (e) Ni, (f) $\mathrm{Co}$, (g) $\mathrm{Fe}$, (h) $\mathrm{W}$ and (i) Mo. The data are replotted from [65].

of hydrocarbon. The decomposition of intermediate carbide led to the supersaturation of metal by carbon. Indeed, the degradation of iron carbide $\mathrm{Fe}_{3} \mathrm{C}$ results in the mixture of carbon and iron with a carbon content of 6-7 wt \%, whereas the saturated solid solution of carbon in iron contains not less than 0.025 wt \% carbon [75]. Thus, a large carbon concentration gradient was created in the bulk of the catalytic particle. This caused the diffusion of carbon atoms from the surface where the hydrocarbon was decomposed through the bulk of metal to the sites of the crystallization into a graphite phase (carbon filaments). The degraded intermediate carbide was restored as a result of the decomposition of hydrocarbon, and this cyclic process took place as long as there were the gaseous source of carbon and active catalyst in the system. A carbide cycle mechanism was proven for the growth of carbon filaments by the decomposition of different hydrocarbons (methane, butane, propylene, isobutylene, butadiene, benzene) on iron catalyst [75] Other authors also reported the formation of intermediate iron carbide phases during the growth of filaments [76-80]. More recent studies on the CVD growth of nanotubes evidenced the presence of intermediate iron carbide and discussed its role in the tube formation $[65,69,81-84]$.

A smaller number of reports was dedicated to the investigation of the chemical state of nickel catalyst during the growth of carbon filaments and nanotubes. The formation of intermediate carbide phases was revealed for nickel catalysts, as in the aforementioned cases of iron catalysts. Buyanov and Chesnokov reported that the above-described carbide cycle mechanism is applied for the growth of carbon filaments on metallic nickel catalyst [75,85-87]. The authors of [88] also observed the formation of intermediate nickel carbide during the growth of filaments. Recent studies on the growth of nanotubes by the CVD method confirmed the presence of an intermediate nickel carbide phase in the nickel catalyst $[65,69,84]$.

The presence of intermediate carbide phases was also reported for cobalt catalysts. Buyanov and Chesnokov suggested that the carbide cycle mechanism could be applied to the growth of carbon filaments on all iron-group metal catalysts, including cobalt [75]. The authors of recent studies on the growth of nanotubes by the CVD method $[65,69,84]$ also showed that iron, cobalt and nickel catalysts followed a similar reaction path with the formation of intermediate carbide phases during the synthesis process.

It should be noted that the formation of intermediate carbide phases was not usually confirmed by in situ TEM analysis of the nanotube growth on nickel catalyst $[41,59,64]$. This is probably caused by the fact that metal and carbide have rather similar lattice constants and thus they can not be easily distinguished by diffraction and TEM [52], especially in the case of partial carburization of catalyst particle at its surface [65]. However, in situ TEM confirmed the structure of iron and cobalt carbides when they were the active catalyst phase of the nanotube growth [61,62,81,89-91].

Some authors reported that iron carbide formed from metallic iron did not decompose and thus it was not an intermediate phase, but served as catalyst of the nanotube growth $[67,89,90,92]$. The stability of $\mathrm{Fe}_{3} \mathrm{C}$ structure was explained by special synthesis conditions, in particular high pressure of hydrocarbon and too low synthesis temperatures for the decomposition of iron carbide [89], which is known to be stable until $\approx 700-750{ }^{\circ} \mathrm{C}[93,94]$. In [90], it was demonstrated that the growth mechanism of nanotubes depended on the phase composition of iron catalyst nanoparticles. It was found that for $\gamma-\mathrm{Fe}$ rich mixtures, metallic iron was the active catalyst phase for the tube growth, implying that the transformation to iron carbide was not necessary (however, the formation of subsurface car- 
bon-rich phases and bulk Fe-C solid solutions were not excluded). In contrast, for $\alpha$-Fe rich mixtures, $\mathrm{Fe}_{3} \mathrm{C}$ formation was dominant and constituted the part of the growth process. On the basis of the data, it was concluded that kinetic effects dominated the catalyst phase evolution.

Other authors also proved that metal carbide can be an active catalyst for the nanotube growth $[61,62]$. The authors of [61] performed the synthesis of SWCNTs and MWCNTs using $\mathrm{C}_{2} \mathrm{H}_{2}$ as carbon source and iron carbide catalyst. Figure $5 \mathrm{a}$ shows in situ HRTEM micrographs of the growth process of individual SWCNT. Before the nucleation of SWCNT, the catalyst nanoparticle shows in every snapshot different facets (e.g., $t=8.05$ and $16.45 \mathrm{~s}$ ). Various carbon cages jut out from the particle frequently and disappear in a few seconds $(t=5.25,13.3$ and $29.05 \mathrm{~s})$. The unstable carbon cage and particle change their shape rapidly (e.g., $t=13.3$ and $29.05 \mathrm{~s}$ ). After an incubation period, the stable dome, which is the nucleus of SWCNT, appears at $t=35.35 \mathrm{~s}$. It grows gradually into $1.5 \mathrm{~nm}$ diameter SWCNT with a length of $3.6 \mathrm{~nm}$ (from $t=40.6 \mathrm{~s}$ to $t=51.8 \mathrm{~s}$ ) [61].

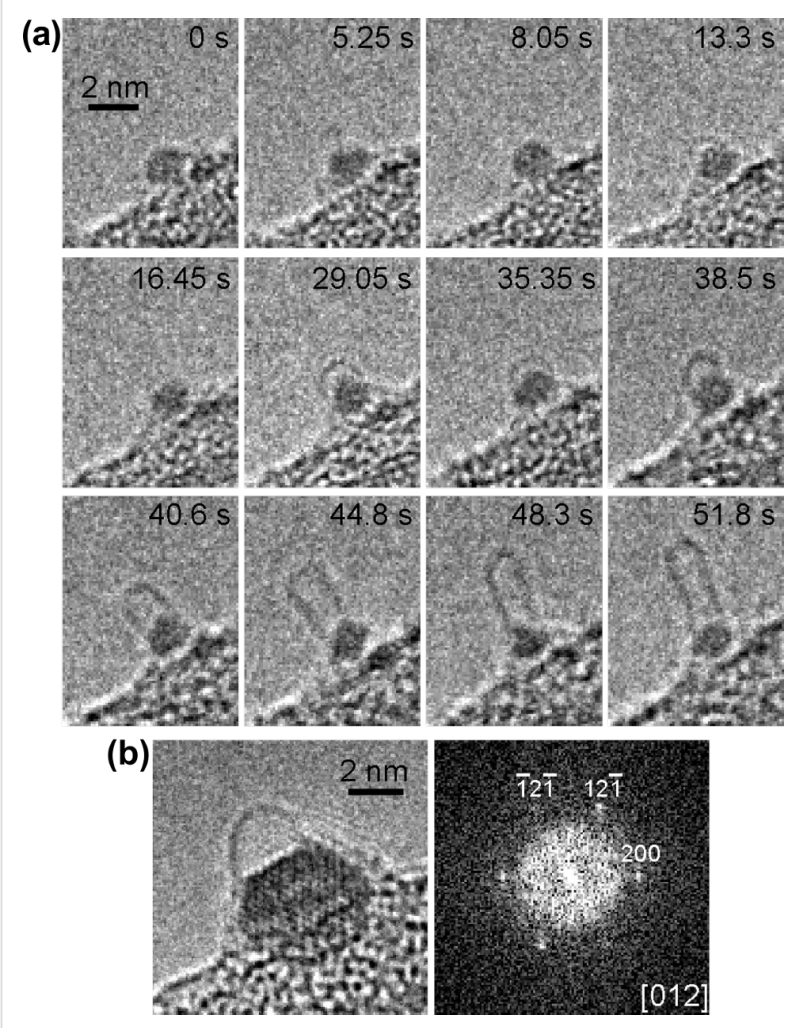

Figure 5: (a) In situ HRTEM micrographs of the nucleation and growth of an individual SWCNT on the catalyst nanoparticle. The recording time of snapshots is denoted. (b) A micrograph of the nanoparticle with a carbon dome. The particle exhibits the lattice image and the respective extra diffraction in the Fourier transform. The particle is identified as iron carbide $\mathrm{Fe}_{3} \mathrm{C}$ viewed along the [012] direction. Reprinted with permission from [61], copyright 2008 American Chemical Society.
Figure $5 \mathrm{~b}$ demonstrates a micrograph of the nanoparticle with a carbon dome. The particle exhibits the lattice image and the respective extra diffraction in the Fourier transform. The particle is identified as iron carbide $\mathrm{Fe}_{3} \mathrm{C}$ viewed along the [012] direction [61].

Tip- and base-growth models. Two growth models were reported for the formation of nanotubes on catalysts with a substrate, which differ in the position of growing nanotube relative to the catalytic particle: tip- and base-growth models [34,45]. In the tip-growth model, precursor molecules dissociate at the active face of catalyst particle. The carbon is dissolved, diffuses through the bulk and is incorporated into a growing nanotube. This mechanism pushes the catalyst particle that resides at the growing tip further away from the substrate. The growth of the nanotube continues as long as fresh feedstock is supplied, unless the catalyst particle becomes deactivated by an impermeable carbon shell. In the base-growth model, the initial precursor dissociation and carbon diffusion occur similarly to those in the tip-growth model, but the carbon precipitation and nanotube formation do not lead to lifting the catalytic particle from the substrate. Carbon precipitates on the apex of the metal, as far as possible from the substrate. The nanotube growth starts from the formation of a hemispherical dome, which is the most preferable closed-carbon structure on a spherical particle. Subsequent hydrocarbon dissociation occurs on the lower surface of the particle, and carbon atoms diffuse upward in the metal. This leads to the elongation of the nanotubes above the particle that remains attached to the substrate [34].

The interaction between the catalyst particle and substrate decides whether the nanotube growth will follow the tip- or base-growth mechanism $[34,45]$. When the interaction is weak (there is an acute contact angle between the catalytic particle and substrate), the tip-growth model is realized. When the interaction is strong (there is an obtuse contact angle between the particle and substrate), the base-growth model is favored [34]. The growth of MWCNTs from Fe catalyst was observed to follow either growth mechanism on different substrates. Namely, the tip-growth on $\mathrm{SiO}_{2}$ and base-growth on $\mathrm{Ta}$ [95]. The authors of [95] found that the catalytic particles on Ta had a hemispherical shape, whereas the particles on $\mathrm{SiO}_{2}$ had a bead shape. The contact angles of the Fe catalyst particles with the $\mathrm{SiO}_{2}$ and Ta substrates revealed that the tip-growth was observed when the surface energy of the bare substrate was smaller than that of the catalyst-substrate interface and the basegrowth was observed in the opposite case.

The base-growth was reported for MWCNTs in [61,96,97] and SWCNTs in $[29,59,61,64,98]$. The tip-growth was observed for MWCNTs in $[41,59,60,81]$ and SWCNTs in [99-101]. In 
[41,59-61,64,99], time-resolved in situ HRTEM was employed for the investigation of the nanotube growth and was shown to be a powerful technique for revealing the growth mechanism. The authors of [59] used environmental HRTEM to study the base-growth of SWCNTs from the acetylene decomposition on $\mathrm{Ni}$ nanoparticles with $\mathrm{SiO}_{\mathrm{x}}$ substrate at $615{ }^{\circ} \mathrm{C}$. Figure 6 demonstrates the HRTEM image sequence of the consecutive stages of the growth, which was extracted from a continuous video recording [59]. The SWCNT growth started from the formation of a carbon cap on the apex of the triangular/pyramidal metallic particle. It replicated the shape of the apex and had smaller diameter than the particle (Figure 6a). The apex of the particle acquired a cylindrical shape, lifting the carbon cap from the particle and forming the nanotube. The growing SWCNT forced further cylindrical reshaping of the particle, which led to increasing the contact angle of the particle with the substrate to approximately $90^{\circ}$ (Figure $6 \mathrm{~b}$ ). The growth process stopped when the nanotube encapsulated the particle down to its substrate interface (Figure 6c). The schematic representation of the above-described stages of the SWCNT growth in a ball-andstick model is shown in Figure 6d-f [59].

It should be noted that although the base-growth of SWCNTs was commonly observed in a number of reports $[29,59,61,64,98]$, the authors of [99-101] demonstrated the growth of SWCNTs by the tip-growth mechanism. In [101], long and aligned SWCNTs were synthesized by the fast-heating CVD process. It was proven that although both growth mechanisms coexisted in the experiments, long and oriented nano- tubes were produced only by the tip-growth mechanism. In [100], SWCNTs were synthesized by the low-temperature CVD process using two different types of $\mathrm{Co}_{\mathrm{x}} \mathrm{Mg}_{1-\mathrm{x}} \mathrm{O}$ catalysts prepared by atomic layer deposition and impregnation. It was shown that the catalyst prepared by atomic layer deposition catalyzed the growth of SWCNTs by the tip-growth mode, whereas the catalyst prepared by impregnation catalyzed the basegrowth of nanotubes. This was explained by weak interactions between Co nanoparticles and $\mathrm{MgO}$ support in the catalyst prepared by atomic layer deposition and extremely strong metalsupport interactions between epitaxial Co nanoparticles and $\mathrm{MgO}$ support in the catalyst prepared by impregnation.

Tangential and perpendicular growth modes. In the recent years, the other two growth modes relying on the diameter ratio between SWCNT and catalyst particle size has become more and more important in controlling SWCNT diameter and even chirality [102-104].

In [102], the statistical analysis of the TEM data was conducted in order to elucidate the correlation between the sizes of SWCNTs or nuclei and the nanoparticles on which they grow. They proved the existence of two nucleation and growth modes of nanotubes: tangential and perpendicular modes. In the tangential growth mode, the carbon wall of growing nanotube is oriented tangentially to the surface of nanoparticle. As a result, the diameter of grown nanotube is close to that of the nanoparticle. In the perpendicular growth mode, the carbon wall of growing nanotube is oriented perpendicular to the surface of

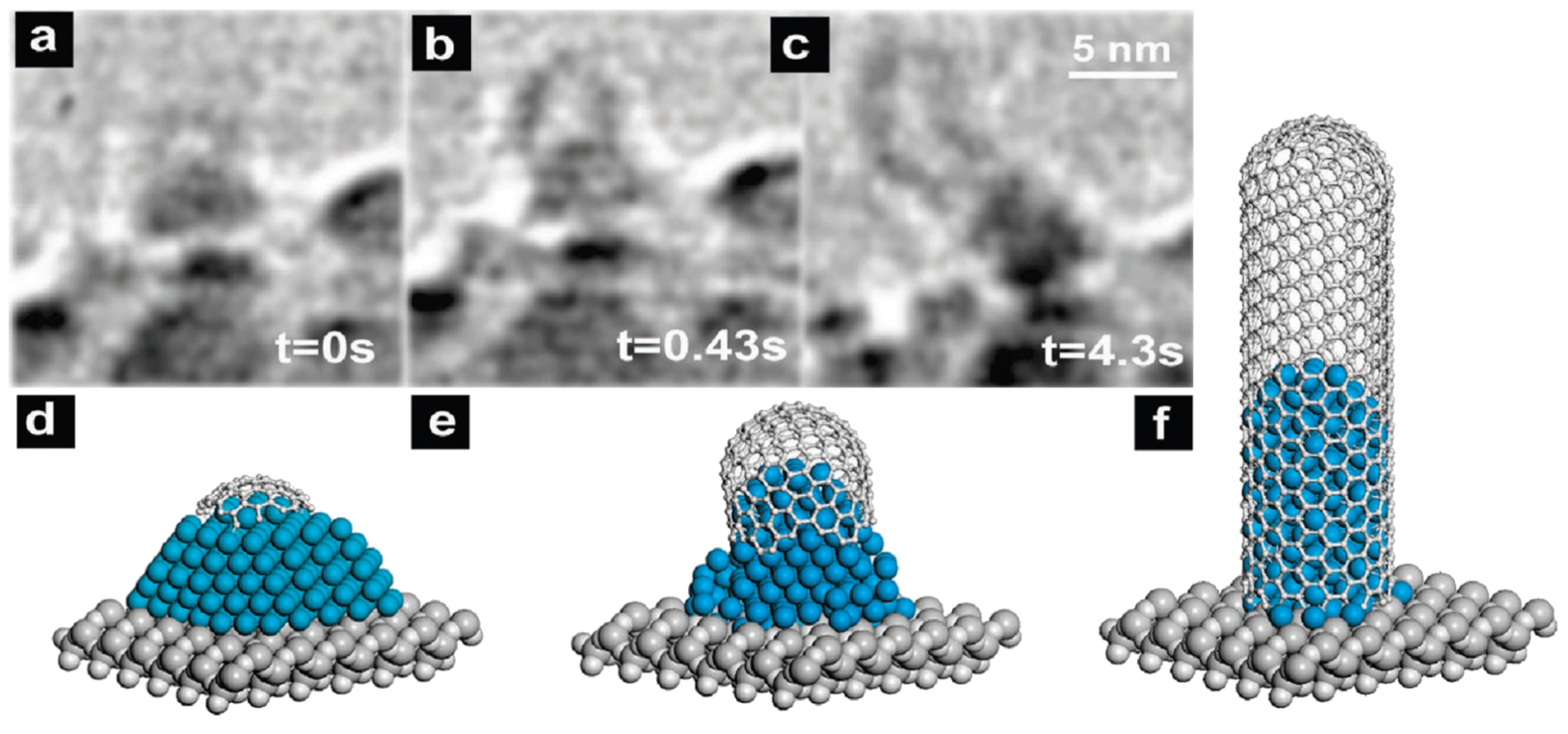

Figure 6: $(\mathrm{a}-\mathrm{c})$ The environmental HRTEM image sequence of the consecutive stages of the base-growth of SWCNT on Ni catalytic nanoparticle with $\mathrm{SiO}_{\mathrm{x}}$ substrate using $\mathrm{C}_{2} \mathrm{H}_{2}$ as carbon precursor at $615^{\circ} \mathrm{C}$. The sequence was extracted from a continuous video recording. The time of the corresponding snapshots is denoted. (d-f) The schematic ball-and-stick model of the stages of the nanotube growth. Reprinted with permission from [59], copyright 2007 American Chemical Society. 
nanoparticle. As a result, the diameter of grown nanotubes is smaller or not correlated with that of the nanoparticle. From statistical observations it was concluded that the growth mode is perpendicular if the ratio of the diameters of nucleus of the nanotube and nanoparticle is lower than 0.75 . It was shown that both growth modes do not depend on the diameter of nanoparticle. The growth mode was demonstrated to be dependent on the synthesis time. At short times ( $40 \mathrm{~s}$ and $2 \mathrm{~min}$ ), the perpendicular growth was observed, whereas at long times (10 and $30 \mathrm{~min}$ ) the tangential mode was dominant. Using tight binding Monte Carlo simulations, it was shown that the tangential growth occurs at reaction conditions that are close to equilibrium, whereas the perpendicular growth occurs at conditions driven by kinetic effects. On the basis of the data, the authors of [102] concluded that the control of chirality of nanotubes should be searched at reaction conditions that are close to thermodynamic equilibrium, when the tangential growth is favored.

The authors of [103], investigated the correlation between the growth mode and the lengths of SWCNTs. Using TEM, they showed that the length of SWCNTs depended on the ratio of diameters of nanotube and nanoparticle, i.e. the growth mode. The SWCNTs grown in perpendicular mode were much longer than those grown in tangential mode. Using Monte Carlo computer simulations, the authors of [103] demonstrated that nanoparticles with low carbon concentration (4\%) catalyzed the tangential growth of SWCNTs, where the particle wets the inner wall of nanotube and can be easily passivated by encapsulating graphitic layers, which leads to stopping of the growth and formation of short SWCNTs. In contrast, the nanoparticles with high carbon concentration (18\%) catalyzed the perpendicular growth of SWCNTs and kept their activity for longer time, which led to the formation of long SWCNTs.

In [104], the control of the growth mode of SWCNTs led to the synthesis of semiconducting SWCNTs with a narrow band-gap distribution. SWCNTs were grown on acorn-like partially carbon-coated Co nanoparticles. The inner Co particle was an active catalytic phase, whereas the outer carbon layer prevented the aggregation of particles and ensured a perpendicular growth mode. As a result, the grown SWCNTs had a very narrow diameter distribution centered at $1.7 \mathrm{~nm}$ and high content of semiconducting fraction of $>95 \%$. The range of band gaps of SWCNTs was $<0.08 \mathrm{eV}$. They demonstrated an excellent thinfilm transistor performance.

Chirality selective growth. The synthesis of SWCNTs with specific chiralities is currently a very active research field. This section reviews the reports on the chirality selective growth of SWCNTs and discusses the growth mechanism of nanotubes.
In 2003, Bachilo and co-authors synthesized SWCNT samples with a great abundance of the $(6,5)$ and $(7,5)$ nanotubes on CoMo catalyst [105]. Since then, chirality selective growth of SWCNTs was succeeded on a number of different catalysts: CoMo [106-108], FeCo [109], FeRu [110], NiFe [111], Co [112-114], $\mathrm{FeCu}$ [115], Au [116], CoMn [117], Ni [118], Fe $[119,120], \mathrm{CoPt}$ [121], $\mathrm{Co}_{\mathrm{x}} \mathrm{Mg}_{1-\mathrm{x}} \mathrm{O}$ [122], $\mathrm{CoSO}_{4}$ [123], WCo alloy $[124,125]$ and $\mathrm{Mo}_{2} \mathrm{C}$ [126]. $\mathrm{SiO}_{2}$ or $\mathrm{MgO}$ were used as catalyst support. The synthesis was conducted using different carbon precursors: CO [105-108,112-115,117-119,122,123], $\mathrm{C}_{2} \mathrm{H}_{5} \mathrm{OH}[107,109,120,121,124-126], \mathrm{CH}_{3} \mathrm{OH}$ [107], $\mathrm{CH}_{4}$ [110,116] and $\mathrm{C}_{2} \mathrm{H}_{2}$ [111]. Table 1 summarizes the reports on the chirality selective synthesis of SWCNTs.

In early and many later works the synthesis of samples of neararmchair SWCNTs with predominant $(6,5)$ chirality was reported [105-110,112,114-118,121,122]. The mechanism of preferential growth of near-armchair SWCNTs is still debated. In [109], the effect was explained by the stability of cap structures of near-armchair nanotubes, which are formed on the catalyst before the growth of the tube wall, as compared to near-zigzag tubes and a small number of possible cap structures for small diameter tubes. Theoretically, the authors of [127] showed that some caps are preferentially stabilized due to their epitaxial relationship to the solid catalyst surface, and the growth of corresponding tubes is favored. In [128], on the basis of the dislocation growth mechanism, it was shown that the abundance of near-armchair nanotubes in the synthesized samples is caused by their higher growth rates as compared to near-zigzag tubes. This trend was proven by several experimental studies $[129,130]$. Therefore, the chiral selectivity can be related to the nucleation of carbon species on catalytic particles and the different growth rates depending on the chiral angle of nanotubes. In other words, the chirality selective growth of SWCNTs is realized through either thermodynamic control, such as building a more stable tube-catalyst interface or kinetic control, such as different growth rates of different SWCNTs. Recently, the authors of [131] combined thermodynamic (preference to low energy) and kinetic (preference to higher rate) arguments within a unified theoretical model, which explains the preferential growth of near-armchair nanotubes.

It was shown that chirality selectivity is influenced by the synthesis parameters: gaseous carbon source [106,107], its pressure [108], catalyst composition [111], type of support [106] and synthesis temperature $[106,109,110,112,115,117,121,122]$. The authors of [107] synthesized SWCNTs using four different carbon precursors: $\mathrm{CO}, \mathrm{C}_{2} \mathrm{H}_{5} \mathrm{OH}, \mathrm{CH}_{3} \mathrm{OH}$ and $\mathrm{C}_{2} \mathrm{H}_{2}$ on CoMo catalyst. Narrowly $(n, m)$ distributed SWCNTs were obtained only using $\mathrm{CO}, \mathrm{C}_{2} \mathrm{H}_{5} \mathrm{OH}$ and $\mathrm{CH}_{3} \mathrm{OH}$. In samples synthesized using $\mathrm{CO}$ the $(7,6),(7,5)$ and $(8,4)$ tubes dominated, whereas 
Table 1: Summary of reports on chirality selective synthesis of SWCNTs by the CVD method. Given are the carbon feedstock, catalyst, catalyst support, synthesis temperature and main chirality of synthesized nanotubes in a chronological order.

\begin{tabular}{|c|c|c|c|c|c|}
\hline $\begin{array}{l}\text { Carbon } \\
\text { feedstock }\end{array}$ & Catalyst & Catalyst support & $\begin{array}{l}\text { Synthesis } \\
\text { temperature }\end{array}$ & Main nanotube chirality ${ }^{a}$ & Ref. \\
\hline $\mathrm{CO}$ & CoMo & $\mathrm{SiO}_{2}$ & $750^{\circ} \mathrm{C}$ & $(6,5)^{*},(7,5)$ & [105] \\
\hline \multirow[t]{3}{*}{$\mathrm{C}_{2} \mathrm{H}_{5} \mathrm{OH}$} & FeCo & USY-zeolite & $650^{\circ} \mathrm{C}$ & $(6,5)^{*},(7,5)$ & [109] \\
\hline & & & $750^{\circ} \mathrm{C}$ & $(6,5),(7,5)^{\star},(7,6)$ & \\
\hline & & & $850^{\circ} \mathrm{C}$ & $(7,5)^{*},(7,6),(8,6),(8,4),(9,4)$ & \\
\hline \multirow[t]{5}{*}{$\mathrm{CO}$} & CoMo & $\mathrm{SiO}_{2}$ & $700^{\circ} \mathrm{C}$ & $(6,5)^{*},(6,6),(7,7)$ & [106] \\
\hline & & & $750^{\circ} \mathrm{C}$ & $(6,5)^{\star},(8,4),(6,6),(7,7)$ & \\
\hline & & & $800^{\circ} \mathrm{C}$ & $(6,5)^{\star},(6,6),(7,7)$ & \\
\hline & & & $850^{\circ} \mathrm{C}$ & $(7,5),(7,6)^{\star},(8,6),(8,7),(6,6),(7,7)$ & \\
\hline & & $\mathrm{MgO}$ & $750^{\circ} \mathrm{C}$ & $(6,5),(7,5)^{*},(6,6)$ & \\
\hline $\mathrm{CO}$ & CoMo & $\mathrm{SiO}_{2}$ & $800^{\circ} \mathrm{C}$ & $(7,5),(7,6)^{*},(8,4)$ & [107] \\
\hline \multicolumn{6}{|l|}{$\mathrm{C}_{2} \mathrm{H}_{5} \mathrm{OH}$} \\
\hline \multicolumn{6}{|l|}{$\mathrm{CH}_{3} \mathrm{OH}$} \\
\hline \multirow[t]{3}{*}{$\mathrm{CH}_{4}$} & FeRu & $\mathrm{SiO}_{2}$ & $600^{\circ} \mathrm{C}$ & $(6,5)^{\star}$ & [110] \\
\hline & & & $700^{\circ} \mathrm{C}$ & $(6,5)^{\star},(7,5),(8,4)$ & \\
\hline & & & $850^{\circ} \mathrm{C}$ & $(7,5)^{*},(7,6),(8,4)$ & \\
\hline $\mathrm{CO}$ & CoMo & $\mathrm{SiO}_{2}$ & $800^{\circ} \mathrm{C}$ & $(6,5)^{\star},(7,5),(7,6)$ & [108] \\
\hline \multirow[t]{2}{*}{$\mathrm{C}_{2} \mathrm{H}_{2}$} & $\mathrm{NiFe}$ & & $600^{\circ} \mathrm{C}$ & $(7,5)^{\star},(8,4),(7,6),(8,3),(6,5)\left(\mathrm{Ni}_{0.5} \mathrm{Fe}_{0.5}\right)$ & [111] \\
\hline & & & & $(8,4)^{*},(7,5),(6,5),(7,6),(8,3)\left(\mathrm{Ni}_{0.27} \mathrm{Fe}_{0.73}\right)$ & \\
\hline \multirow[t]{5}{*}{$\mathrm{CO}$} & Co & MCM-41 (mesoporous $\mathrm{SiO}_{2}$ ) & $550^{\circ} \mathrm{C}$ & $(6,5)^{\star},(8,4)$ & [112] \\
\hline & & & $650^{\circ} \mathrm{C}$ & $(6,5)^{*},(7,5),(8,4)$ & \\
\hline & & & $750^{\circ} \mathrm{C}$ & $(6,5),(7,5)^{*},(7,6),(8,4),(8,6)$ & \\
\hline & & & $850^{\circ} \mathrm{C}$ & $(7,5),(7,6)^{\star},(8,4),(8,6)$ & \\
\hline & & & $950^{\circ} \mathrm{C}$ & $(7,5),(7,6)^{*},(8,4),(8,6)$ & \\
\hline \multirow[t]{3}{*}{$\mathrm{CO}$} & $\mathrm{FeCu}$ & $\mathrm{MgO}$ & $600^{\circ} \mathrm{C}$ & $(6,5)^{*}$ & [115] \\
\hline & & & $750^{\circ} \mathrm{C}$ & $(6,5),(7,5)^{\star},(7,6),(8,3),(8,4)$ & \\
\hline & & & $800^{\circ} \mathrm{C}$ & $(6,5),(7,5)^{\star},(7,6),(8,3),(8,4),(8,6),(9,4)$ & \\
\hline $\mathrm{CO}$ & Co & TUD-1 (mesoporous $\mathrm{SiO}_{2}$ ) & $800^{\circ} \mathrm{C}$ & $(9,8)^{*}$ & [113] \\
\hline $\mathrm{CH}_{4}$ & $\mathrm{Au}$ & $\mathrm{SiO}_{2}$ & $700-750^{\circ} \mathrm{C}$ & $(6,5)^{\star}$ & [116] \\
\hline \multirow[t]{3}{*}{$\mathrm{CO}$} & CoMn & $\mathrm{MCM}-41$ (mesoporous $\mathrm{SiO}_{2}$ ) & $600^{\circ} \mathrm{C}$ & $(6,5)^{\star},(7,3),(8,3)$ & {$[117]$} \\
\hline & & & $700^{\circ} \mathrm{C}$ & $(6,5)^{\star},(7,3),(8,3)$ & \\
\hline & & & $800^{\circ} \mathrm{C}$ & $(6,5)^{*},(7,5)$ & \\
\hline $\mathrm{CO}$ & $\mathrm{Ni}$ & $\mathrm{SiO}_{2}$ & $500^{\circ} \mathrm{C}$ & $(6,5)^{\star},(7,5)$ & [118] \\
\hline $\mathrm{CO}$ & $\mathrm{Fe}$ & & $880^{\circ} \mathrm{C}$ & $(13,12)^{\star},(12,11),(13,11)$ & [119] \\
\hline $\mathrm{CO}$ & Co & $\mathrm{SiO}_{2}$ & $600^{\circ} \mathrm{C}$ & $(6,5)^{\star},(7,5),(6,4),(7,6),(8,3),(8,4)$ & [114] \\
\hline \multirow[t]{2}{*}{$\mathrm{C}_{2} \mathrm{H}_{5} \mathrm{OH}$} & CoPt & $\mathrm{SiO}_{2}$ & $800^{\circ} \mathrm{C}$ & $(6,5)^{\star},(7,5),(7,6)$ & [121] \\
\hline & & & $850^{\circ} \mathrm{C}$ & $(6,5),(7,5),(7,6)^{\star}$ & \\
\hline $\mathrm{CO}$ & $\mathrm{Co}_{x} \mathrm{Mg}_{1-x} \mathrm{O}$ & & $\begin{array}{l}400^{\circ} \mathrm{C} \\
500^{\circ} \mathrm{C} \\
600^{\circ} \mathrm{C}\end{array}$ & $\begin{array}{l}(7,6)^{\star},(9,4) \\
(6,5)^{\star} \\
(6,5)^{\star},(7,5),(8,3)\end{array}$ & [122] \\
\hline $\mathrm{CO}$ & $\mathrm{CoSO}_{4}$ & $\mathrm{SiO}_{2}$ & $780^{\circ} \mathrm{C}$ & $(9,8)^{*}$ & [123] \\
\hline $\mathrm{C}_{2} \mathrm{H}_{5} \mathrm{OH}$ & WCo alloy & $\mathrm{SiO}_{2}$ & $1030^{\circ} \mathrm{C}$ & $(12,6)^{*}$ & [124] \\
\hline $\mathrm{C}_{2} \mathrm{H}_{5} \mathrm{OH}$ & WCo alloy & $\mathrm{SiO}_{2}$ & $1050^{\circ} \mathrm{C}$ & $(16,0)^{\star}$ & [125] \\
\hline $\mathrm{C}_{2} \mathrm{H}_{5} \mathrm{OH}$ & $\mathrm{Mo}_{2} \mathrm{C}$ & $\mathrm{SiO}_{2}$ & $850^{\circ} \mathrm{C}$ & $(14,4),(13,6),(10,9)$ & [126] \\
\hline $\mathrm{C}_{2} \mathrm{H}_{5} \mathrm{OH}$ & $\mathrm{Fe}$ & $\mathrm{SiO}_{2}$ & $850^{\circ} \mathrm{C}$ & $(15,2)^{\star}$ & [120] \\
\hline
\end{tabular}

asterisk marks the dominant nanotube chirality.

the samples obtained using $\mathrm{C}_{2} \mathrm{H}_{5} \mathrm{OH}$ and $\mathrm{CH}_{3} \mathrm{OH}$ contained more $(8,6),(9,5)$ and $(8,7)$ nanotubes. In [106], it was shown that the $\mathrm{CH}_{4}$ feed did not result in such a narrow $(n, m)$ distribution dominated by near-armchair nanotubes as the $\mathrm{CO}$ feed.
The authors of [108] performed a systematic study of the chirality distribution of SWCNTs varying the pressure of CO feed on CoMo catalysts between 2 and 18 bar. Three nanotube chiralities $(6,5),(7,5)$ and $(7,6)$ were dominant in the samples. 
However, their relative content depended on the pressure of the carbon feedstock. The $(6,5)$ tube had the largest content at 18 bar $\mathrm{CO}$ and its content decreased with decreasing the pressure from 18 to 2 bar. In contrast, the $(7,6)$ tube had the largest content at 2 bar $\mathrm{CO}$ and its content decreased with the increase of CO pressure. The yield of the $(7,5)$ tube was the largest at 12 bar CO pressure.

The authors of [111] investigated the changes in the chirality distribution of SWCNTs by tuning the composition of $\mathrm{Ni}_{\mathrm{X}} \mathrm{Fe}_{1-\mathrm{x}}$ catalytic nanoparticles. They showed that pure Ni catalyst yielded a relatively wide chirality distribution of SWCNTs, where the $(9,4)$ tubes dominated and smaller amounts of $(8,4)$, $(7,5),(10,2),(8,6),(9,5)$ and $(10,3)$ tubes were present. The $\mathrm{Ni}_{0.67} \mathrm{Fe}_{0.33}$ catalysed sample showed a similar chirality distribution with dominating $(7,6)$ tubes. In comparison, the samples obtained with $\mathrm{Ni}_{0.5} \mathrm{Fe}_{0.5}$ and $\mathrm{Ni}_{0.27} \mathrm{Fe}_{0.73}$ catalysts were characterized by dramatic changes in chirality distributions. The sample obtained with $\mathrm{Ni}_{0.5} \mathrm{Fe}_{0.5}$ was composed of mainly $(7,5)$ and $(8,4)$ tubes with smaller amounts of the $(7,6),(8,3)$ and $(6,5)$ tubes. The sample grown with $\mathrm{Ni}_{0.27} \mathrm{Fe}_{0.73}$ has a much narrower chirality distribution with dominating $(8,4)$ tube and smaller amounts of $(7,5),(6,5),(7,6)$ and $(8,3)$ tubes. The authors of [111] suggested that changes in the catalyst structure, which are a result of the tuning of the catalyst composition, affected the lattice mismatch of the catalyst with certain nanotube chiralities and led to the observed changes in the chirality distribution.

In [106], the effect of catalyst supports, such as $\mathrm{SiO}_{2}$ and $\mathrm{MgO}$, on the chirality distribution of SWCNTs was studied. The difference in the morphology of these catalyst supports resulted in the growth of different SWCNTs. In both cases, SWCNTs with near-armchair chiralities were obtained. In the samples synthesized with $\mathrm{SiO}_{2}$ support, the $(6,5)$ tubes dominated. The samples obtained using $\mathrm{MgO}$ support contained less $(6,5)$ tubes and more $(7,5),(8,4)$ and $(6,6)$ tubes. The average diameters of these four nanotubes are similar, but the chiral angle was reduced in the $\mathrm{MgO}$ sample.

In most works, it was observed that the increase in the synthesis temperature led to increase in the nanotube diameters and broadening of the chirality distribution $[106,109,110,112,115,117,121,122]$. The $(6,5)$ nanotube dominated in the samples synthesized at temperatures around 500-700 ${ }^{\circ} \mathrm{C}$, whereas such selectivity disappeared at higher temperatures. In [121], a bimetallic CoPt catalyst was suggested for the selective growth of the $(6,5)$ tubes at synthesis temperatures as high as $800-850^{\circ} \mathrm{C}$. The formation of $\mathrm{CoPt}$ alloy and its improved stability was suggested to be responsible for the selective growth of small diameter SWCNTs with a narrow chirality distribution.
The authors of recent works $[113,119,120,123-126]$ succeeded in the selective growth of SWCNTs with chiralities that are different from $(6,5)$. In $[113,123]$, near-armchair SWCNTs with a chirality of $(9,8)$ were selectively synthesized. The authors of [113] produced the SWCNT samples using Co catalyst on TUD-1 (mesoporous $\mathrm{SiO}_{2}$ ) support. 59.1\% of semiconducting SWCNTs had the $(9,8)$ chirality. It was suggested that strong metal-support interaction stabilized the Co clusters with a narrow diameter distribution around $1.2 \mathrm{~nm}$, which were responsible for the selective growth of the $(9,8)$ tubes. In [123], the $(9,8)$ nanotubes were selectively synthesized on $\mathrm{CoSO}_{4}$ catalyst supported by $\mathrm{SiO}_{2}$ with $51.7 \%$ abundance among semiconducting SWCNTs. The chirality selectivity was explained by the formation of Co particles with an average size of $1.23 \mathrm{~nm}$, which matched the diameter of the $(9,8)$ tube. Additionally, the presence of sulfur, which limited the aggregation of Co particles and formed Co-S compounds, was suggested to enable the chirality selectivity toward the $(9,8)$ tubes.

In [119], large diameter SWCNTs with a narrow $(n, m)$ distribution and dominant $(13,12)$ tubes $(d=1.67 \mathrm{~nm})$ were synthesized in aerosol floating-catalyst CVD process with a use of ferrocene as catalyst precursor and a small amount of ammonia. Over $90 \%$ of SWCNTs had near-armchair structure. It was suggested that $\mathrm{NH}_{3}$, which is a strong etchant, selectively etched off SWCNTs with small chiral angles due to their higher reactivity and lower stability as compared to high chiral angle tubes. The same applied to small diameter nanotubes due to their higher curvature. Additionally, the presence of $\mathrm{NH}_{3}$ could affect the catalyst clusters already during nucleation, suppressing the growth of tubes with small chiral angles.

In most recent works, efforts were aimed at the optimization of the SWCNT-catalyst interface for the chirality-selective growth. The authors of $[124,125]$ used WCo alloy particles with specific structure as template to realize the chirality-controlled growth of SWCNTs. In [124], the $(12,6)$ tubes $(d=1.28 \mathrm{~nm})$ with an abundance higher than $92 \%$ were selectively synthesized using ethanol as carbon source. $\mathrm{W}_{6} \mathrm{Co}_{7}$ alloy nanoparticles were found to be responsible for catalyzing the nanotube growth. It was suggested that the selective growth was a result of good structural match between the arrangement of carbon atoms around the circumference of nanotube and the arrangement of metal atoms of the nanocrystal catalyst.

In contrast to most previous reports on the selective growth of near-armchair nanotubes, the authors of [125] synthesized zigzag nanotubes with chirality of $(16,0)$ using $\mathrm{W}_{6} \mathrm{Co}_{7}$ catalyst. The abundance of the $(16,0)$ tubes in the samples was estimated to be $\approx 80 \%$. It was suggested that the (116) planes of the nanocrystal catalyst acted as templates for the $(16,0)$ tubes due to the 
structural match between the open end of the tube and the arrangements of metal atoms of the (116) planes of the catalyst. The authors of [125] noted that the structural match between the tubes and nanocrystal catalyst represented the thermodynamic ascendancy for the growth of SWCNTs with specific chiralities, but the growth kinetic was also important. They concluded that zigzag SWCNTs can be dominantly produced by combining the structural template effect of nanocrystal catalyst and the optimization of growth kinetics. The authors of recent report [120] also succeeded in the CVD synthesis of near-zigzag SWCNTs with the dominant chirality of $(15,2)$ using Fe catalyst.

It should be noted that besides the CVD method the single chirality SWCNTs can also be obtained by the "cloning growth" and organic synthesis, as described in detail in review [132].

\section{Inner tube growth inside SWCNTs}

While the coalescence mechanism is generally accepted for the formation of inner tubes from fullerene-filled SWCNTs [133142], only a few works discussed the mechanism of the inner tube growth from SWCNTs filled with other molecules.

In [143], the authors grew inner tubes via the thermally-induced chemical transformation of ferrocene molecules inside the host SWCNTs. They mentioned that ferrocene molecules are decomposed upon annealing, and they act as catalyst source and provide carbon atoms for the inner tube growth at the same time. From the analysis of ex situ HRTEM data, it was concluded that iron carbide catalyzed the inner tube growth.

The authors of [144] traced the growth process of inner tubes inside Pt acetylacetonate-filled SWCNTs by HRTEM. Figure 7a shows a room-temperature HRTEM micrograph of DWCNTs formed via the annealing of the filled SWCNTs at $700{ }^{\circ} \mathrm{C}$. It is visible that the inner tube is connected with its open end to a nanocrystal inside a SWCNT. It was determined that the interplanar distances of the nanocrystal correspond to those of a Pt crystal. This proved that metallic Pt catalyzed the inner tube growth. In situ HRTEM further confirmed that the inner tube wall remained terminated at a Pt crystal even at the growth temperature of $760{ }^{\circ} \mathrm{C}$ (Figure 7b). The authors of [144] suggested that the growth of the inner tube stopped when the carbon source was depleted. They mentioned that this growth mechanism is different from conventional bulk-scale synthesis of SWCNTs. The key difference to conventional synthesis with uncontrolled catalyst particle is the exceptional stability of the growth mechanism. Without a templating outer nanotube, fluctuations in growth conditions result in a finite lifetime of the catalyst. And growth stops once the particle is deactivated by a passivating layer of carbon. However, inside the atomically tight tubular confinement provided the outer nanotube, the formation of a passivating carbon shell is sterically hindered. The templating provides prolonged catalyst lifetimes and the growth is maintained for many hours until all feedstock is consumed [144].
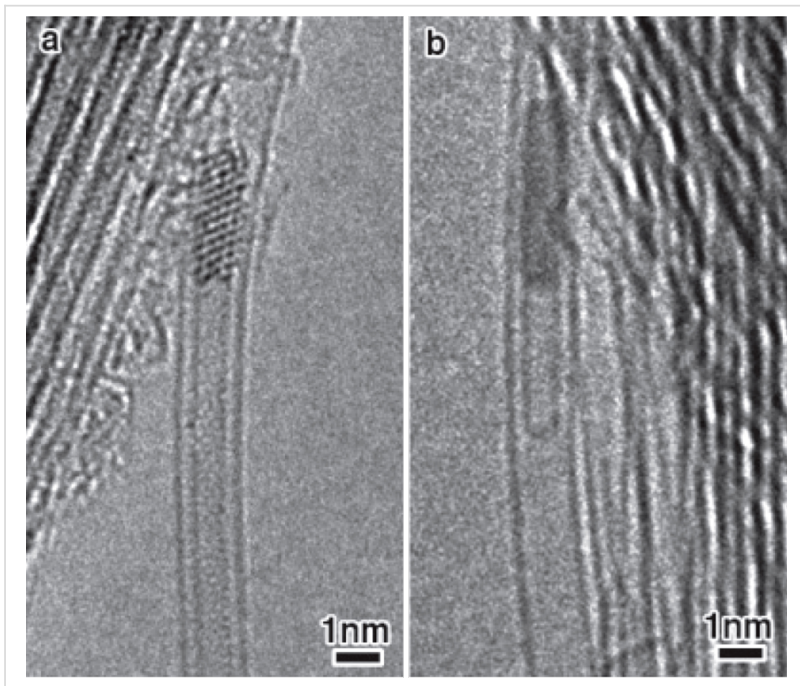

Figure 7: The HRTEM images of Pt acetylacetonate-filled SWCNTs ex situ annealed at $700{ }^{\circ} \mathrm{C}$ for $2 \mathrm{~h}$ (a) and in situ annealed at temperatures up to $760^{\circ} \mathrm{C}$ (b). Reprinted with permission from [144], copyright 2010 Wiley-VCH Verlag GmbH \& Co. KGaA, Weinheim.

In [145], the nickelocene-filled SWCNTs were annealed at temperatures ranging from 250 to $1200{ }^{\circ} \mathrm{C}$ to form DWCNTs. Using Raman spectroscopy, it was shown that upon annealing the molecules reacted with one another and formed inner tubes inside the outer SWCNTs at a high yield. Figure 8a demonstrates the RBM-band of Raman spectra of the pristine, filled and annealed samples acquired at a laser wavelength of $633 \mathrm{~nm}$ $\left(E_{\mathrm{ex}}=1.96 \mathrm{eV}\right)$ [145]. The RBM-band of the pristine SWCNTs is positioned at frequencies between 125 and $160 \mathrm{~cm}^{-1}$. The RBM-band of the $\mathrm{NiCp}_{2}$-filled SWCNTs is shifted towards higher frequencies by $4 \mathrm{~cm}^{-1}$, which was previously reported for molecule-filled SWCNTs [143,144,146,147]. In the spectra of the annealed samples, additional peaks appear at 212, 216 and $253 \mathrm{~cm}^{-1}$, which correspond to inner tubes. The peak at $212 \mathrm{~cm}^{-1}$ was assigned to the $(12,3)$ tube with a diameter of $1.08 \mathrm{~nm}$, the peak at $216 \mathrm{~cm}^{-1}$ was attributed to the $(13,1)$ tube with a diameter of $1.06 \mathrm{~nm}$, and the peak at $253 \mathrm{~cm}^{-1}$ was assigned to the $(11,1)$ tube with a diameter of $0.91 \mathrm{~nm}$ [145]. The diameter of the $(12,3)$ and $(13,1)$ tubes was close to the mean diameter, which allowed evaluating the formation of the major part of inner nanotubes. Figure $8 \mathrm{~b}$ presents the relative area intensity of the RBM peak of the $(12,3)$ and $(13,1)$ tubes plotted versus annealing temperature [145]. The inner tubes grow fast with increasing temperature from 400 to $700{ }^{\circ} \mathrm{C}$ [145]. 
(a)

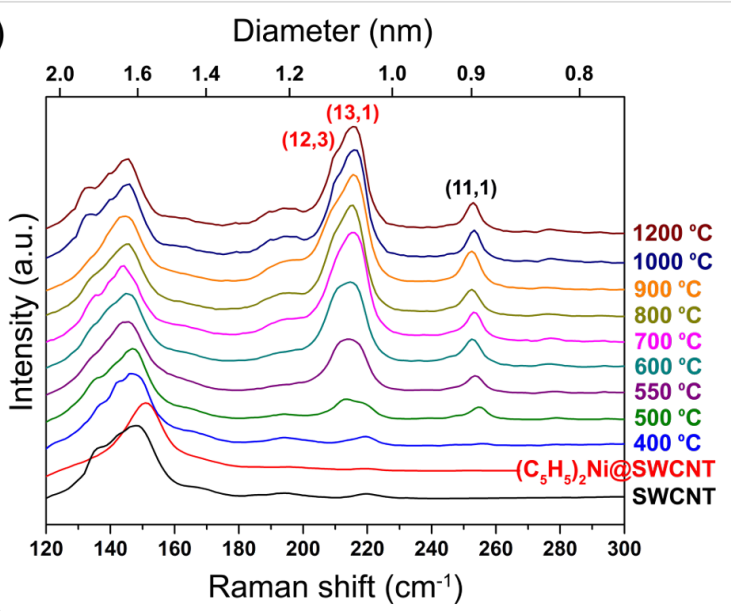

(b)

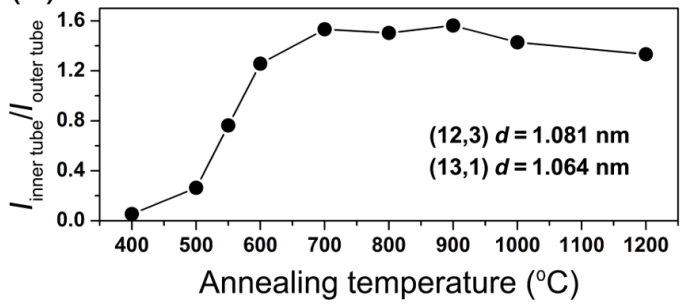

Figure 8: (a) The RBM-band of Raman spectra of the pristine, nickelocene-filled SWCNTs and samples annealed temperatures ranging from 400 to $1200{ }^{\circ} \mathrm{C}$ for $2 \mathrm{~h}$ acquired at a laser wavelength of $633 \mathrm{~nm}$. (b) The normalized area intensity of the RBM peak of the $(12,3)$ and $(13,1)$ inner tubes plotted versus annealing temperature. Reproduced from [145]. Published by The Royal Society of Chemistry under a Creative Commons Attribution 3.0 Unported License.

The evolution of the chemical state of the encapsulated compounds at every annealing step was analyzed by X-ray photoelectron spectroscopy. Figure 9a presents the Ni $2 p$ spectra of the $\mathrm{NiCp}_{2}$-filled SWCNTs and samples annealed at temperatures between 250 and $1200{ }^{\circ} \mathrm{C}$ for $2 \mathrm{~h}$ [145]. The spectrum of the $\mathrm{NiCp}_{2}$-filled SWCNTs includes two peaks positioned at binding energies of 854.53 and $871.80 \mathrm{eV}$, which belong to the Ni $2 p_{3 / 2}$ and Ni $2 p_{1 / 2}$ edges, respectively. The Ni $2 p$ spectra of the samples annealed at $250-340{ }^{\circ} \mathrm{C}$ demonstrate a successive downshift by up to $0.96 \mathrm{eV}$ and broadening of the Ni $2 \mathrm{p}_{3 / 2}$ and $\mathrm{Ni} 2 \mathrm{p}_{1 / 2}$ peaks with increasing temperature. These features were explained by changes in the chemical state of nickel, because of the decomposition of $\mathrm{NiCp}_{2}$ with the formation of nickel carbides $\left(\mathrm{Ni}_{\mathrm{X}} \mathrm{C}\right)$ [145]. In the spectra of the samples annealed at temperatures above $400{ }^{\circ} \mathrm{C}$, the peaks are further downshifted and narrowed, and at $600{ }^{\circ} \mathrm{C}$ they reach the position of metallic nickel ( $\mathrm{Ni} 2 \mathrm{p}_{3 / 2}$ peak is centered at $\approx 853 \mathrm{eV}[148,149]$ ). These observations were assigned to the chemical transformation of nickel carbides into metallic nickel [145], which was in agreement with previous reports that nickel carbides (in particular, $\mathrm{Ni}_{3} \mathrm{C}$ ) are metastable [150] and that $\mathrm{Ni}_{3} \mathrm{C}$ degrades at temperatures above $400-500{ }^{\circ} \mathrm{C}$ [151-153]. At temperatures above $800{ }^{\circ} \mathrm{C}$, nickel atoms are observed to be removed rather rapidly from the tubes, which is seen as decreased nickel Ni $2 \mathrm{p}$ signals to $3 \%$ of the initial value at $1200{ }^{\circ} \mathrm{C}$. Figure $9 \mathrm{~b}$ demonstrates the calculated nickel-to-carbon atomic ratio $N_{\mathrm{at}}(\mathrm{Ni}) / N_{\mathrm{at}}(\mathrm{C})$ and $\mathrm{Ni}$ content plotted versus annealing temperature [145]. For the $\mathrm{NiCp}_{2}$-filled SWCNTs, the nickel-to-carbon ratio amounts to 0.0141 . At temperatures below $400{ }^{\circ} \mathrm{C}$, the $\mathrm{Ni}$ content is decreased only to $90 \%$ or higher. At $450-600{ }^{\circ} \mathrm{C}$, it is reduced to $69 \%$. At higher temperatures, the loss becomes substantial. The Ni content drops to $33 \%$ at $800{ }^{\circ} \mathrm{C}, 13 \%$ at $1000{ }^{\circ} \mathrm{C}$, and then at $1200{ }^{\circ} \mathrm{C}$ almost all nickel is released from the sample [145].

The study of the growth process of inner tubes inside the host SWCNTs facilitates understanding the growth mechanism of nanotubes. SWCNTs filled with organometallic molecules represent a unique system for the investigation of the growth mechanism of nanotubes. They are a stable system where the inner tube growth takes place with a slow enough rate over a
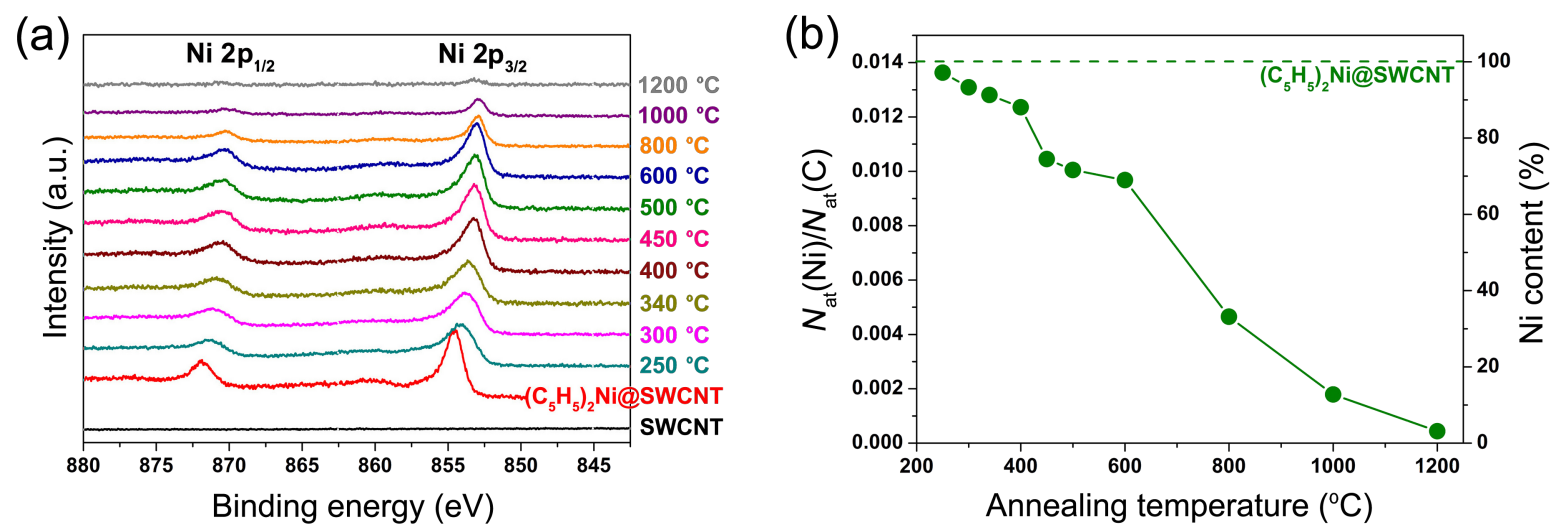

Figure 9: (a) The Ni 2p XPS spectra of the pristine, nickelocene-filled SWCNTs and samples annealed at temperatures between 250 and $1200{ }^{\circ} \mathrm{C}$ for $2 \mathrm{~h}$. (b) The nickel-to-carbon atomic ratio $N_{\mathrm{at}}(\mathrm{Ni}) / N_{\mathrm{at}}(\mathrm{C})$ and nickel content plotted versus annealing temperature. The dashed horizontal line denotes the value for the $\mathrm{NiCp}_{2}$-filled SWCNTs. Reproduced from [145]. Published by The Royal Society of Chemistry under a Creative Commons Attribution 3.0 Unported License. 
long time. The synthesis conditions of nanotubes are well-controlled. The filled SWCNTs act as a catalyst source, carbon feedstock and container providing shielded environment for the tube growth at the same time. A fixed stoichiometry of metal to carbon atoms is achieved by the thermally-induced decomposition of organometallic molecule, and therefore the chemical composition of catalyst and carbon source is specified. The diameter of the outer SWCNTs defines the diameter of inner tubes, and thus it can be controlled by the choice of pristine SWCNT material.

\section{Investigation of growth dynamics of nano- tubes \\ Nanotube growth in the CVD process}

Growth model of nanotubes. Growth kinetics was actively studied for carbon nanotubes synthesized by the CVD method. The growth of nanotubes is characterized by the growth rate, which is their elongation rate during the synthesis process, and a growth time, which is the period of time during that the elongation of nanotubes occurs [23]. The quantity of nanotubes (a thickness of nanotube forests or length of individual tubes) increases with synthesis time until some saturation value $[64,154-$ 161]. The growth process is hindered because of several factors, which may not be mutually exclusive [162]. Among them are the diffusion limitation factor, when a gaseous carbon precursor is restricted from a catalyst by the increasing height of a nanotube forest $[163,164]$, the catalyst lifetime factor, when the activity of the catalyst decreases as growth proceeds $[154,155,159]$, and the factor of carbon overcoating on the surface of the metal catalyst from excessive gas-phase decomposition $[160,165]$.

The catalyst lifetime-limited kinetics of the nanotube growth is a self-exhausting process that can be expressed by the following differential equation:

$$
\frac{\mathrm{d}^{2} C}{\mathrm{~d} \tau^{2}}=-\frac{1}{v},
$$

where $C$ is the quantity of the grown nanotubes, $\tau$ is the synthesis time and $v$ is the lifetime of the catalyst [155]. After integration, Equation 2 is written in the form:

$$
C(\tau)=\gamma v\left(1-e^{-\tau / v}\right)
$$

where $C(\tau)$ is the evolution of the quantity of nanotubes, $\gamma$ is an initial growth rate of nanotubes. Many authors reported that this model fitted the observed growth curves of nanotube forests well $[129,130,154,155,159,166-171]$.
Figure 10 demonstrates typical time evolution of the height (yield) of SWCNT forest at a fixed growth condition in the water-assisted CVD using $\mathrm{C}_{2} \mathrm{H}_{4}$ as a carbon source (the so-called "supergrowth" CVD) [159]. It shows that the growth rate is highest at the beginning of growth, gradually decreases over the subsequent $20 \mathrm{~min}$ and finally terminates with a height of $970 \mu \mathrm{m}$. The growth curve was fitted using the Equation 2 . The fitting parameters are initial growth rate of nanotubes $\gamma$ of $207 \mu \mathrm{m} / \mathrm{min}$ and catalyst lifetime $v$ of $4.74 \mathrm{~min}$. The authors of [159] reported that similar behavior with varying terminal heights was observed on a number of time-evolution experiments that covered a broad range of growth conditions (growth temperature, $\mathrm{C}_{2} \mathrm{H}_{4}$ level and water level). Therefore, this behavior was regarded as a general feature of the supergrowth.

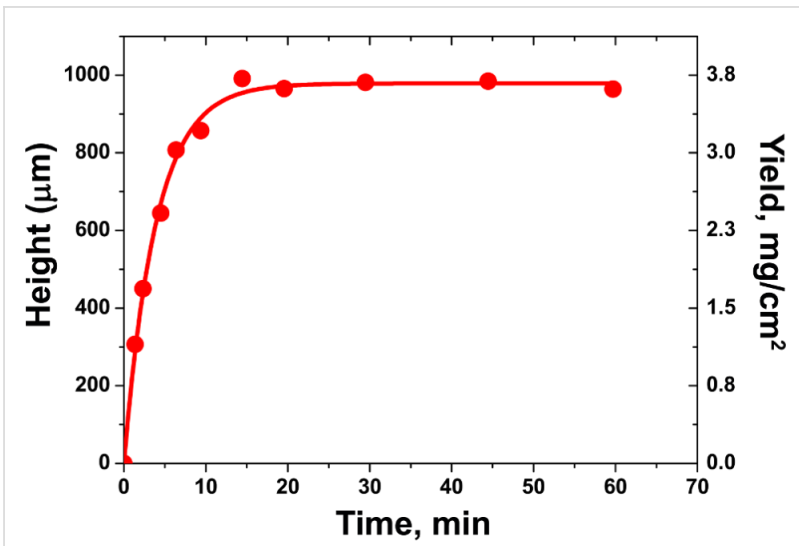

Figure 10: Time evolution of the height (yield) of SWCNT forest. Plot of the height of SWCNT forest as a function of the growth time. The experimental data (red circles) are presented together with the curve fitting using the Equation 2 (solid line). The data are replotted from [159].

Some authors demonstrated that the growth dynamics did not follow a simple exponential model, because other factors than the catalyst decay or combination of several factors hindered the growth process $[162,172-175]$.

Growth rate of nanotubes. The growth rate of nanotubes depends on the synthesis conditions: the pressure of gaseous carbon source, size of catalyst particles, chemical nature of catalyst and synthesis temperature. Table 2 summarizes the influence of the synthesis parameters on the growth rate of nanotubes.

\section{Dependence of growth rate on pressure of carbon precur-} sor. Most studies reported on an increase of the growth rate of nanotubes with raising the pressure of gaseous carbon precursor: $\mathrm{C}_{2} \mathrm{H}_{4}[159,164,175-177], \mathrm{C}_{2} \mathrm{H}_{2}[161,178,179], \mathrm{CH}_{4}$ [180] and $\mathrm{C}_{2} \mathrm{H}_{5} \mathrm{OH}[154,155]$. The same trend was reported in theoretical work [205]. This effect was explained by the increased 
Table 2: Dependence of the growth rate of nanotubes on synthesis parameters.

\begin{tabular}{|c|c|c|}
\hline Synthesis parameter & Type of dependence & Reference \\
\hline pressure of gaseous carbon source & $\begin{array}{l}\text { growth rate increases with raising the pressure } \\
\text { of carbon precursor }\end{array}$ & {$[154,155,159,161,164,175-180]$} \\
\hline size of catalyst particles & $\begin{array}{l}\text { growth rate increases with decreasing the size of } \\
\text { catalyst particles }\end{array}$ & {$[97,181-185]$} \\
\hline chemical nature of catalyst & no significant trend was revealed & {$[42,183,186-188]$} \\
\hline synthesis temperature & $\begin{array}{l}\text { growth rate increases nonlinearly with } \\
\text { temperature }\end{array}$ & $\begin{array}{l}{[42,82,154,155,160-162,164,166-168,} \\
174,175,177-180,183,187-204]\end{array}$ \\
\hline
\end{tabular}

amount of available carbon for the nanotube growth. On the basis of these data, it was concluded that the reaction of the nanotube growth could not be zero order. A linear dependence of the growth rate of nanotubes on the pressure of gaseous hydrocarbon testified that the reaction order was unity [164,175,178-180,205]. However, there are also reports where the reaction orders were estimated to be between 0 and 1 $[161,176]$ and were observed to change with growth temperature [176]. Several authors reported that the growth rate was linearly proportional to the precursor pressure (first order reaction) until some critical value of pressure. Above this critical value, the growth rate became independent on the precursor pressure $[154,155]$. This was explained by a change of the kinetic regime of the nanotube growth from gas-phase diffusion limited to surface processes limited [155]. The authors of [177] observed linear dependences of the growth rate on precursor pressure with different slopes at low and high pressures. This was explained by the fact that at low precursor pressures the kinetic regime of the tube growth was surface diffusion limited and at high pressures - dissociation limited [177].

Dependence of growth rate on size of catalyst particles. Many authors reported that the growth rate of nanotubes increases with decreasing the size of catalyst particles. This trend was observed in the synthesis processes using different catalysts: Ni, Co, Fe [181], Co [97], Ni [182,183] and Fe [184,185]. For example, the authors of [183] showed that the growth rate of nanotubes in the CVD synthesis using nickelocene as catalyst precursor and $\mathrm{C}_{2} \mathrm{H}_{2}$ as carbon source increased by a factor of 3 while decreasing the size of Ni catalyst particles from 3.1 to $2.2 \mathrm{~nm}$. This effect can be explained by the increased catalytic activity of smaller diameter particles due to their larger specific surface area, larger curvature of surface and, consequently, larger amount of active sites [23,206]. Indeed, larger catalytic activity for smaller particles is a commonly observed effect [207-209]. Several authors also related the increased catalytic activity of smaller particles for the nanotube growth to their modified electronic structure [23] as well as increased carbon solubility [183] and shortened diffusion length of carbon atoms to arrive at the growth site [182].
It was shown that the diameter of grown nanotubes is strongly correlated with the size of catalyst particles, i.e., smaller particles lead to the growth of smaller diameter nanotubes [64,97,182,186,202-204]. Consequently, many studies report that smaller diameter nanotubes have higher growth rates $[97,182]$. The nanotube growth rate was found to be inversely proportional to the tube diameter in [97,203]. Additionally, it was reported that coarsening the catalyst particles with increasing growth temperature of nanotubes led to the shift of their diameter distribution towards larger diameters [187,200202,204,210]. For example, the authors of [200] showed that the average diameter of nanotubes synthesized by the thermal CVD method using $\mathrm{C}_{2} \mathrm{H}_{2}$ as carbon source increased from 20 to $150 \mathrm{~nm}$ while increasing growth temperature from 800 to $1100{ }^{\circ} \mathrm{C}$.

\section{Dependence of growth rate on chemical nature of catalyst.} The chemical nature of the catalyst defines its chemical and physical properties and thus may influence the growth rate of nanotubes [23]. Several reports were dedicated to the comparison of kinetics of the growth of nanotubes in the CVD synthesis using different catalysts [42,183,186-188]. The authors of [186] performed a systematic study of the influence of Fe, Co and $\mathrm{Ni}$ catalysts on the growth of aligned nanotubes by the PECVD method. They found that the nature of catalyst has a strong effect on the diameter of nanotubes, their growth rate, wall thickness and morphology. Ni catalyst yielded the highest growth rate, largest diameter, thickest walls and cleanest wall surface of nanotubes, whereas Co catalyst resulted in the lowest growth rate, smallest diameter and thinnest walls of nanotubes covered with amorphous carbon. Similarly, it was shown in [42] that the growth rates of nanotubes on $\mathrm{Ni}$ and Co catalysts were very similar, whereas the rate on Fe catalyst was lower in the PECVD synthesis at temperatures of $250-500{ }^{\circ} \mathrm{C}$. The authors of [183] demonstrated that the growth rate of nanotubes on $\mathrm{Ni}$ nanoparticles was about 2 times larger than the one on Fe particles with similar diameter in the thermal CVD synthesis using ferrocene and nickelocene as catalyst source and $\mathrm{C}_{2} \mathrm{H}_{2}$ as carbon source. Also, the growth rates of nanotubes varied for bimetallic $(\mathrm{Ni} / \mathrm{Fe})$ catalytic particles with different metal con- 
centrations. These results were in agreement with the theoretical study [211] that predicted the increased growth rate of nanotubes on Ni catalyst as compared to the one on Fe catalyst due to faster integration of carbon into growing nanotubes. In contrast, the authors of $[187,188]$ showed that the growth rate of nanotubes on Fe catalyst was about 2 times higher than the one on $\mathrm{Co}$ and $\mathrm{Ni}$ catalysts in the thermal CVD synthesis using $\mathrm{C}_{2} \mathrm{H}_{2}$ as carbon source at temperatures of $900-1000{ }^{\circ} \mathrm{C}$ [188] and in the pyrolysis of metal phthalocyanines at temperatures of $700-1000{ }^{\circ} \mathrm{C}$ [187]. This was explained by the fact that $\mathrm{Fe}$ is a more efficient metal in terms of carbon saturation than $\mathrm{Co}$ and Ni. Also, nanotubes grown on Fe catalyst had a better crystallinity of walls.

Dependence of growth rate on synthesis temperature. All studies dedicated to the investigation of the dependence of the growth rate of nanotubes on temperature reported that the rate increased nonlinearly with temperature $[42,82,154,155,160$ $162,164,166-168,174,175,177-180,183,187-204]$. For example, the authors of [200] found that the growth rate of nanotubes increased exponentially from 1.6 to $28 \mu \mathrm{m} / \mathrm{min}$ (by a factor of 18 ) while increasing the growth temperature from 800 to $1100{ }^{\circ} \mathrm{C}$ in the thermal CVD process using $\mathrm{Fe}$ as catalyst and $\mathrm{C}_{2} \mathrm{H}_{2}$ as carbon source. Similarly, the authors of [187] found that the growth rate of nanotubes increased exponentially from 0.075 to $3.5 \mu \mathrm{m} / \mathrm{min}$ (by a factor of 47) while increasing the growth temperature from 700 to $1000{ }^{\circ} \mathrm{C}$ in the pyrolysis process using iron phthalocyanine as catalyst and carbon source. Figure 11 shows the obtained plots of the growth rate as a function of synthesis temperature for the nanotubes grown via pyrolysis of iron,

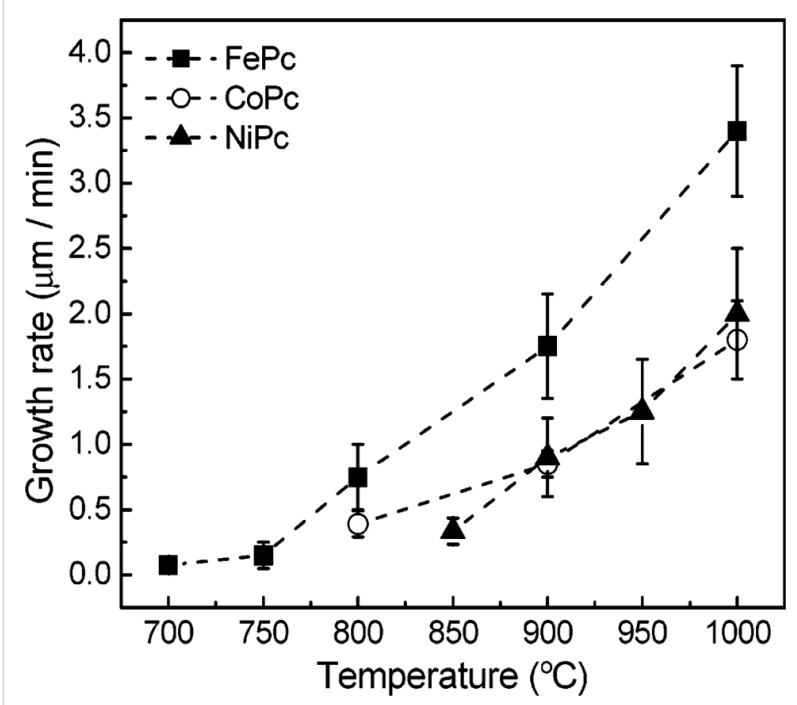

Figure 11: The plots of the growth rate as a function of synthesis temperature for the nanotubes grown via pyrolysis of iron, nickel and cobalt phthalocyanines. Reprinted with permission from [187], copyright 2003 American Chemical Society. nickel and cobalt phthalocyanines [187]. They show a nonlinear increase of the growth rate with temperature. The growth rate of nanotubes using iron phthalocyanine is about 2 times higher than in the case of nickel and cobalt phthalocyanines. These results are in agreement with studies on the growth of carbon filaments, where the growth rates also increased exponentially with temperature $[19,20,181,212,213]$.

This behavior is caused by the fact that the catalytic nanotube growth is a thermally-activated process. The dependence of the growth rate on temperature obeys the Arrhenius equation [214]:

$$
\gamma=B e^{-\frac{E_{\mathrm{a}}}{k_{\mathrm{B}} T}},
$$

where $\gamma$ is the growth rate of nanotubes, $E_{\mathrm{a}}$ is the activation energy of the nanotube growth, $k_{\mathrm{B}}$ is the Boltzmann constant, $T$ is the absolute temperature and $B$ is a proportionality coefficient.

Activation energy of nanotube growth. Many studies reported the calculation of activation energies of the nanotube growth, taking into consideration the Arrhenius equation (Equation 4). Indeed, if we take the natural logarithm from both parts of Equation 4, we get the following expression:

$$
\ln \gamma=-\frac{E_{\mathrm{a}}}{k_{\mathrm{B}} T}+\ln B .
$$

According to Equation 5, the natural logarithm of the growth rate shows a linear dependence on the inverse growth temperature. The slope of this linear dependence is $-E_{\mathrm{a}} / k_{\mathrm{B}}$. Thus, the linear fitting of the dependence $\ln \gamma(1 / T)$ yields directly the value of the activation energy of the nanotube growth.

Figure 12 shows an example of the Arrhenius plot for the growth rates of MWCNTs synthesized by thermal CVD using $\mathrm{C}_{2} \mathrm{H}_{2}$ as carbon source and $\mathrm{Fe}$ catalyst at $800-1100{ }^{\circ} \mathrm{C}$ in [200]. The experimental data fit well to a linear function, providing the activation energy of $1.3 \mathrm{eV}$.

The activation energies calculated in the literature vary in the range from 0.1 to $2.8 \mathrm{eV}$. Table 3 summarizes the activation energies of the nanotube growth by different synthesis methods using various carbon precursors and catalysts in a chronological order.

Baker with co-authors performed the first calculations of the activation energies of the growth of carbon filaments by the catalytic thermal decomposition of $\mathrm{C}_{2} \mathrm{H}_{2}$ on different catalysts in 1970-1980s: Ni [19], Co [20], Fe [20,213], V [212] and Mo 


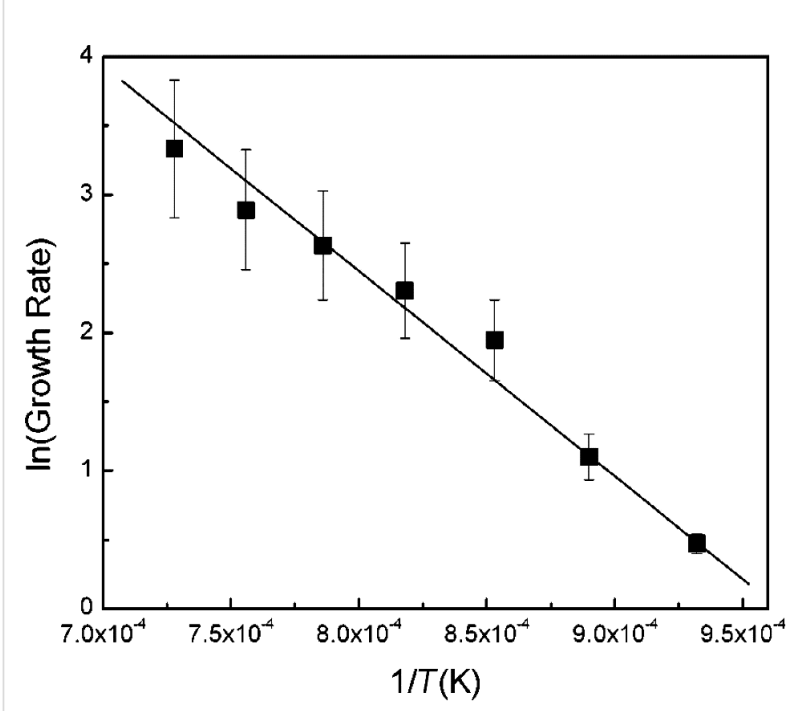

Figure 12: The Arrhenius plot for the growth rates of MWCNTs synthesized by thermal CVD using $\mathrm{C}_{2} \mathrm{H}_{2}$ as carbon source and Fe catalyst at $800-1100{ }^{\circ} \mathrm{C}$. The experimental data (black squares) are shown together with linear fitting, providing the activation energy of $1.3 \mathrm{eV}$. Reprinted with permission from [200], copyright 2002 American Chemical Society.
[212]. The obtained values $(0.7-1.68 \mathrm{eV})$ were similar to the activation energies for the solid-state carbon diffusion through the corresponding bulk metals. On the basis of these data, it was concluded that the bulk diffusion through the solid-state catalyst particle was the growth rate-limiting process. The same correlation was reported in [85], where the activation energy of the growth of carbon filaments by the catalytic thermal decomposition of 1,3-butadiene on $\mathrm{Ni}$ was estimated to range from 1.35 to $1.55 \mathrm{eV}$. Similar values and explanations were reported by other authors for the growth of carbon nanotubes. The activation energies of the MWCNT growth were calculated to be $1.3 \mathrm{eV}$ [200], $1.79 \mathrm{eV}$ [82] and $1.21 \mathrm{eV}$ [204] for the thermal CVD synthesis using $\mathrm{C}_{2} \mathrm{H}_{2}$ as carbon source and Fe or Ni catalysts, $1.52 \mathrm{eV}$ [191] and $1.30 \mathrm{eV}$ [193] for the thermal CVD synthesis using $\mathrm{C}_{2} \mathrm{H}_{2}$ as carbon source and ferrocene as precursor of catalyst, $1.30 \mathrm{eV}$ for the pyrolysis of $\mathrm{Fe}, \mathrm{Co}$ and $\mathrm{Ni}$ phthalocyanines [187] and $1.41 \mathrm{eV}$ for the thermal CVD synthesis using xylene as carbon source and ferrocene as precursor of catalyst [174]. The authors of $[154,166]$ found that the activation energy of SWCNT growth by the thermal CVD synthesis using $\mathrm{C}_{2} \mathrm{H}_{5} \mathrm{OH}$ as carbon source equaled $1.5 \mathrm{eV}$ for Co-Mo catalyst [154] and $1.1 \mathrm{eV}$ for Co catalyst [166]. In [161], the ac-

\begin{tabular}{|c|c|c|c|c|c|c|c|}
\hline $\begin{array}{l}\text { Type of } \\
\text { synthesized } \\
\text { nanotubes }\end{array}$ & $\begin{array}{l}\text { Method of } \\
\text { synthesis }\end{array}$ & $\begin{array}{l}\text { Source of } \\
\text { carbon }\end{array}$ & Catalyst/support & $\begin{array}{l}\text { Synthesis } \\
\text { temperature }\end{array}$ & $\begin{array}{l}\text { Calculated } \\
\text { activation } \\
\text { energy of } \\
\text { nanotube } \\
\text { growth }\end{array}$ & $\begin{array}{l}\text { Assigned } \\
\text { growth-rate-limiting } \\
\text { process, reported } \\
\text { activation energy } \\
\text { for this process }\end{array}$ & Ref. \\
\hline carbon filaments & $\begin{array}{l}\text { catalytic } \\
\text { thermal } \\
\text { decomposition }\end{array}$ & $\mathrm{C}_{2} \mathrm{H}_{2}$ & $\begin{array}{l}\mathrm{Ni}(30-50 \mathrm{~nm}) / \\
\text { support }\end{array}$ & $\approx 600^{\circ} \mathrm{C}$ & $1.51 \mathrm{eV}$ & $\begin{array}{l}\text { bulk diffusion of } \\
\text { carbon through the } \\
\text { solid catalyst } \\
\text { particle } \\
(1.43-1.51 \mathrm{eV} \\
[215])\end{array}$ & [19] \\
\hline \multirow[t]{2}{*}{ carbon filaments } & \multirow[t]{2}{*}{$\begin{array}{l}\text { catalytic } \\
\text { thermal } \\
\text { decomposition }\end{array}$} & \multirow[t]{2}{*}{$\mathrm{C}_{2} \mathrm{H}_{2}$} & $\begin{array}{l}\text { a-Fe/support } \\
\text { (graphite, } \\
\text { silicon) }\end{array}$ & $\approx 600{ }^{\circ} \mathrm{C}$ & $0.70 \mathrm{eV}$ & $\begin{array}{l}\text { bulk diffusion } \\
(0.46-0.72 \mathrm{eV} \\
[216,217])\end{array}$ & \multirow[t]{2}{*}{ [20] } \\
\hline & & & $\begin{array}{l}\text { Co/support } \\
\text { (graphite, } \\
\text { silicon) }\end{array}$ & $\approx 600^{\circ} \mathrm{C}$ & $1.44 \mathrm{eV}$ & $\begin{array}{l}\text { bulk diffusion } \\
\text { (1.51 eV [218]) }\end{array}$ & \\
\hline \multirow[t]{2}{*}{ carbon filaments } & \multirow{2}{*}{$\begin{array}{l}\text { catalytic } \\
\text { thermal } \\
\text { decomposition }\end{array}$} & \multirow[t]{2}{*}{$\mathrm{C}_{2} \mathrm{H}_{2}$} & $\begin{array}{l}\text { V }(50 \mathrm{~nm}) / \\
\text { graphite }\end{array}$ & $600-825^{\circ} \mathrm{C}$ & $1.20 \mathrm{eV}$ & $\begin{array}{l}\text { bulk diffusion } \\
\text { (1.21 eV [219]) }\end{array}$ & \multirow[t]{2}{*}{ [212] } \\
\hline & & & $\begin{array}{l}\text { Mo }(10-25 \mathrm{~nm}) / \\
\text { graphite }\end{array}$ & $445-680^{\circ} \mathrm{C}$ & $1.68 \mathrm{eV}$ & $\begin{array}{l}\text { bulk diffusion } \\
\text { (1.78 eV [220]) }\end{array}$ & \\
\hline \multirow[t]{2}{*}{ carbon filaments } & \multirow{2}{*}{$\begin{array}{l}\text { catalytic } \\
\text { thermal } \\
\text { decomposition }\end{array}$} & \multirow{2}{*}{$\mathrm{C}_{2} \mathrm{H}_{2}$} & a-Fe/silica & $530-900{ }^{\circ} \mathrm{C}$ & $0.79 \mathrm{eV}$ & bulk diffusion & \multirow[t]{2}{*}{ [213] } \\
\hline & & & $\begin{array}{l}\text { Y-Fe }(20 \mathrm{~nm}) / \\
\text { graphite }\end{array}$ & $380-685^{\circ} \mathrm{C}$ & $1.47 \mathrm{eV}$ & $\begin{array}{l}\text { bulk diffusion } \\
(1.45-1.62 \mathrm{eV} \\
[221,222])\end{array}$ & \\
\hline carbon filaments & $\begin{array}{l}\text { catalytic } \\
\text { thermal } \\
\text { decomposition }\end{array}$ & $\begin{array}{l}\text { 1,3-butadiene } \\
\left(\mathrm{C}_{4} \mathrm{H}_{6}\right)+\mathrm{H}_{2}+ \\
\mathrm{Ar}\end{array}$ & $\begin{array}{l}\mathrm{Ni}(10-30 \mathrm{~nm}) / \\
\mathrm{Al}_{2} \mathrm{O}_{3}\end{array}$ & $400-800{ }^{\circ} \mathrm{C}$ & $1.35-1.55 \mathrm{eV}$ & $\begin{array}{l}\text { bulk diffusion of } \\
\text { carbon through the } \\
\text { solid catalyst } \\
\text { particle }\end{array}$ & [85] \\
\hline
\end{tabular}


Table 3: Summary of reports dedicated to the investigation of growth dynamics of nanotubes. Given are the type of synthesized nanotubes, synthesis conditions, calculated activation energy of the nanotube growth and assigned growth rate-limiting process (together with the reported activation energy for this process) in a chronological order. (continued)

\begin{tabular}{|c|c|c|c|c|c|c|c|}
\hline $\begin{array}{l}\text { VA tubular } \\
\text { MWCNT } \\
\text { (20-30 walls) }\end{array}$ & PECVD & $\mathrm{C}_{2} \mathrm{H}_{2}+\mathrm{NH}_{3}$ & $\begin{array}{l}\mathrm{Ni} \text { (or } \mathrm{Co} \text { ) thin } \\
\text { film } \\
(0.5-20 \mathrm{~nm}) / \mathrm{Si} \\
\text { with } \mathrm{SiO}_{2} \text { layer }\end{array}$ & $500-900{ }^{\circ} \mathrm{C}$ & $0.56 \mathrm{eV}$ & $\begin{array}{l}\text { surface diffusion of } \\
\text { carbon across the } \\
\text { catalyst particle }\end{array}$ & [203] \\
\hline SWCNT & laser ablation & $\begin{array}{l}\text { Graphite } \\
\text { target }\end{array}$ & $\begin{array}{l}0.6 \text { atom } \% \mathrm{Ni}+ \\
0.6 \text { atom } \% \mathrm{Co}\end{array}$ & $850-1250^{\circ} \mathrm{C}$ & $0.38 \mathrm{eV}$ & $\begin{array}{l}\text { carbon diffusion } \\
\text { through the molten } \\
\text { catalytic particle }\end{array}$ & [189] \\
\hline $\begin{array}{l}\text { randomly } \\
\text { oriented } \\
\text { MWCNT } \\
(d=5-100 \mathrm{~nm})\end{array}$ & thermal CVD & $\mathrm{C}_{2} \mathrm{H}_{2}+\mathrm{NH}_{3}$ & $\begin{array}{l}\mathrm{Ni} \text { thin film } \\
(3 \mathrm{~nm}) / \mathrm{Si} \text { with } \\
\mathrm{SiO}_{2} \text { layer }\end{array}$ & $550-850^{\circ} \mathrm{C}$ & $1.21 \mathrm{eV}$ & $\begin{array}{l}\text { bulk diffusion of } \\
\text { carbon through the } \\
\text { solid catalyst } \\
\text { particle }\end{array}$ & [204] \\
\hline $\begin{array}{l}\text { VA bamboo-like } \\
\text { CNT } \\
(d=30-100 \mathrm{~nm})\end{array}$ & PECVD & & & & $0.76 \mathrm{eV}$ & $\begin{array}{l}\text { surface diffusion of } \\
\text { carbon across the } \\
\text { catalyst particle }\end{array}$ & \\
\hline $\begin{array}{l}\text { VA bamboo-like } \\
\text { MWCNT } \\
(d=20-150 \mathrm{~nm})\end{array}$ & thermal CVD & $\mathrm{C}_{2} \mathrm{H}_{2}$ & $\mathrm{Fe} / \mathrm{Si}$ & $800-1100^{\circ} \mathrm{C}$ & $1.30 \mathrm{eV}$ & $\begin{array}{l}\text { bulk diffusion of } \\
\text { carbon through the } \\
\text { solid catalyst } \\
\text { particle }\end{array}$ & [200] \\
\hline $\begin{array}{l}\text { VA bamboo-like } \\
\text { CNT }\end{array}$ & PECVD & $\mathrm{C}_{2} \mathrm{H}_{2}+\mathrm{NH}_{3}$ & $\begin{array}{l}\mathrm{Ni} \text { thin film } \\
(6 \mathrm{~nm}) / \mathrm{Si} \text { with } \\
\mathrm{SiO}_{2} \text { layer }\end{array}$ & $120-550^{\circ} \mathrm{C}$ & $0.23 \mathrm{eV}$ & $\begin{array}{l}\text { surface diffusion of } \\
\text { carbon across the } \\
\text { solid catalyst } \\
\text { particle } \\
(0.3 \mathrm{eV}[223])\end{array}$ & [190] \\
\hline $\begin{array}{l}\text { VA MWCNT } \\
(d=10-120 \mathrm{~nm})\end{array}$ & pyrolysis & \multicolumn{2}{|c|}{$\begin{array}{l}\text { Fe, } \mathrm{Co} \text { and } \mathrm{Ni} \text { phthalocyanines } \\
\left(+\mathrm{Ar}+\mathrm{H}_{2}, \mathrm{SiO}_{2} \text { substrate) }\right.\end{array}$} & $700-1000^{\circ} \mathrm{C}$ & $1.30 \mathrm{eV}$ & $\begin{array}{l}\text { bulk diffusion of } \\
\text { carbon through the } \\
\text { solid catalyst } \\
\text { particle } \\
\left(E_{\mathrm{a}}(\mathrm{Y}-\mathrm{Fe})=1.52 \mathrm{eV},\right. \\
E_{\mathrm{a}}(\mathrm{Co})=1.61 \mathrm{eV}, \\
E_{\mathrm{a}}(\mathrm{Ni})=1.43 \mathrm{eV} \\
[181,224])\end{array}$ & [187] \\
\hline $\begin{array}{l}\text { VA MWCNT } \\
(d=10-30 \mathrm{~nm})\end{array}$ & pyrolysis & \multicolumn{2}{|c|}{$\mathrm{C}_{2} \mathrm{H}_{2}+$ ferrocene $(+\mathrm{Ar})$} & $700-1000^{\circ} \mathrm{C}$ & $1.52 \mathrm{eV}$ & $\begin{array}{l}\text { bulk diffusion of } \\
\text { carbon through the } \\
\text { solid catalyst } \\
\text { particle }\end{array}$ & [191] \\
\hline MWCNT & $\begin{array}{l}\text { catalytic } \\
\text { thermal } \\
\text { decomposition }\end{array}$ & $\begin{array}{l}\mathrm{C}_{2} \mathrm{H}_{2}+\mathrm{N}_{2}+ \\
\mathrm{H}_{2}\end{array}$ & $\mathrm{Fe} / \mathrm{SiO}_{2}$ & $600-800^{\circ} \mathrm{C}$ & $1.79 \mathrm{eV}$ & $\begin{array}{l}\text { bulk diffusion of } \\
\text { carbon through the } \\
\text { solid catalyst } \\
\text { particle }\end{array}$ & [82] \\
\hline $\begin{array}{l}\text { tubular MWCNT } \\
(d \approx 10 \mathrm{~nm})\end{array}$ & $\begin{array}{l}\text { microwave } \\
\text { CVD }\end{array}$ & $\mathrm{CH}_{4}+\mathrm{H}_{2}$ & $\begin{array}{l}\mathrm{Fe} \text { (or } \mathrm{Co}, \text { or } \mathrm{Ni}) \\
\text { thin film } \\
(2 \mathrm{~nm}) / \mathrm{Si} \text { with } \\
\mathrm{SiO}_{2} \text { layer }\end{array}$ & $900-1100{ }^{\circ} \mathrm{C}$ & $\begin{array}{l}0.32 \mathrm{eV}(\mathrm{Fe}) \\
0.32 \mathrm{eV}(\mathrm{Co}) \\
0.55 \mathrm{eV}(\mathrm{Ni})\end{array}$ & $\begin{array}{l}\text { bulk diffusion of } \\
\text { carbon through the } \\
\text { molten catalyst } \\
\text { particle }\end{array}$ & [192] \\
\hline $\begin{array}{l}\text { bamboo-like } \\
\text { CNT } \\
(d \approx 10 \mathrm{~nm})\end{array}$ & & & & $800-950^{\circ} \mathrm{C}$ & $\begin{array}{l}1.4 \mathrm{eV}(\mathrm{Fe}) \\
1.5 \mathrm{eV}(\mathrm{Co}) \\
1.6 \mathrm{eV}(\mathrm{Ni})\end{array}$ & $\begin{array}{l}\text { bulk diffusion of } \\
\text { carbon through the } \\
\text { solid catalyst } \\
\text { particle }\end{array}$ & \\
\hline $\begin{array}{l}\text { VA MWCNT } \\
(d=10-20 \mathrm{~nm})\end{array}$ & thermal CVD & $\begin{array}{l}\mathrm{C}_{2} \mathrm{H}_{2}+\text { ferroce } \\
(+\mathrm{Ar}, \text { Si with } \mathrm{S}\end{array}$ & $\begin{array}{l}\text { ne } \\
\mathrm{O}_{2} \text { substrate) }\end{array}$ & $600-800{ }^{\circ} \mathrm{C}$ & $1.30 \mathrm{eV}$ & $\begin{array}{l}\text { bulk diffusion of } \\
\text { carbon through the } \\
\text { solid catalyst } \\
\text { particle }\end{array}$ & [193] \\
\hline VA MWCNT & thermal CVD & $\mathrm{C}_{2} \mathrm{H}_{2}+\mathrm{Ar}$ & $\begin{array}{l}\text { Fe thin film } \\
(3-5 \mathrm{~nm}) / \mathrm{Si} \text { with } \\
\mathrm{SiO}_{2} \text { layer }\end{array}$ & $600-727^{\circ} \mathrm{C}$ & $1.65 \mathrm{eV}$ & $\begin{array}{l}\text { surface reaction at } \\
\text { the gas-catalyst } \\
\text { interface } \\
\left(E_{\mathrm{a}} \text { (heterogeneous }\right. \\
\text { decomposition of } \\
\left.\mathrm{C}_{2} \mathrm{H}_{2}\right)=1.86 \mathrm{eV} \text { at } \\
352-472^{\circ} \mathrm{C}[225] \\
\text { and } 1.13 \mathrm{eV} \text { at } \\
1060-1255^{\circ} \mathrm{C} \\
[226])\end{array}$ & [178] \\
\hline
\end{tabular}


Table 3: Summary of reports dedicated to the investigation of growth dynamics of nanotubes. Given are the type of synthesized nanotubes, synthesis conditions, calculated activation energy of the nanotube growth and assigned growth rate-limiting process (together with the reported activation energy for this process) in a chronological order. (continued)

\begin{tabular}{|c|c|c|c|c|c|c|c|}
\hline $\begin{array}{l}\text { carbon } \\
\text { nanofiber } \\
(d \approx 50 \mathrm{~nm})\end{array}$ & PECVD & $\mathrm{C}_{2} \mathrm{H}_{2}+\mathrm{NH}_{3}$ & $\begin{array}{l}\mathrm{Ni}(\text { or } \mathrm{Co}, \text { or } \mathrm{Fe}) \\
\text { thin film } \\
(5-15 \mathrm{~nm}) / \mathrm{Si} \\
\text { with } \mathrm{SiO}_{2} \text { layer }\end{array}$ & $120-500^{\circ} \mathrm{C}$ & $\begin{array}{l}0.23 \mathrm{eV}(\mathrm{Ni}) \\
0.30 \mathrm{eV}(\mathrm{Co}) \\
0.35 \mathrm{eV}(\mathrm{Fe})\end{array}$ & $\begin{array}{l}\text { surface diffusion of } \\
\text { carbon on the } \\
\text { catalyst particle }\end{array}$ & [42] \\
\hline $\begin{array}{l}\text { VA MWCNT, } \\
\text { DWCNT or } \\
\text { SWCNT }\end{array}$ & thermal CVD & $\underset{\mathrm{Ar}}{\mathrm{C}_{2} \mathrm{H}_{2}}+\mathrm{H}_{2}+$ & $\begin{array}{l}\text { Fe }(1 \mathrm{~nm})+ \\
\text { Mo }(0.2 \mathrm{~nm}) \\
\text { thin films/Al } \\
(10 \mathrm{~nm}) / \mathrm{Si}\end{array}$ & $535-900{ }^{\circ} \mathrm{C}$ & $2.2 \mathrm{eV}$ & $\begin{array}{l}\text { contribution of } \\
\text { multiple chemical } \\
\text { processes input } \\
\text { into activation } \\
\text { energy }\end{array}$ & [160] \\
\hline $\begin{array}{l}\text { SWCNT } \\
(d=0.6-3.5 \mathrm{~nm})\end{array}$ & $\begin{array}{l}\text { catalytic } \\
\text { thermal } \\
\text { decomposition } \\
\text { (inside UHV } \\
\text { TEM) }\end{array}$ & $\mathrm{C}_{2} \mathrm{H}_{2}$ & $\mathrm{Ni}(<6 \mathrm{~nm}) / \mathrm{MgO}$ & $650^{\circ} \mathrm{C}$ & $\begin{array}{l}2.7 \text { eV } \\
\text { (nucleation } \\
\text { barrier for } \\
\text { carbon } \\
\text { adatoms to } \\
\text { form the } \\
\text { hemispherical } \\
\text { graphene cap) }\end{array}$ & $\begin{array}{l}\text { formation of a } \\
\text { hemispherical } \\
\text { graphene cap on } \\
\text { the catalyst particle }\end{array}$ & [64] \\
\hline $\begin{array}{l}\text { MWCNT } \\
(d \approx 15 \mathrm{~nm})\end{array}$ & thermal CVD & $\begin{array}{l}\mathrm{C}_{2} \mathrm{H}_{2} \text { or } \mathrm{C}_{2} \mathrm{H}_{4} \\
+\mathrm{H}_{2}\end{array}$ & $\begin{array}{l}\text { Ni nanoparticles } \\
(\approx 15 \mathrm{~nm}) \\
\text { generated in the } \\
\text { pulsed laser } \\
\text { ablation particle } \\
\text { source }\end{array}$ & $400-600^{\circ} \mathrm{C}$ & $\begin{array}{l}0.80 \mathrm{eV}\left(\mathrm{C}_{2} \mathrm{H}_{2}\right) \\
0.83 \mathrm{eV}\left(\mathrm{C}_{2} \mathrm{H}_{4}\right)\end{array}$ & $\begin{array}{l}\text { both surface } \\
\text { diffusion and bulk } \\
\text { diffusion of carbon } \\
\text { through the catalyst } \\
\text { particle }\end{array}$ & [194] \\
\hline $\begin{array}{l}\text { small diameter } \\
\text { (3-10 nm) } \\
\text { MWCNT }\end{array}$ & $\begin{array}{l}\text { thermal CVD } \\
\text { with a fixed } \\
\text { bed flow }\end{array}$ & $\mathrm{CH}_{4}+\mathrm{N}_{2}$ & $\begin{array}{l}\mathrm{Mo}_{x} \mathrm{Co}_{y-}- \\
\mathrm{Mg}_{1-x-y} \mathrm{O}\end{array}$ & $650-800{ }^{\circ} \mathrm{C}$ & $1.55-1.69 \mathrm{eV}$ & $\begin{array}{l}\text { Decomposition of } \\
\text { gaseous carbon } \\
\text { source }\end{array}$ & [180] \\
\hline $\begin{array}{l}\text { large diameter } \\
(10-30 \mathrm{~nm}) \\
\text { MWCNT }\end{array}$ & reactor & & $\mathrm{Co}_{x} \mathrm{Mg}_{1-x} \mathrm{O}$ & $550-650^{\circ} \mathrm{C}$ & $1.00 \mathrm{eV}$ & (0.69 eV [227]) & \\
\hline $\begin{array}{l}\text { bamboo-like } \\
\text { CNT }\end{array}$ & $\begin{array}{l}\text { catalytic } \\
\text { thermal } \\
\text { decomposition } \\
\text { (inside UHV } \\
\text { TEM) }\end{array}$ & $\mathrm{C}_{2} \mathrm{H}_{2}$ & $\begin{array}{l}\mathrm{Ni}(7-30 \mathrm{~nm}) / \\
\mathrm{MgO}\end{array}$ & $650^{\circ} \mathrm{C}$ & $\begin{array}{l}2.91 \mathrm{eV} \\
\text { (nucleation } \\
\text { barrier for C } \\
\text { adatoms to } \\
\text { form the } \\
\text { circular cap) }\end{array}$ & $\begin{array}{l}\text { formation of a } \\
\text { hemispherical cap } \\
\text { on the catalyst } \\
\text { particle }\end{array}$ & {$[60]$} \\
\hline VA MWCNT & thermal CVD & $\begin{array}{l}\mathrm{C}_{2} \mathrm{H}_{4}+\mathrm{H}_{2}+ \\
\mathrm{Ar}+\mathrm{H}_{2} \mathrm{O}\end{array}$ & $\begin{array}{l}\text { Fe layer } \\
(1.5 \mathrm{~nm}) / \mathrm{Al}_{2} \mathrm{O}_{3} \\
(10 \mathrm{~nm}) \text { layer } \\
\text { on } \mathrm{Si}\end{array}$ & $670-710^{\circ} \mathrm{C}$ & $2.09 \mathrm{eV}$ & surface reaction & [164] \\
\hline $\begin{array}{l}\text { VA MWCNT } \\
(d=10-20 \mathrm{~nm})\end{array}$ & thermal CVD & $\mathrm{C}_{2} \mathrm{H}_{4}$ & $\begin{array}{l}\text { Fe thin film } \\
(2.5 \mathrm{~nm}) / \mathrm{Si} \text { with } \\
\mathrm{SiO}_{2} \text { or } \mathrm{Al}_{2} \mathrm{O}_{3} \\
\text { barrier layers }\end{array}$ & $600-700^{\circ} \mathrm{C}$ & $\begin{array}{l}2.00 \mathrm{eV} \\
\text { (with } \mathrm{Al}_{2} \mathrm{O}_{3} \text { ) } \\
2.16 \mathrm{eV} \\
\text { (with } \mathrm{SiO}_{2} \text { ) }\end{array}$ & $\begin{array}{l}\text { contribution of } \\
\text { multiple chemical } \\
\text { processes input } \\
\text { into activation } \\
\text { energies }\end{array}$ & [195] \\
\hline $\begin{array}{l}\text { MWCNT } \\
(d \approx 10 \mathrm{~nm})\end{array}$ & thermal CVD & $\mathrm{C}_{2} \mathrm{H}_{2}+\mathrm{H}_{2}$ & $\begin{array}{l}\text { Ferrocene or } \\
\text { nickelocene } \\
\text { (produced Fe or } \\
\text { Ni particles of } \\
\approx 3 \mathrm{~nm} \text { size } \\
\text { inside } \\
\text { microplasma } \\
\text { reactor) }\end{array}$ & $475-605^{\circ} \mathrm{C}$ & $\begin{array}{l}1.21 \mathrm{eV}(\mathrm{Fe}) \\
0.76 \mathrm{eV}(\mathrm{Ni})\end{array}$ & $\begin{array}{l}\text { surface diffusion of } \\
\text { carbon on the } \\
\text { catalyst particle }\end{array}$ & [196] \\
\hline MWCNT & thermal CVD & $\underset{\mathrm{He}}{\mathrm{C}_{2} \mathrm{H}_{4}+\mathrm{H}_{2}+}$ & $\mathrm{Fe}-\mathrm{Co} / \mathrm{Al}_{2} \mathrm{O}_{3}$ & $600-700^{\circ} \mathrm{C}$ & $1.35 \mathrm{eV}$ & $\begin{array}{l}\text { elimination of the } \\
\text { first atom of } \\
\text { hydrogen from the } \\
\text { adsorbed } \\
\text { ethylene }\end{array}$ & [176] \\
\hline VA SWCNT & thermal CVD & $\mathrm{C}_{2} \mathrm{H}_{5} \mathrm{OH}$ & (Co,Mo)/quartz & $750-825^{\circ} \mathrm{C}$ & $1.5 \mathrm{eV}$ & $\begin{array}{l}\text { bulk diffusion of } \\
\text { carbon through the } \\
\text { solid catalyst } \\
\text { particle }\end{array}$ & [154] \\
\hline
\end{tabular}


Table 3: Summary of reports dedicated to the investigation of growth dynamics of nanotubes. Given are the type of synthesized nanotubes, synthesis conditions, calculated activation energy of the nanotube growth and assigned growth rate-limiting process (together with the reported activation energy for this process) in a chronological order. (continued)

\begin{tabular}{|c|c|c|c|c|c|c|}
\hline VA MWCNT & thermal CVD & \multicolumn{2}{|c|}{$\begin{array}{l}\text { xylene }+ \text { ferrocene } \\
\left(+\mathrm{H}_{2}+\mathrm{Ar} \text {, conductive substrate }\right)\end{array}$} & $500-820^{\circ} \mathrm{C}$ & $1.41 \mathrm{eV}$ & $\begin{array}{l}\text { bulk diffusion of } \\
\text { carbon through the } \\
\text { catalyst particle }\end{array}$ \\
\hline $\begin{array}{l}\text { MWCNT } \\
(d \approx 10 \mathrm{~nm})\end{array}$ & thermal CVD & $\mathrm{C}_{2} \mathrm{H}_{2}+\mathrm{H}_{2}$ & $\begin{array}{l}\text { ferrocene and } \\
\text { nickelocene } \\
\text { (produced } \mathrm{Ni} \text {, } \\
\text { Fe or } \mathrm{NiFe} \\
\text { particles of } \\
\approx 3-4 \mathrm{~nm} \text { size } \\
\text { inside } \\
\text { microplasma } \\
\text { reactor) }\end{array}$ & $400-600^{\circ} \mathrm{C}$ & $\begin{array}{l}0.76 \mathrm{eV}(\mathrm{Ni}) \\
0.57 \mathrm{eV} \\
\left(\mathrm{Ni}_{0.88} \mathrm{Fe}_{0.12}\right) \\
0.38 \mathrm{eV} \\
\left(\mathrm{Ni}_{0.67} \mathrm{Fe}_{0.33}\right) \\
0.42 \mathrm{eV} \\
\left(\mathrm{Ni}_{0.27} \mathrm{Fe}_{0.73}\right) \\
1.23 \mathrm{eV}(\mathrm{Fe})\end{array}$ & $\begin{array}{l}\text { both surface } \\
\text { diffusion and bulk } \\
\text { diffusion of carbon } \\
\text { through the catalyst } \\
\text { particle }\end{array}$ \\
\hline SWCNT & thermal CVD & $\mathrm{C}_{2} \mathrm{H}_{5} \mathrm{OH}$ & $\begin{array}{l}\mathrm{Ni}(\text { or } \mathrm{Co} \text { ) thin } \\
\text { film/Si with } \mathrm{SiO}_{2}\end{array}$ & $500-900^{\circ} \mathrm{C}$ & $\begin{array}{l}2.8 \mathrm{eV}(\mathrm{Ni}) \\
2.4 \mathrm{eV}(\mathrm{Co})(\text { at } \\
\text { temperatures } \\
\left.\text { of } 500-580^{\circ} \mathrm{C}\right)\end{array}$ & $\begin{array}{l}\text { catalytic } \\
\text { decomposition of } \\
\text { the carbon } \\
\text { precursor } \\
\left(E_{\mathrm{a}}(\text { decomposition }\right. \\
\text { of ethanol into } \\
\text { ethylene })=2.7 \mathrm{eV} \\
[228])\end{array}$ \\
\hline VA SWCNT & thermal CVD & $\mathrm{C}_{2} \mathrm{H}_{5} \mathrm{OH}$ & $\begin{array}{l}\text { Co thin film } \\
(0.8 \mathrm{~nm}) / \mathrm{Al}_{2} \mathrm{O}_{3} \\
(250 \mathrm{~nm}) / \mathrm{Si} \text { with } \\
\mathrm{SiO}_{2}\end{array}$ & $650-1000{ }^{\circ} \mathrm{C}$ & $\begin{array}{l}1.1 \mathrm{eV} \text { (at } \\
\text { temperatures } \\
\text { of } 650-870^{\circ} \mathrm{C} \text { ) }\end{array}$ & $\begin{array}{l}\text { bulk diffusion of } \\
\text { carbon through the } \\
\text { catalyst particle }\end{array}$ \\
\hline $\begin{array}{l}\text { VA MWCNT or } \\
\text { SWCNT }\end{array}$ & $\begin{array}{l}\text { thermal CVD } \\
\text { (atmospheric } \\
\text { or low } \\
\text { pressure) }\end{array}$ & $\underset{\mathrm{Ar}}{\mathrm{C}_{2} \mathrm{H}_{2}}+\mathrm{H}_{2}+$ & $\begin{array}{l}\mathrm{Fe} \text { thin film } \\
(0.5-1 \mathrm{~nm}) / \\
\mathrm{Al}_{2} \mathrm{O}_{3} \\
(10 \mathrm{~nm}) / \mathrm{Si} \text { with } \\
\mathrm{SiO}_{2}\end{array}$ & $560-800^{\circ} \mathrm{C}$ & $\begin{array}{l}0.95 \mathrm{eV} \\
\left(14 \mathrm{mbar} \mathrm{C}_{2} \mathrm{H}_{2}\right) \\
0.93 \mathrm{eV} \\
(0.37 \mathrm{mbar} \\
\left.\mathrm{C}_{2} \mathrm{H}_{2}\right) \\
0.98 \mathrm{eV} \\
\left(10^{-3} \text { mbar }\right. \\
\left.\mathrm{C}_{2} \mathrm{H}_{2}\right)\end{array}$ & $\begin{array}{l}\text { bulk diffusion of } \\
\text { carbon through the } \\
\text { catalyst particle }\end{array}$ \\
\hline $\begin{array}{l}\text { VA MWCNT } \\
(d \approx 10 \mathrm{~nm})\end{array}$ & $\begin{array}{l}\text { decoupled } \\
\text { thermal CVD } \\
\text { (with } \\
\text { preheating of } \\
\text { gaseous } \\
\text { carbon } \\
\text { source) }\end{array}$ & $\begin{array}{l}\mathrm{C}_{2} \mathrm{H}_{4}+\mathrm{H}_{2}+ \\
\mathrm{He}\end{array}$ & $\begin{array}{l}\text { Fe thin film } \\
(1 \mathrm{~nm}) / \mathrm{Al}_{2} \mathrm{O}_{3} \\
(10 \mathrm{~nm}) / \mathrm{Si} \text { with } \\
\mathrm{SiO}_{2}\end{array}$ & $\begin{array}{l}900-1120^{\circ} \mathrm{C} \\
\text { (preheating, } \\
T_{\mathrm{p}} \text { ) } \\
675-875^{\circ} \mathrm{C} \\
(\mathrm{CVD})\end{array}$ & $\begin{array}{l}1.02 \mathrm{eV} \\
\left(T_{p}=980{ }^{\circ} \mathrm{C}\right) \\
1.28 \mathrm{eV} \\
\left(T_{p}=1020^{\circ} \mathrm{C}\right) \\
1.44 \mathrm{eV} \\
\left(T_{p}=1070{ }^{\circ} \mathrm{C}\right) \\
1.88 \mathrm{eV} \\
\left(T_{p}=1120^{\circ} \mathrm{C}\right)\end{array}$ & $\begin{array}{l}\text { cumulative process } \\
\text { of gaseous carbon } \\
\text { source } \\
\text { decomposition and } \\
\text { rearrangement }\end{array}$ \\
\hline \multirow[t]{2}{*}{ VA MWCNT } & $\begin{array}{l}\text { thermal CVD } \\
\text { (with } \\
\text { preheating of } \\
\text { gaseous }\end{array}$ & $\begin{array}{l}\mathrm{C}_{2} \mathrm{H}_{4} \\
\mathrm{Ar}\end{array}$ & $\begin{array}{l}\text { Fe thin film on } \\
\text { conductive } \\
\text { metallic } \\
\text { substrate }\end{array}$ & $\begin{array}{l}650-750{ }^{\circ} \mathrm{C} \\
\text { (preheating) } \\
475^{\circ} \mathrm{C} \\
\text { (substrate) }\end{array}$ & $0.9 \mathrm{eV}$ & $\begin{array}{l}\text { thermal } \\
\text { decomposition of } \\
\text { gaseous carbon } \\
\text { source }\end{array}$ \\
\hline & $\begin{array}{l}\text { carbon } \\
\text { source) }\end{array}$ & & & $\begin{array}{l}\text { no preheating } \\
475-600{ }^{\circ} \mathrm{C} \\
\text { (substrate) }\end{array}$ & $0.1 \mathrm{eV}$ & \\
\hline $\begin{array}{l}\text { MWCNT } \\
(d \approx 15-30 \mathrm{~nm})\end{array}$ & $\begin{array}{l}\text { thermal CVD } \\
\text { with a } \\
\text { fluidized bed } \\
\text { reactor }\end{array}$ & $\begin{array}{l}\mathrm{C}_{2} \mathrm{H}_{2}+\mathrm{H}_{2}+ \\
\mathrm{N}_{2}\end{array}$ & $\begin{array}{l}\mathrm{Fe} \text { (or } \\
\mathrm{Ni} / \text { mesoporous } \\
\mathrm{Al}_{2} \mathrm{O}_{3} \text { (specific } \\
\text { surface area of } \\
157 \mathrm{~m}^{2} / \mathrm{g} \text { ) }\end{array}$ & $700-850^{\circ} \mathrm{C}$ & $\begin{array}{l}0.68 \mathrm{eV}(\mathrm{Ni}) \\
0.27 \mathrm{eV}(\mathrm{Fe})\end{array}$ & not assigned \\
\hline $\begin{array}{l}\text { MWCNT } \\
(d \approx 20-30 \mathrm{~nm})\end{array}$ & $\begin{array}{l}\text { thermal CVD } \\
\text { with a } \\
\text { fluidized bed } \\
\text { reactor }\end{array}$ & $\begin{array}{l}\mathrm{C}_{2} \mathrm{H}_{2}+\mathrm{H}_{2}+ \\
\mathrm{N}_{2}\end{array}$ & $\begin{array}{l}\mathrm{Ni}(\text { or } \\
\mathrm{Co}) / \mathrm{CaCO}_{3} \\
\text { (particle size of } \\
100 \mu \mathrm{m})\end{array}$ & $700-850^{\circ} \mathrm{C}$ & $\begin{array}{l}1.08 \mathrm{eV}(\mathrm{Ni}) \\
0.64 \mathrm{eV}(\mathrm{Co})\end{array}$ & not assigned \\
\hline $\begin{array}{l}\text { VA SWCNT + } \\
\text { MWCNT }\end{array}$ & thermal CVD & $\begin{array}{l}\mathrm{C}_{2} \mathrm{H}_{4}+\mathrm{H}_{2}+ \\
\mathrm{He}\end{array}$ & $\begin{array}{l}\text { Fe thin film } \\
(2 \mathrm{~nm}) / \mathrm{Al}_{2} \mathrm{O}_{3} \\
(30 \mathrm{~nm}) / \mathrm{Si}\end{array}$ & $750-850^{\circ} \mathrm{C}$ & $2.6 \mathrm{eV}$ & $\begin{array}{l}\text { gas phase reaction } \\
\text { that generates } \\
\text { active precursors } \\
\text { for the nanotube } \\
\text { synthesis }\end{array}$ \\
\hline
\end{tabular}


Table 3: Summary of reports dedicated to the investigation of growth dynamics of nanotubes. Given are the type of synthesized nanotubes, synthesis conditions, calculated activation energy of the nanotube growth and assigned growth rate-limiting process (together with the reported activation energy for this process) in a chronological order. (continued)

\begin{tabular}{|c|c|c|c|c|c|c|c|}
\hline VA SWCNT & $\begin{array}{l}\text { water-assisted } \\
\text { thermal CVD }\end{array}$ & $\begin{array}{l}\mathrm{C}_{2} \mathrm{H}_{4}+\mathrm{H}_{2}+ \\
\mathrm{He}\left(+\mathrm{H}_{2} \mathrm{O}\right)\end{array}$ & $\begin{array}{l}\text { Fe thin film } \\
(1 \mathrm{~nm}) / \mathrm{Al}_{2} \mathrm{O}_{3} \\
(10 \mathrm{~nm}) / \mathrm{Si}\end{array}$ & $750-850^{\circ} \mathrm{C}$ & $2.83 \mathrm{eV}$ & not assigned & [167] \\
\hline \multirow[t]{4}{*}{ VA MWCNT } & $\begin{array}{l}\text { laser-assisted } \\
\text { CVD }\end{array}$ & $\begin{array}{l}\mathrm{C}_{2} \mathrm{H}_{4}+\mathrm{H}_{2}+ \\
\mathrm{Ar}\end{array}$ & $\begin{array}{l}\text { Fe thin film } \\
(1.5 \mathrm{~nm}) / \mathrm{Al}_{2} \mathrm{O}_{3} \\
(20 \mathrm{~nm}) / \mathrm{Si}\end{array}$ & $600-1000{ }^{\circ} \mathrm{C}$ & $\begin{array}{l}0.76 \mathrm{eV} \\
\left(\mathrm{Ar} / \mathrm{C}_{2} \mathrm{H}_{4} / \mathrm{H}_{2}=\right. \\
200 / 25 / 50 \\
\text { sccm) }\end{array}$ & $\begin{array}{l}\text { surface diffusion of } \\
\text { carbon on the } \\
\text { catalyst particle }\end{array}$ & [177] \\
\hline & & & & & $\begin{array}{l}0.57 \mathrm{eV} \\
\left(\mathrm{Ar} / \mathrm{C}_{2} \mathrm{H}_{4} / \mathrm{H}_{2}=\right. \\
200 / 250 / 50 \\
\text { sccm })\end{array}$ & $\begin{array}{l}\text { dissociation of } \\
\text { gaseous carbon } \\
\text { source into carbon }\end{array}$ & \\
\hline & & & & & $\begin{array}{l}0.25 \mathrm{eV} \\
\left(\mathrm{Ar} / \mathrm{C}_{2} \mathrm{H}_{4} / \mathrm{H}_{2}=\right. \\
500 / 10 / 50 \\
\text { sccm })\end{array}$ & $\begin{array}{l}\text { adsorption of } \\
\text { gaseous carbon } \\
\text { source on the } \\
\text { catalyst particle }\end{array}$ & \\
\hline & & & & & $\begin{array}{l}0.36 \mathrm{eV} \\
\left(\mathrm{Ar} / \mathrm{C}_{2} \mathrm{H}_{4} / \mathrm{H}_{2}=\right. \\
10 / 10 / 50 \mathrm{sccm})\end{array}$ & $\begin{array}{l}\text { mass diffusion of } \\
\text { gaseous carbon } \\
\text { source }\end{array}$ & \\
\hline MWCNT & $\begin{array}{l}\text { thermal CVD } \\
\text { with a fixed } \\
\text { bed reactor }\end{array}$ & $\begin{array}{l}\mathrm{C}_{2} \mathrm{H}_{4} \\
\mathrm{Ar}\end{array}$ & $\begin{array}{l}\text { Co-Mn-Al-Mg } \\
\text { mixed oxide } \\
\text { catalyst (pore } \\
\text { size of } 4-8 \mathrm{~nm} \text {, } \\
\text { specific surface } \\
\text { area of } \\
\approx 130 \mathrm{~m}^{2} / \mathrm{g} \text { ) }\end{array}$ & $600-700^{\circ} \mathrm{C}$ & $1.11 \mathrm{eV}$ & $\begin{array}{l}\text { possible influence } \\
\text { of mass transfer } \\
\text { phenomena inside } \\
\text { catalyst particles on } \\
\text { the effective } \\
\text { reaction rate }\end{array}$ & [199] \\
\hline \multirow[t]{2}{*}{ VA SWCNT } & $\begin{array}{l}\text { water-assisted } \\
\text { thermal CVD }\end{array}$ & $\begin{array}{l}\mathrm{C}_{2} \mathrm{H}_{4} \text { or } \mathrm{C}_{2} \mathrm{H}_{2} \\
\text { or } \mathrm{C}_{4} \mathrm{H}_{10} \text { or } \\
\mathrm{C}_{3} \mathrm{H}_{8}+\mathrm{He} \\
\left(+\mathrm{H}_{2} \mathrm{O}\right)\end{array}$ & $\begin{array}{l}\text { Fe thin film } \\
(1.8 \mathrm{~nm}) / \mathrm{Al}_{2} \mathrm{O}_{3} \\
(40 \mathrm{~nm})\end{array}$ & $725-825^{\circ} \mathrm{C}$ & $\begin{array}{l}1.0-2.8 \text { eV } \\
\left(\mathrm{C}_{2} \mathrm{H}_{4}, \text { carbon }\right. \\
\text { concentration } \\
\text { in reacting gas } \\
\text { mixture varies } \\
\text { from } 10 \text { to } 3 \%)\end{array}$ & $\begin{array}{l}\text { Increasing carbon } \\
\text { concentration } \\
\text { changes the } \\
\text { rate-limiting process } \\
\text { from gas } \\
\text { dissociation/ } \\
\text { adsorption on the } \\
\text { catalyst to bulk } \\
\text { diffusion of carbon } \\
\text { through the catalyst } \\
\text { particle }\end{array}$ & [168] \\
\hline & & & & & $\begin{array}{l}1.9-2.4 \text { eV } \\
\left(\mathrm{C}_{4} \mathrm{H}_{10} \text {, carbon }\right. \\
\text { concentration } \\
\text { in reacting gas } \\
\text { mixture varies } \\
\text { from } 4 \text { to } 8 \%)\end{array}$ & $\begin{array}{l}\text { At all carbon } \\
\text { concentrations, the } \\
\text { rate limiting } \\
\text { process is gas } \\
\text { dissociation/ } \\
\text { adsorption on the } \\
\text { catalyst }\end{array}$ & \\
\hline
\end{tabular}

tivation energy of the growth of a mixture of MWCNTs and SWCNTs by the thermal CVD synthesis using $\mathrm{C}_{2} \mathrm{H}_{2}$ and $\mathrm{Fe}$ catalyst was estimated to be $0.93-0.98 \mathrm{eV}$ for a broad range of $\mathrm{C}_{2} \mathrm{H}_{2}$ pressures (from $10^{-3}$ to 14 mbar).

The bulk diffusion was also proposed as the growth ratelimiting process in the laser-ablation growth of SWCNTs using a graphitic target with $\mathrm{Ni-Co}$ catalyst [189]. However, low activation energy $(0.38 \mathrm{eV})$ testified that carbon was diffused through the molten catalyst particle. Indeed, the laser ablation process was conducted at higher temperatures (up to $1250^{\circ} \mathrm{C}$ ) than usually used in the thermal CVD synthesis. The authors of [192] found that in the microwave CVD process using $\mathrm{CH}_{4}$ as carbon source and metallic ( $\mathrm{Fe}, \mathrm{Co}, \mathrm{Ni})$ catalysts, the bamboolike MWCNTs were synthesized at temperatures of $800-950{ }^{\circ} \mathrm{C}$ and tubular MWCNTs at $900-1100{ }^{\circ} \mathrm{C}$. The activation energies of the growth of bamboo-like MWCNTs were estimated to be $1.4(\mathrm{Fe}), 1.5(\mathrm{Co})$ and $1.6 \mathrm{eV}(\mathrm{Ni})$, whereas the values for the tubular MWCNTs were 0.32 (Fe and $\mathrm{Co}$ ) and $0.55 \mathrm{eV}$ (Ni). The observed differences were explained by the fact that bulk diffusion was the growth rate-limiting process in both cases, but through solid or molten catalyst particle at different growth temperatures.

Much lower activation energies of the nanotube growth were observed in the PECVD synthesis. In [190], the activation 
energy of the MWCNT growth in the process using $\mathrm{C}_{2} \mathrm{H}_{2}$ as carbon source and $\mathrm{Ni}$ catalyst at low temperatures $\left(120-550^{\circ} \mathrm{C}\right)$ was estimated to be $0.23 \mathrm{eV}$. This value was close to the activation energy of surface diffusion of carbon on polycrystalline $\mathrm{Ni}$. On the basis of these data, it was concluded that the diffusion of carbon on the catalyst surface was the growth rate-limiting step at low temperatures. The use of plasma in the synthesis process increased the dissociation of $\mathrm{C}_{2} \mathrm{H}_{2}$. At low temperatures, the solubility of carbon in Ni was low and thus the bulk diffusion of carbon was limited. However, carbon atoms adsorbed on the surface of the catalyst particle could diffuse across the surface much faster [190]. The similar values of activation energies were calculated by the authors of [42] in the PECVD synthesis using $\mathrm{C}_{2} \mathrm{H}_{2}$ and metallic ( $\left.\mathrm{Fe}, \mathrm{Co}, \mathrm{Ni}\right)$ catalysts: $0.23(\mathrm{Ni}), 0.30$ (Co) and $0.35 \mathrm{eV}(\mathrm{Fe})$. The authors of $[203,204]$ synthesized MWCNTs by the PECVD method using $\mathrm{C}_{2} \mathrm{H}_{2}$ with $\mathrm{Ni}$ and Co catalysts at higher temperatures $\left(500-900{ }^{\circ} \mathrm{C}\right)$ and obtained slightly higher values: $0.56 \mathrm{eV}$ [203] and $0.76 \mathrm{eV}$ [204]. However, they were also attributed to the surface diffusion of carbon on catalyst particles.

The intermediate values of activation energies between bulk and surface carbon diffusion energies obtained in $[183,194,196]$ were attributed to the contribution of both these processes in the nanotube growth. The authors of [194] found that the activation energy of MWCNT growth by the thermal CVD process on $\mathrm{Ni}$ catalyst did not depend on the carbon source: the value equaled 0.80 and $0.83 \mathrm{eV}$ for $\mathrm{C}_{2} \mathrm{H}_{2}$ and $\mathrm{C}_{2} \mathrm{H}_{4}$, respectively. In $[183,196]$, it was demonstrated that the activation energy of MWCNT growth by the thermal CVD method using $\mathrm{C}_{2} \mathrm{H}_{2}$ as carbon source depended on the used catalyst. It equaled $1.21 \mathrm{eV}$ for $\mathrm{Fe}, 0.76 \mathrm{eV}$ for $\mathrm{Ni}$ and $0.38-0.57 \mathrm{eV}$ for bimetallic $\mathrm{Ni}-\mathrm{Fe}$ catalysts.

Several authors found that the reaction at the gaseous carbon source-catalyst interface was the rate-limiting process in the nanotube growth $[155,162,164,175,176,178,180,197]$. In these reports, the calculated activation energies were usually larger than the values for bulk carbon diffusion in metals. For example, the authors of [164] estimated the activation energy of the MWCNT growth by the thermal CVD method using $\mathrm{C}_{2} \mathrm{H}_{4}$ as carbon source and Fe catalyst at $670-710{ }^{\circ} \mathrm{C}$ to be $2.09 \mathrm{eV}$. The authors of [175] calculated the activation energy of the growth of the mixture of SWCNTs and MWCNTs of $2.6 \mathrm{eV}$ in the similar process conducted at higher temperatures $\left(750-850^{\circ} \mathrm{C}\right)$. In [155], the estimated activation energy of SWCNT growth by the thermal CVD method using $\mathrm{C}_{2} \mathrm{H}_{5} \mathrm{OH}$ as carbon source and $\mathrm{Ni}$ or Co catalysts depended on the nature of catalyst. It equaled $2.8 \mathrm{eV}$ for $\mathrm{Ni}$ and $2.4 \mathrm{eV}$ for $\mathrm{Co}$. These values were similar to the activation energy of the decomposition of ethanol into ethylene.
The authors of $[162,197]$ showed that the activation energy of the nanotube growth depended strongly on the pre-treatment of gaseous carbon source. In [162], the carbon precursor $\left(\mathrm{C}_{2} \mathrm{H}_{4}\right)$ was pre-heated at temperatures of $980-1120^{\circ} \mathrm{C}$ before introducing into the CVD reactor with $\mathrm{Fe}$ catalyst on a substrate heated up to $675-875{ }^{\circ} \mathrm{C}$. The calculated activation energy of the nanotube growth depended on the pre-heating temperature of carbon precursor: the value increased from 1.02 to $1.88 \mathrm{eV}$ with increasing temperature from 980 to $1120^{\circ} \mathrm{C}$. On the basis of these data, it was suggested that the cumulative process of gaseous carbon source decomposition and rearrangement was the rate-limiting step. The authors of [197] compared the activation energies of the MWCNT growth in the thermal CVD process using $\mathrm{C}_{2} \mathrm{H}_{4}$ and $\mathrm{Fe}$ catalyst with and without preheating of carbon source. Without preheating of the carbon precursor, the nanotubes grew at temperatures of substrate of $475-600{ }^{\circ} \mathrm{C}$ with the activation energy of $0.1 \mathrm{eV}$. When the carbon precursor was pre-heated at temperatures of $650-750{ }^{\circ} \mathrm{C}$, the nanotubes grew at temperature of substrate of $475^{\circ} \mathrm{C}$ with the activation energy of $0.9 \mathrm{eV}$.

In recent reports $[168,177]$, it was demonstrated that varying the concentration of gaseous carbon precursor in the reacting gas mixture may lead to changes of the activation energy of the nanotube growth due to switching between different growth rate-limiting processes. The authors of [177] performed the growth of MWCNTs by the laser-assisted CVD method using $\mathrm{C}_{2} \mathrm{H}_{4}$ as carbon source ( $\mathrm{Ar}$ and $\mathrm{H}_{2}$ were used as gas carriers) and $\mathrm{Fe}$ catalyst at temperatures of $600-1000{ }^{\circ} \mathrm{C}$. Varying the concentration of $\mathrm{C}_{2} \mathrm{H}_{4}$ allowed changing the activation energy between the values of $0.25 \mathrm{eV}$, which was assigned to the adsorption of gaseous carbon source on the catalyst particle, $0.36 \mathrm{eV}$, which corresponded to the mass diffusion of the carbon source, $0.57 \mathrm{eV}$, which was assigned to the dissociation of the carbon precursor to carbon, and $0.76 \mathrm{eV}$, which corresponded to the surface diffusion of carbon on the catalyst particle. In [168], the SWCNTs were grown by the water-assisted thermal CVD method using $\mathrm{C}_{2} \mathrm{H}_{4}$ or $\mathrm{C}_{4} \mathrm{H}_{10}$ as carbon source (in the mixture with $\mathrm{He}$ and $\mathrm{H}_{2} \mathrm{O}$ ) and $\mathrm{Fe}$ catalyst at $725-825{ }^{\circ} \mathrm{C}$. When $\mathrm{C}_{2} \mathrm{H}_{4}$ was used, the activation energy of the nanotube growth decreased from 2.8 to $1.0 \mathrm{eV}$ with increasing the carbon concentration in the reacting gas mixture from 3 to $10 \%$. This was explained by the fact that the growth rate-limiting process switched from the carbon precursor dissociation/adsorption on the catalyst to the bulk diffusion of carbon through the catalyst particle. When $\mathrm{C}_{4} \mathrm{H}_{10}$ was used, the activation energy increased from 1.9 to $2.4 \mathrm{eV}$ with increasing the carbon concentration in the initial gas mixture from 4 to $8 \%$. This was explained by the fact that the growth rate-limiting step was the gaseous carbon source dissociation/adsorption on the catalyst at all carbon concentrations. 
Lifetime of catalyst. The authors of reports on the nanotube growth where growth kinetics employed a first order exponential model of the catalyst decay demonstrated that the lifetime of catalyst depended on the pressure of gaseous carbon precursor and growth temperature. In [159], it was shown that an increase of the $\mathrm{C}_{2} \mathrm{H}_{4}$ pressure in the water-assisted thermal CVD synthesis of SWCNTs on Fe catalyst led to a gradual decrease of the lifetime of the catalyst. The authors of [168] demonstrated that the lifetime evolution with changing precursor pressure depended on the used carbon feedstock. An increase in the $\mathrm{C}_{2} \mathrm{H}_{4}$ and $\mathrm{C}_{4} \mathrm{H}_{10}$ pressures in the thermal CVD synthesis with Fe catalyst caused a decrease and increase of the lifetime, respectively, and it pointed out different rate-limiting processes of the nanotube growth. Using another carbon precursor $\left(\mathrm{C}_{2} \mathrm{H}_{5} \mathrm{OH}\right)$ and catalysts ( $\mathrm{Ni}$ and $\left.\mathrm{Co}\right)$, the authors of [155] found that the lifetime decreased with increasing the precursor pressure. Additionally, they showed that the lifetime decreased with increasing growth temperature until a critical temperature, above which it increased with temperature. The authors of $[166,168,195]$ reported a decrease of the lifetime with increasing the growth temperature while using different carbon precursors and catalysts.

The correlation between the growth rate of nanotubes and lifetime of catalyst was discussed $[155,159,166,168,195]$. In $[159,195]$, the values were found to be inversely correlated: the lifetime increased while the growth rate decreased and vice versa. In $[155,166]$, it was reported that the evolution of the growth rate and lifetime with temperature was opposite in a limited range of temperatures. The authors of recent publication [168] performed a systematic study of the relationship between the growth rate and lifetime for over 300 SWCNT forests synthesized by the thermal CVD method using different carbon precursors $\left(\mathrm{C}_{2} \mathrm{H}_{2}, \mathrm{C}_{2} \mathrm{H}_{4}, \mathrm{C}_{4} \mathrm{H}_{10}\right.$ and $\left.\mathrm{C}_{3} \mathrm{H}_{8}\right)$, carbon concentrations and growth temperatures. In all cases, they found an inverse relationship between the growth rate of nanotubes and lifetime of catalyst. On the basis of these data, they suggested that this dependence is a fundamental phenomenon that stems from the growth mechanism of nanotubes.

The initial growth rate of SWCNTs in the CVD synthesis is in the order of tens $\mu \mathrm{m} / \mathrm{min}$ and the growth time is in the order of tens of minutes. Depending on the growth rate and growth time of nanotubes, the reported synthesis procedures of SWCNT forests can be classified into two groups [167]. The first group includes processes with low growth rates, long lifetimes of catalysts and long growth times of nanotubes. The long synthesis was conducted by the microwave plasma CVD method with an initial rate of $\approx 2.6 \mu \mathrm{m} / \mathrm{min}$ for $\approx 32 \mathrm{~h}$, and it led to $5 \mathrm{~mm}$ SWCNT forests [229]. Also, long growth of SWCNTs by the water-assisted CVD method with a rate of $1.5 \mu \mathrm{m} / \mathrm{min}$ for $6 \mathrm{~h}$ was reported [230]. The second group includes processes with high growth rates, short lifetimes of catalysts and short growth times of nanotubes. For example, the water-assisted CVD synthesis of SWCNTs (called "supergrowth") was conducted with a rate of $\approx 200 \mu \mathrm{m} / \mathrm{min}$ for $\approx 20 \mathrm{~min}$ [159]. Recently, the authors of [167] managed to increase the growth rate of SWCNTs up to $620 \mu \mathrm{m} / \mathrm{min}$ in the water-assisted CVD process with a growth time of $10 \mathrm{~min}$.

\section{Inner tube growth inside filled SWCNTs}

\section{Growth properties of inner tubes inside fullerene-filled}

SWCNTs. The first attempt to investigate the growth properties of inner tubes was made in 2004 [134]. The authors of [134] traced the time evolution of intensities of inner tube peaks in the RBM band of Raman spectra of fullerene $\mathrm{C}_{60}$-filled SWCNTs annealed at temperatures between 800 and $1200{ }^{\circ} \mathrm{C}$ for up to $250 \mathrm{~h}$. They observed that inner tubes grew faster at higher temperatures. A clear difference between the growth curves of inner tubes with diameters smaller than $\approx 0.7 \mathrm{~nm}$ and those with larger diameters was revealed. For inner tubes with diameters $\leq 0.7 \mathrm{~nm}$, the peak intensities increased in the beginning of annealing and then the rates became flattened. In contrast, for inner tubes with diameters $\geq 0.7 \mathrm{~nm}$, the peak intensities kept growing. On the basis of these data, the growth model of inner tubes was suggested. In the beginning of annealing, adjacent $\mathrm{C}_{60}$ molecules polymerize and form inner tubes with a diameter close to that of $\mathrm{C}_{60}(\approx 0.7 \mathrm{~nm})$. After that, the inner tubes increase their diameter to adjust the spacing between the inner and outer carbon shells to fit the van der Waals distance. As a result, the amount of the $\approx 0.7 \mathrm{~nm}$ diameter inner tubes is decreased and the amount of larger diameter tubes is increased with the annealing time.

The authors of [140] performed a detailed investigation of growth dynamics of inner tubes inside fullerene $\mathrm{C}_{60}$-filled SWCNTs. They monitored the increase of the peak intensities of inner tubes in the RBM-band of Raman spectra of the filled SWCNTs annealed at $1250{ }^{\circ} \mathrm{C}$ for up to $300 \mathrm{~min}$. Figure 13a demonstrates the plot of the RBM peak intensities as a function of transformation time for the $(7,2)$ tube with a diameter of $0.64 \mathrm{~nm}$ and $(8,3)$ tube with a diameter of $0.77 \mathrm{~nm}$. It is clearly visible that the growth of the smaller diameter $(7,2)$ tube starts much earlier than the growth of the $(8,3)$ tube, and it also saturates much earlier. The growth half-times of the $(7,2)$ and $(8,3)$ tubes were estimated to be 16 and $38 \mathrm{~min}$, respectively. Using different excitation laser wavelengths, the authors of [140] also analyzed the growth dynamics of other inner tubes with chiralities of $(5,4),(6,4),(6,5)$ and $(7,5)$ and diameters ranging between 0.61 and $0.82 \mathrm{~nm}$. The growth half-time of these nanotubes was in the range from 16 to $38 \mathrm{~min}$. Figure $13 \mathrm{~b}$ presents the plot of the growth half-time as a function of the inner tube 

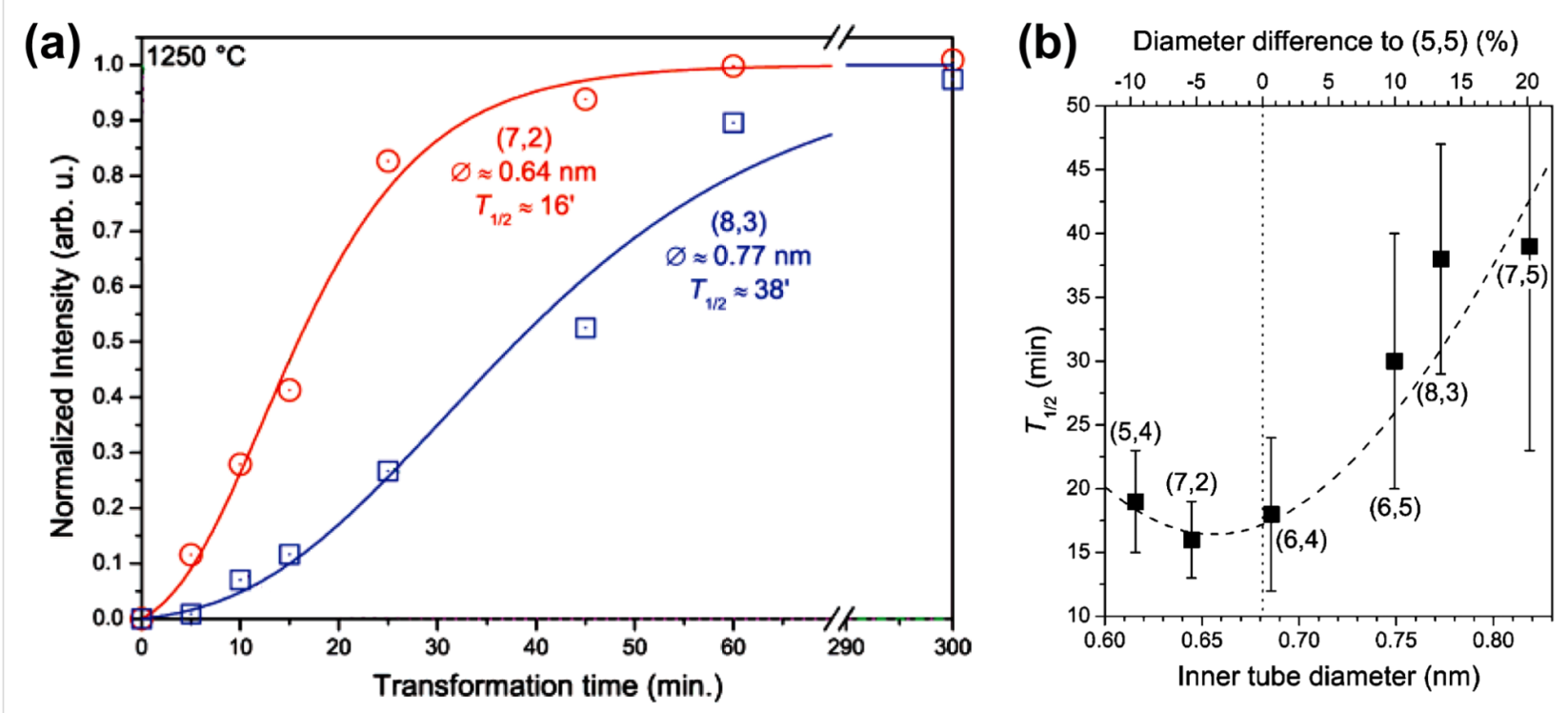

Figure 13: (a) The plot of the RBM peak intensities as a function of transformation time for the $(7,2)$ and $(8,3)$ inner tubes. The experimental data (circles and squares) are shown together with the fitting curves. The intensities for each tube were normalized to the respective maxima of the fitting curves. The tube diameter and estimated growth half-times of the tubes are indicated. (b) The growth half-time as a function of the tube diameter for the $(5,4),(7,2),(6,4),(6,5),(8,3)$ and $(7,5)$ inner tubes. The dotted line indicates the diameter of the $(5,5)$ tube, which is the same as for $C_{60}$ fullerene molecule. The dashed curve is a guide for the eye. Reprinted with permission from [140], copyright 2007 American Chemical Society.

diameter. It was found that the nanotubes with a diameter close to that of $\mathrm{C}_{60}$ (the $(7,2)$ and $(6,4)$ tubes) grew most rapidly, and the growth time increased with increasing the inner tube diameter. These results were in agreement with the above-discussed data reported in [134]. However, the authors did not observe that the amount of smaller diameter inner tubes decreased while the amount of larger diameter tubes increased. Therefore, they did not support the growth model of inner tubes proposed in [134] that small inner tubes were transformed into large tubes with increasing annealing time.

In [137], fullerene $\mathrm{C}_{60}$-filled SWCNTs were converted into DWCNTs by laser and furnace annealings, and the evolution of the transformation process was studied by Raman spectroscopy as a function of the laser power and annealing temperature. In the case of laser annealing, the power of $1064 \mathrm{~nm}$ laser was successively increased from 100 to $500 \mathrm{~mW}$ at a fixed annealing time of $1 \mathrm{~min}$. The intensity of the RBM peaks of inner tubes increased with increasing laser power and reached the maximum at a power of $260 \mathrm{~mW}$. At further increase of laser power, the amount of inner tubes decreased until a complete removal at $500 \mathrm{~mW}$. In the case of furnace annealing, temperature was successively increased from 1000 to $1550{ }^{\circ} \mathrm{C}$ at a fixed annealing time of $1 \mathrm{~h}$. The RBM peaks of inner tubes appeared at temperature of $1250{ }^{\circ} \mathrm{C}$, and their intensity increased gradually with increasing temperature. The smaller diameter inner tubes were formed at lower temperatures than larger diameter ones. These finding was in line with the data reported in [134]. Nevertheless, the authors did not confirm the growth model suggested in [134]. They proposed that the diameter of inner tubes was fully determined by the diameter of the outer nanotubes and it stayed constant during annealing.

In recent theoretical study [231], the mechanisms of fullerene coalescence and transformations of $\mathrm{sp}^{2}$ carbon network to grow inner tubes were studied. A key step of such transformation was shown to be a rotation of a $\mathrm{C}-\mathrm{C}$ bond in a $\mathrm{sp}^{2}$ carbon network (called the Stone-Wales transformation). The growth of inner tubes occurred though the cooperative motion of Stone-Wales defects, and it led to a preferential formation of tubes with high chiral angles and the abundance of metallic armchair tubes in the inner walls of the formed DWCNTs.

\section{Growth properties of inner tubes inside SWCNTs filled with} organometallic molecules. The authors of [232] investigated the temperature-dependent inner tube growth inside SWCNTs filled with ferrocene molecules. The evolution of the Raman spectra of the filled nanotubes with increasing annealing temperature from 500 to $1300{ }^{\circ} \mathrm{C}$ at a fixed growth time of $2 \mathrm{~h}$ was traced. It was found that inner tubes start to be formed at temperature of $500{ }^{\circ} \mathrm{C}$ and they grew rapidly with increasing temperature. Small diameter inner tubes $(\approx 0.5 \mathrm{~nm})$ were stable only until $1000^{\circ} \mathrm{C}$, whereas larger diameter tubes $(\approx 1 \mathrm{~nm})$ were not destructed until $1300^{\circ} \mathrm{C}$. This was explained by a higher reactivity of smaller diameter inner tubes towards oxidation. 
In [233], the inner tubes were formed by laser annealing of ferrocene-filled SWCNTs using a $532 \mathrm{~nm}$ laser. The dependence of the inner tube growth on the laser power at a fixed annealing time of 1 min was investigated by Raman spectroscopy. The laser powers between 80 and $800 \mathrm{~mW}$ were used. The formation of inner tubes was observed at a laser power of $160 \mathrm{~mW}$. The amount of large diameter inner tubes $(\approx 1 \mathrm{~nm})$ increased with increasing laser power, whereas the smaller diameter tubes $(\approx 0.5 \mathrm{~nm})$ were destroyed. The inner tubes with intermediate diameter $(\approx 0.7 \mathrm{~nm})$ were stable at laser powers below $700 \mathrm{~mW}$.

The authors of [144] investigated the growth properties of inner tubes inside SWCNTs filled with ferrocene and Pt (II) acetylacetonate molecules by Raman spectroscopy. It was found that the growth properties were strongly dependent on annealing temperature of the filled SWCNTs. The intensities of RBM peaks of inner tubes were significantly enhanced with increasing temperature. The inner tube growth depended on the type of metal catalyst. The inner nanotubes grew at higher temperatures with a Pt catalyst than with a Fe catalyst. It was observed that smaller diameter inner tubes were formed at lower annealing temperatures than larger diameter ones.

In [234], SWCNTs were filled with ferrocene and annealed at temperatures between 500 and $1000{ }^{\circ} \mathrm{C}$. The analysis of the temperature and diameter-dependent growth of inner tubes was performed by multifrequency Raman spectroscopy. The growth temperatures of three individual-chirality inner tubes with chiralities of $(6,5)\left(d_{\mathrm{t}}=0.753 \mathrm{~nm}\right),(14,1)\left(d_{\mathrm{t}}=1.142 \mathrm{~nm}\right)$ and $(10,4)\left(d_{\mathrm{t}}=0.983 \mathrm{~nm}\right)$ were compared by tracing changes in the intensity of the tube RBM peaks with increasing annealing temperature [234]. The peak intensities of all of these inner tubes increased with increasing annealing temperature from 500 to $800{ }^{\circ} \mathrm{C}$ [234]. The different-diameter inner tubes were characterized by different growth rates. The larger diameter tubes had higher temperature of start of the growth. This temperature amounted to $\approx 500{ }^{\circ} \mathrm{C}$ for the 0.753 and $0.983 \mathrm{~nm}$ diameter tubes and $600{ }^{\circ} \mathrm{C}$ for the $1.142 \mathrm{~nm}$ diameter tubes. Also, the temperature at which the intensity of the inner tube peak was saturated increased from $\approx 700{ }^{\circ} \mathrm{C}$ for the $0.753 \mathrm{~nm}$ diameter tubes to $\approx 800{ }^{\circ} \mathrm{C}$ for the $1.142 \mathrm{~nm}$ diameter tubes [234].

The authors of [235] investigated the temperature-dependent inner tube growth inside the nickelocene-filled SWCNTs and samples annealed at temperatures ranging from 375 to $1200{ }^{\circ} \mathrm{C}$. The changes in the intensity of the inner tube RBM peaks in Raman spectra of the annealed samples were traced (Figure 14a). For eight inner tubes with chiralities of $(12,6)$, $(14,2),(11,5),(12,3),(10,3),(7,6),(8,4)$ and $(7,5)$ the temperature at which the intensity of inner tube RBM peak reaches half of its maximum was determined. This temperature was in the range from 490 to $600{ }^{\circ} \mathrm{C}$ for different inner tubes. Figure $14 \mathrm{~b}$ shows the dependence of the growth temperature on the inner tube diameter and chiral angle [235]. It is clearly seen that the growth temperature is increased for larger diameter tubes. At the same time, the growth temperature does not depend on chiral angle of inner tubes [235]. (a)

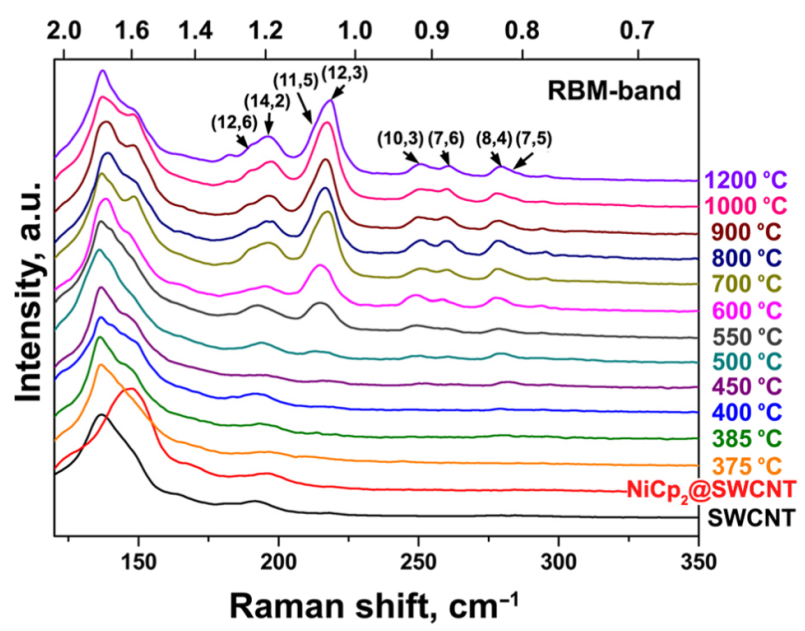

(b)

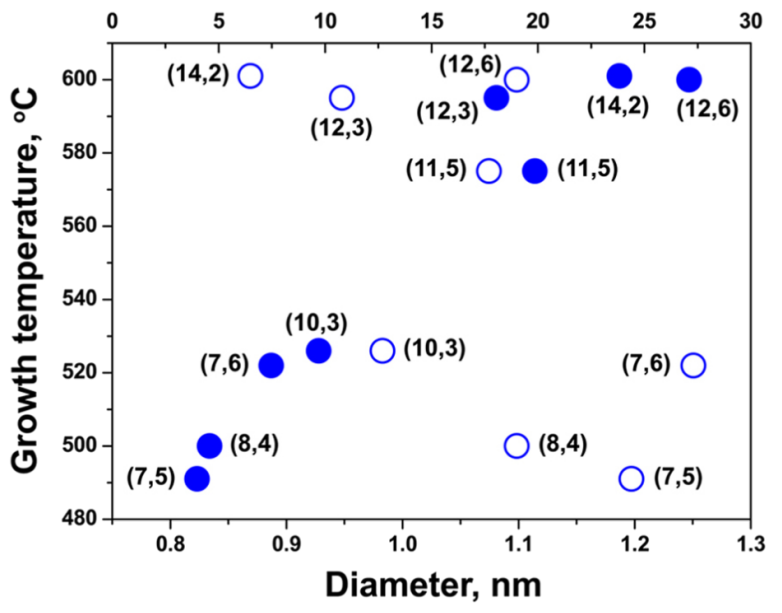

Figure 14: (a) The RBM-band of Raman spectra of the pristine, NiCp 2 -filled SWCNTs and samples annealed at temperatures between 375 and $1200{ }^{\circ} \mathrm{C}$ for $2 \mathrm{~h}$ acquired at a laser wavelength of $647 \mathrm{~nm}\left(E_{\mathrm{ex}}=1.92 \mathrm{eV}\right)$. The chiral indexes of inner tubes are indicated above the respective peaks. (b) The temperature at which the intensity of inner tube RBM peak reaches half of its maximum plotted against the inner tube diameter (filled circles) and chiral angle (empty circles). The chirality indexes of the respective inner tubes are indicated near every circle. Reprinted with permission from [235], copyright 2015 Wiley-VCH Verlag GmbH \& Co. KGaA, Weinheim. 


\section{Conclusion}

This paper presented the comprehensive review of the current status of research on growth dynamics of carbon nanotubes. The progress in synthesis methods of nanotubes, in particular the CVD approach, allowed obtaining high purity nanotube forests or individual tubes on substrates and even single chirality tubes, which is the key for the detailed investigation of their growth dynamics.

At present, vapor-liquid-solid and vapor-solid-solid models, the tip- and base-growth models as well as the tangential and perpendicular growth modes are well accepted for the growth of nanotubes. The authors debated whether the catalyst particle is in liquid or solid state during the nanotube growth. However, in situ HRTEM showed that the catalytic particles for SWCNTs and MWCNTs are solid at typical synthesis conditions. The still open questions are whether metallic catalyst particle does transform to carbide particle during the growth process, whether subsurface intermediate carbide is formed on the metallic particle and whether the synthesis on purely metal carbide catalytic particle is possible. However, recent reports showed that typical catalysts undergo carburization (full or partial) under usual synthesis conditions of nanotubes and that metal carbides can catalyze the nanotube growth. The tuning of synthesis conditions of nanotubes allows obtaining the samples of single chirality tubes. However, the mechanism of chirality selective growth of nanotubes is still debated. The growth mechanism of inner tubes inside the host SWCNTs is different as compared to the mechanism of the nanotube growth in the CVD process. In the conventional bulk-scale synthesis, the nanotube growth terminates when the catalytic particle becomes deactivated by graphitic carbons shells. In contrast, the growth conditions of inner tubes inside the host SWCNTs are homogeneous and constant. The inner tube growth continues for many hours until the entire carbon source is exhausted.

Significant progress was achieved in the investigation of growth dynamics of carbon nanotubes. A mathematical growth model for description of catalyst lifetime-limited kinetics of the nanotube growth was obtained. It allowed quantifying the characteristics of growth dynamics, such as growth rate of nanotubes, lifetime of catalyst and activation energy of the tube growth. On the basis of the systematization and classification of the reports on the calculation of growth rates, the parameters on which the growth rate depends were highlighted. It was found that the growth rate of nanotubes depends on the pressure of carbon precursor, size and chemical nature of catalyst particle and synthesis temperature. On the basis of the systematization of the reports on the calculation of activation energy, the values characterizing the tube growth in the processes using various synthesis parameters (carbon precursor, catalyst, synthesis tempera- ture, pressure) were classified. The assignment of the growth rate-limiting mechanisms on the basis of the calculated activation energies was analyzed. In many cases of the thermal CVD synthesis of nanotubes, bulk diffusion of carbon through the catalyst particle was found to be the process limiting the growth rate. In contrast, in the PECVD surface diffusion of carbon across the catalyst particle was the rate-limiting step. In some cases, contributions of multiple chemical processes were reflected in the activation energies, and the growth rate-limiting process changed during the synthesis procedure, depending on process parameters. The correlation between the growth rate of nanotubes and lifetime of the catalyst was revealed. The values were found to be inversely correlated: the lifetime increased while the growth rate decreased and vice versa. The systematization of the reports on the investigation of the growth properties of inner tubes inside SWCNTs filled with fullerene molecules showed that the nanotubes with a diameter close to that of $\mathrm{C}_{60}$ grew most rapidly, and the growth time increased with increasing the inner tube diameter. For the inner tubes formed inside SWCNTs filled with organometallic compounds, the growth temperatures were found to be higher for larger diameter tubes.

This review is a result of a detailed systematic investigation of 235 reports. It provides a valuable insight into growth dynamics of carbon nanotubes grown either in a CVD process or by nanochemical reactions inside host SWCNTs. The reports on the synthesis and investigation of nanotubes are for the first time summarized by the growth rates and calculated activation energies of the nanotube growth and growth rate-limiting steps. The conducted investigations allowed revealing the parameters on which growth dynamics of nanotubes depends, which opens a way of controlling the growth mechanism of nanotubes.

In conclusion, despite a large progress in the synthesis of nanotubes and understanding of their growth dynamics, many peculiarities of the growth mechanism are still debated. The synthesis of nanotubes in stable conditions with well-controllable synthesis parameters such as carbon precursor, catalyst, pressure and temperature is demanded for the production of nanotubes with well-defined properties.

\section{References}

1. Bethune, D. S.; Kiang, C. H.; de Vries, M. S.; Gorman, G.; Savoy, R.; Vazquez, J.; Beyers, R. Nature 1993, 363, 605-607. doi:10.1038/363605a0

2. Iijima, S.; Ichihashi, T. Nature 1993, 363, 603-605. doi:10.1038/363603a0

3. Saito, R.; Dresselhaus, G.; Dresselhaus, M. S. Physical properties of carbon nanotube; Imperial College Press: London, UK, 1998.

4. Charlier, J.-C.; Blase, X.; Roche, S. Rev. Mod. Phys. 2007, 79, 677-732. doi:10.1103/RevModPhys.79.677 
5. Dai, H. J. Nanotube growth and characterization. In Carbon Nanotubes: Topics in Applied Physics; Dresselhaus, M. S.; Dresselhaus, G.; Avouris, P., Eds.; Springer-Verlag: Berlin, Germany, 2001; Vol. 80, pp 29-53. doi:10.1007/3-540-39947-x_3

6. Joselevich, E.; Dai, H. J.; Liu, J.; Hata, K.; Windle, A. H. Carbon nanotube synthesis and organization. In Carbon Nanotubes: Topics in Applied Physics; Jorio, A.; Dresselhaus, G.; Dresselhaus, M. S., Eds.; Springer-Verlag: Berlin, Germany, 2008; Vol. 111, pp 101-165. doi:10.1007/978-3-540-72865-8_4

7. Ding, L.; Tselev, A.; Wang, J. Y.; Yuan, D. N.; Chu, H. B.; McNicholas, T. P.; Li, Y.; Liu, J. Nano Lett. 2009, 9, 800-805. doi:10.1021/nl803496s

8. Li, Y. M.; Mann, D.; Rolandi, M.; Kim, W.; Ural, A.; Hung, S.; Javey, A.; Cao, J.; Wang, D. W.; Yenilmez, E.; Wang, Q.; Gibbons, J. F.; Nishi, Y.; Dai, H. J. Nano Lett. 2004, 4, 317-321. doi:10.1021/nl035097c

9. Avouris, P.; Chen, Z. H.; Perebeinos, V. Nat. Nanotechnol. 2007, 2, 605-615. doi:10.1038/nnano.2007.300

10. Bachtold, A.; Hadley, P.; Nakanishi, T.; Dekker, C. Science 2001, 294, 1317-1320. doi:10.1126/science.1065824

11. Chen, Z. H.; Appenzeller, J.; Lin, Y. M.; Sippel-Oakley, J.; Rinzler, A. G.; Tang, J. Y.; Wind, S. J.; Solomon, P. M.; Avouris, P. Science 2006, 311, 1735. doi:10.1126/science.1122797

12. Tans, S. J.; Verschueren, A. R. M.; Dekker, C. Nature 1998, 393, 49-52. doi:10.1038/29954

13. Artukovic, E.; Kaempgen, M.; Hecht, D. S.; Roth, S.; Grüner, G. Nano Lett. 2005, 5, 757-760. doi:10.1021/nl050254o

14. Cao, Q.; Kim, H.-S.; Pimparkar, N.; Kulkarni, J. P.; Wang, C. J.; Shim, M.; Roy, K.; Alam, M. A.; Rogers, J. A. Nature 2008, 454, 495-500. doi:10.1038/nature07110

15. Huang, Y. X.; Palkar, P. V.; Li, L.-J.; Zhang, H.; Chen, P. Biosens. Bioelectron. 2010, 25, 1834-1837. doi:10.1016/j.bios.2009.12.011

16. Kharlamova, M. V. Single-walled Carbon Nanotubes: Synthesis and Modification of the Electronic Structure. In Handbook of Carbon Nano Materials; D'Souza, F.; Kadish, K. M., Eds.; World Scientific Publishing, 2015; Vol. 7, pp 185-229. doi:10.1142/9789814678919_0005

17. Yan, Y. B.; Miao, J. W.; Yang, Z. H.; Xiao, F.-X.; Yang, H. B.; Liu, B.; Yang, Y. H. Chem. Soc. Rev. 2015, 44, 3295-3346. doi:10.1039/C4CS00492B

18. Kharlamova, M. V. Prog. Mater. Sci. 2016, 77, 125-211. doi:10.1016/j.pmatsci.2015.09.001

19. Baker, R. T. K.; Barber, M. A.; Harris, P. S.; Feates, F. S.; Waite, R. J. J. Catal. 1972, 26, 51. doi:10.1016/0021-9517(72)90032-2

20. Baker, R. T. K.; Harris, P. S.; Thomas, R. B.; Waite, R. J. J. Catal. 1973, 30, 86-95. doi:10.1016/0021-9517(73)90055-9

21. Baker, R. T. K.; Harris, P. S. The formation of filamentous carbon. In Chemistry and Physics of Carbon; Walker, P. L.; Thrower, P. A., Eds.; Marcel Dekker: New York, USA, 1978; Vol. 14, pp 83-165.

22. Wagner, R. S.; Ellis, W. C. Appl. Phys. Lett. 1964, 4, 89-90. doi:10.1063/1.1753975

23. Jourdain, V.; Bichara, C. Carbon 2013, 58, 2-39. doi:10.1016/j.carbon.2013.02.046

24. Benissad, F.; Gadelle, P.; Coulon, M.; Bonnetain, L. Carbon 1988, 26, 425-432. doi:10.1016/0008-6223(88)90141-8

25. Tibbetts, G. G.; Bernardo, C. A.; Gorkiewicz, D. W.; Alig, R. L. Carbon 1994, 32, 569-576. doi:10.1016/0008-6223(94)90074-4

26. Madroñero, A. J. Mater. Sci. 1995, 30, 2061-2066. doi:10.1007/BF00353034
27. Kukovitsky, E. F.; L'vov, S. G.; Sainov, N. A. Chem. Phys. Lett. 2000, 317, 65-70. doi:10.1016/S0009-2614(99)01299-3

28. Kanzow, H.; Ding, A. Phys. Rev. B 1999, 60, 11180-11186. doi:10.1103/PhysRevB.60.11180

29. Gavillet, J.; Loiseau, A.; Journet, C.; Willaime, F.; Ducastelle, F.; Charlier, J.-C. Phys. Rev. Lett. 2001, 87, No. 275504. doi:10.1103/PhysRevLett.87.275504

30. Ding, F.; Rosén, A.; Bolton, K. Chem. Phys. Lett. 2004, 393, 309-313. doi:10.1016/j.cplett.2004.06.056

31. Ding, F.; Bolton, K.; Rosén, A. J. Phys. Chem. B 2004, 108, 17369-17377. doi:10.1021/jp046645t

32. Ding, F.; Bolton, K.; Rosén, A. Comput. Mater. Sci. 2006, 35 , 243-246. doi:10.1016/j.commatsci.2004.08.010

33. Tessonnier, J.-P.; Su, D. S. ChemSusChem 2011, 4, 824-847. doi:10.1002/cssc.201100175

34. Kumar, M. Carbon Nanotube Synthesis and Growth Mechanism. In Carbon Nanotubes - Synthesis, Characterization, Applications; Yellampalli, S., Ed.; InTech: Rijeka, Croatia, 2011; pp 147-170. doi:10.5772/19331

35. Baird, T.; Fryer, J. R.; Grant, B. Nature 1971, 233, 329-330. doi:10.1038/233329b0

36. Evans, E. L.; Thomas, J. M.; Thrower, P. A.; Walker, P. L. Carbon 1973, 11, 441-445. doi:10.1016/0008-6223(73)90302-3

37. Rostrup-Nielsen, J.; Trimm, D. L. J. Catal. 1977, 48, 155-165. doi:10.1016/0021-9517(77)90087-2

38. Klinke, C.; Bonard, J.-M.; Kern, K. Phys. Rev. B 2005, 71, 035403. doi:10.1103/PhysRevB.71.035403

39. Oberlin, A.; Endo, M.; Koyama, T. J. Cryst. Growth 1976, 32, 335-349. doi:10.1016/0022-0248(76)90115-9

40. Yang, R. T.; Chen, J. P. J. Catal. 1989, 115, 52-64. doi:10.1016/0021-9517(89)90006-7

41. Helveg, S.; López-Cartes, C.; Sehested, J.; Hansen, P. L.; Clausen, B. S.; Rostrup-Nielsen, J. R.; Abild-Pedersen, F.; Nørskov, J. K. Nature 2004, 427, 426-429. doi:10.1038/nature02278

42. Hofmann, S.; Csányi, G.; Ferrari, A. C.; Payne, M. C.; Robertson, J. Phys. Rev. Lett. 2005, 95, No. 036101. doi:10.1103/PhysRevLett.95.036101

43. Seidel, R.; Duesberg, G. S.; Unger, E.; Graham, A. P.; Liebau, M.; Kreupl, F. J. Phys. Chem. B 2004, 108, 1888-1893. doi:10.1021/jp037063z

44. Raty, J.-Y.; Gygi, F.; Galli, G. Phys. Rev. Lett. 2005, 95, No. 096103. doi:10.1103/PhysRevLett.95.096103

45. Nessim, G. D. Nanoscale 2010, 2, 1306-1323. doi:10.1039/b9nr00427k

46. Chen, Y. B.; Zhang, J. Carbon 2011, 49, 3316-3324. doi:10.1016/j.carbon.2011.04.016

47. Takagi, D.; Kobayashi, Y.; Hommam, Y. J. Am. Chem. Soc. 2009, 131, 6922-6923. doi:10.1021/ja901295j

48. Steiner, S. A., III; Baumann, T. F.; Bayer, B. C.; Blume, R.; Worsley, M. A.; MoberlyChan, W. J.; Shaw, E. L.; Schlögl, R.; Hart, A. J.; Hofmann, S.; Wardle, B. L. J. Am. Chem. Soc. 2009, 131, 12144-12154. doi:10.1021/ja902913r

49. Liu, B. L.; Tang, D.-M.; Sun, C. H.; Liu, C.; Ren, W. C.; Li, F.; Yu, W.-J.; Yin, L.-C.; Zhang, L. L.; Jiang, C. B.; Cheng, H.-M. J. Am. Chem. Soc. 2011, 133, 197-199. doi:10.1021/ja107855q

50. Moisala, A.; Nasibulin, A. G.; Kauppinen, E. I. J. Phys.: Condens. Matter 2003, 15, S3011-S3035. doi:10.1088/0953-8984/15/42/003

51. Friedlander, S. K. Smoke, Dust, and Haze, 2nd ed.; Oxford University Press: New York, USA, 2000. 
52. Wirth, C. T.; Hofmann, S.; Robertson, J. Diamond Relat. Mater. 2009, 18, 940-945. doi:10.1016/j.diamond.2009.01.030

53. Ding, F.; Bolton, K.; Rosén, A. J. Vac. Sci. Technol., A 2004, 22, 1471-1476. doi:10.1116/1.1752895

54. Qi, Y.; Çağin, T.; Johnson, W. L.; Goddard, W. A., III. J. Chem. Phys. 2001, 115, 385-394. doi:10.1063/1.1373664

55. Diarra, M.; Zappelli, A.; Amara, H.; Ducastelle, F.; Bichara, C. Phys. Rev. Lett. 2012, 109, No. 185501. doi:10.1103/physrevlett.109.185501

56. Harutyunyan, A. R.; Tokune, T.; Mora, E. Appl. Phys. Lett. 2005, 87, No. 051919. doi:10.1063/1.2005395

57. Ago, H.; Ohshima, S.; Uchida, K.; Yumura, M. J. Phys. Chem. B 2001, 105, 10453-10456. doi:10.1021/jp012084j

58. Saito, T.; Ohshima, S.; Xu, W.-C.; Ago, H.; Yumura, M.; lijima, S. J. Phys. Chem. B 2005, 109, 10647-10652. doi:10.1021/jp044200z

59. Hofmann, S.; Sharma, R.; Ducati, C.; Du, G.; Mattevi, C.; Cepek, C.; Cantoro, M.; Pisana, S.; Parvez, A.; Cervantes-Sodi, F.; Ferrari, A. C.; Dunin-Borkowski, R.; Lizzit, S.; Petaccia, L.; Goldoni, A.; Robertson, J. Nano Lett. 2007, 7, 602-608. doi:10.1021/n10624824

60. Lin, M.; Tan, J. P. Y.; Boothroyd, C.; Loh, K. P.; Tok, E. S.; Foo, Y.-L. Nano Lett. 2007, 7, 2234-2238. doi:10.1021/nl070681x

61. Yoshida, H.; Takeda, S.; Uchiyama, T.; Kohno, H.; Homma, Y. Nano Lett. 2008, 8, 2082-2086. doi:10.1021/nI080452q

62. Yoshida, H.; Shimizu, T.; Uchiyama, T.; Kohno, H.; Homma, Y.; Takeda, S. Nano Lett. 2009, 9, 3810-3815. doi:10.1021/n19019903

63. Hofmann, S.; Blume, R.; Wirth, C. T.; Cantoro, M.; Sharma, R.; Ducati, C.; Hävecker, M.; Zafeiratos, S.; Schnoerch, P.; Oestereich, A.; Teschner, D.; Albrecht, M.; Knop-Gericke, A.; Schlögl, R.; Robertson, J. J. Phys. Chem. C 2009, 113, 1648-1656. doi:10.1021/jp808560p

64. Lin, M.; Tan, J. P. Y.; Boothroyd, C.; Loh, K. P.; Tok, E. S.; Foo, Y.-L. Nano Lett. 2006, 6, 449-452. doi:10.1021/nl052356k

65. Esconjauregui, S.; Whelan, C. M.; Maex, K. Carbon 2009, 47, 659-669. doi:10.1016/j.carbon.2008.10.047

66. Emmenegger, C.; Bonard, J.-M.; Mauron, P.; Sudan, P.; Lepora, A.; Grobety, B.; Züttel, A.; Schlapbach, L. Carbon 2003, 41, 539-547. doi:10.1016/S0008-6223(02)00362-7

67. Nishimura, K.; Okazaki, N.; Pan, L. J.; Nakayama, Y. Jpn. J. Appl. Phys. 2004, 43, L471-L474. doi:10.1143/JJAP.43.L471

68. Mattevi, C.; Hofmann, S.; Cantoro, M.; Ferrari, A. C.; Robertson, J.; Castellarin-Cudia, C.; Dolafi, S.; Goldoni, A.; Cepek, C. Physica E 2008, 40, 2238-2242. doi:10.1016/j.physe.2007.10.024

69. Ni, L.; Kuroda, K.; Zhou, L.-P.; Ohta, K.; Matsuishi, K.; Nakamura, J. Carbon 2009, 47, 3054-3062. doi:10.1016/j.carbon.2009.07.009

70. Buyanov, R. A.; Chesnokov, V. V.; Afanasev, A. D.; Babenko, V. S. Kinet. Catal. 1977, 18, 839-845.

71. Buyanov, R. A.; Chesnokov, V. V.; Afanasev, A. D. Kinet. Catal. 1979, 20, 166-169.

72. Chesnokov, V. V.; Buyanov, R. A.; Afanasev, A. D. Kinet. Catal. 1979, 20, 390-393.

73. Chesnokov, V. V.; Buyanov, R. A.; Afanasev, A. D. Kinet. Catal. 1983, 24, 1066-1069.

74. Chesnokov, V. V.; Buyanov, R. A. Kinet. Catal. 1987, 28, 353-357.

75. Chesnokov, V. V.; Buyanov, R. A. Usp. Khim. 2000, 69, 675-692. doi:10.1070/RC2000v069n07ABEH000540

76. de Bokx, P. K.; Kock, A. J. H. M.; Boellaard, E.; Klop, W.; Geus, J. W. J. Catal. 1985, 96, 454-467. doi:10.1016/0021-9517(85)90314-8

77. Kock, A. J. H. M.; de Bokx, P. K.; Boellaard, E.; Klop, W.; Geus, J. W. J. Catal. 1985, 96, 468-480. doi:10.1016/0021-9517(85)90315-X
78. Manning, M. P.; Garmirian, J. E.; Reid, R. C. Ind. Eng. Chem. Process Des. Dev. 1982, 21, 404-409. doi:10.1021/i200018a010

79. Alstrup, I. J. Catal. 1988, 109, 241-251. doi:10.1016/0021-9517(88)90207-2

80. Schouten, F. C.; Kaleveld, E. W.; Bootsma, G. A. Surf. Sci. 1977, 63, 460-474. doi:10.1016/0039-6028(77)90359-4

81. Schaper, A. K.; Hou, H. Q.; Greiner, A.; Phillipp, F. J. Catal. 2004, 222, 250-254. doi:10.1016/j.jcat.2003.11.011

82. Pérez-Cabero, M.; Romeo, E.; Royo, C.; Monzón, A.; Guerrero-Ruíz, A.; Rodríguez-Ramos, I. J. Catal. 2004, 224, 197-205. doi:10.1016/j.jcat.2004.03.003

83. Pérez-Cabero, M.; Rodríguez-Ramos, I.; Guerrero-Ruíz, A. J. Catal. 2003, 215, 305-316. doi:10.1016/S0021-9517(03)00026-5

84. Latorre, N.; Romeo, E.; Cazaña, F.; Ubieto, T.; Royo, C.; Villacampa, J. J.; Monzón, A. J. Phys. Chem. C 2010, 114, 4773-4782. doi:10.1021/jp906893m

85. Zaikovskii, V. I.; Chesnokov, V. V.; Buyanov, R. A. Kinet. Catal. 2001, 42, 813-820. doi:10.1023/A:1013235300777

86. Chesnokov, V. V.; Buyanov, R. A.; Afanasiev, A. D. Izv. Sib. Otd. Akad. Nauk SSSR, Ser. Khim. Nauk 1982, 60-64.

87. Chesnokov, V. V.; Zaikovskii, V. I.; Buyanov, R. A.; Molchanov, V. V.; Plyasova, L. M. Kinet. Catal. 1994, 35, 130-135.

88. De Jong, K. P.; Geus, J. W. Catal. Rev.: Sci. Eng. 2000, 42, 481-510. doi:10.1081/CR-100101954

89. Sharma, R.; Moore, E.; Rez, P.; Treacy, M. M. J. Nano Lett. 2009, 9 , 689-694. doi:10.1021/nl803180e

90. Wirth, C. T.; Bayer, B. C.; Gamalski, A. D.; Esconjauregui, S.; Weatherup, R. S.; Ducati, C.; Baehtz, C.; Robertson, J.; Hofmann, S. Chem. Mater. 2012, 24, 4633-4640. doi:10.1021/cm301402g

91. Picher, M.; Lin, P. A.; Gomez-Ballesteros, J. L.; Balbuena, P. B.; Sharma, R. Nano Lett. 2014, 14, 6104-6108. doi:10.1021/nl501977b

92. Landois, P.; Rouziére, S.; Pinault, M.; Porterat, D.; Mocuta, C.; Elkaim, E.; Mayne-L'Hermite, M.; Launois, P. Phys. Status Solidi B 2011, 248, 2449-2453. doi:10.1002/pssb.201100201

93. Wang, Z. H.; Zhang, Z. D.; Choi, C. J.; Kim, B. K. J. Alloys Compd. 2003, 361, 289-293. doi:10.1016/S0925-8388(03)00441-9

94. Zhang, J. Q.; Ostrovski, O. ISIJ Int. 2001, 41, 333-339. doi:10.2355/isijinternational.41.333

95. Wang, Y. Y.; Li, B.; Ho, P. S.; Yao, Z.; Shi, L. Appl. Phys. Lett. 2006, 89, No. 183113. doi:10.1063/1.2382735

96. Li, J.; Papadopoulos, C.; Xu, J. M.; Moskovits, M. Appl. Phys. Lett. 1999, 75, 367-369. doi:10.1063/1.124377

97. Bower, C.; Zhou, O.; Zhu, W.; Werder, D. J.; Jin, S. H. Appl. Phys. Lett. 2000, 77, 2767-2769. doi:10.1063/1.1319529

98. Li, Y. M.; Kim, W.; Zhang, Y. G.; Rolandi, M.; Wang, D. W.; Dai, H. J. J. Phys. Chem. B 2001, 105, 11424-11431. doi:10.1021/jp012085b

99. Sharma, R.; Rez, P.; Treacy, M. M. J.; Stuart, S. J. J. Electron Microsc. 2005, 54, 231-237. doi:10.1093/jmicro/dfi037

100.He, M. S.; Jiang, H.; Kauppi, I.; Fedotov, P. V.; Chernov, A. I.; Obraztsova, E. D.; Cavalca, F.; Wagner, J. B.; Hansen, T. W.; Sainio, J.; Sairanen, E.; Lehtonen, J.; Kauppinen, E. I. J. Mater. Chem. A 2014, 2, 5883-5889. doi:10.1039/c3ta15325h

101. Huang, S. M.; Woodson, M.; Smalley, R.; Liu, J. Nano Lett. 2004, 4, 1025-1028. doi:10.1021/nl049691d

102.Fiawoo, M.-F. C.; Bonnot, A.-M.; Amara, H.; Bichara, C.; Thibault-Pénisson, J.; Loiseau, A. Phys. Rev. Lett. 2012, 108, No. 195503. doi:10.1103/physrevlett.108.195503 
103.He, M.; Magnin, Y.; Amara, H.; Jiang, H.; Cui, H.; Fossard, F.; Castan, A.; Kauppinen, E.; Loiseau, A.; Bichara, C. Carbon 2017, 113 231-236. doi:10.1016/j.carbon.2016.11.057

104.Zhang, F.; Hou, P.-X.; Liu, C.; Wang, B.-W.; Jiang, H.; Chen, M.-L.; Sun, D.-M.; Li, J.-C.; Cong, H.-T.; Kauppinen, E. I.; Cheng, H.-M. Nat. Commun. 2016, 7, No. 11160. doi:10.1038/ncomms 11160

105.Bachilo, S. M.; Balzano, L.; Herrera, J. E.; Pompeo, F.; Resasco, D. E.; Weisman, R. B. J. Am. Chem. Soc. 2003, 125 , 11186-11187. doi:10.1021/ja036622c

106.Lolli, G.; Zhang, L. A.; Balzano, L.; Sakulchaicharoen, N.; Tan, Y. Q.; Resasco, D. E. J. Phys. Chem. B 2006, 110, 2108-2115. doi:10.1021/jp056095e

107.Wang, B.; Poa, C. H. P.; Wei, L.; Li, L.-J.; Yang, Y. H.; Chen, Y. J. Am. Chem. Soc. 2007, 129, 9014-9019. doi:10.1021/ja070808k

108.Wang, B.; Wei, L.; Yao, L.; Li, L.-J.; Yang, Y. H.; Chen, Y. J. Phys. Chem. C 2007, 111, 14612-14616. doi:10.1021/jp0762525

109. Miyauchi, Y. H.; Chiashi, S. H.; Murakami, Y.; Hayashida, Y.; Maruyama, S. Chem. Phys. Lett. 2004, 387, 198-203. doi:10.1016/j.cplett.2004.01.116

110.Li, X. L.; Tu, X. M.; Zaric, S.; Welsher, K.; Seo, W. S.; Zhao, W.; Dai, H. J. J. Am. Chem. Soc. 2007, 129, 15770-15771. doi:10.1021/ja077886s

111.Chiang, W.-H.; Sankaran, R. M. Nat. Mater. 2009, 8, 882-886. doi:10.1038/nmat2531

112.Li, N.; Wang, X. M.; Ren, F.; Haller, G. L.; Pfefferle, L. D. J. Phys. Chem. C 2009, 113, 10070-10078. doi:10.1021/jp903129h

113.Wang, H.; Wang, B.; Quek, X.-Y.; Wei, L.; Zhao, J. W.; Li, L.-J.; Chan-Park, M. B.; Yang, Y. H.; Chen, Y. A. J. Am. Chem. Soc. 2010, 132, 16747-16749. doi:10.1021/ja106937y

114.He, M. S. A.; Chernov, A. I.; Fedotov, P. V.; Obraztsova, E. D.; Rikkinen, E.; Zhu, Z.; Sainio, J.; Jiang, H.; Nasibulin, A. G.; Kauppinen, E. I.; Niemelä, M.; Krause, A. O. I. Chem. Commun. 2011, 47, 1219-1221. doi:10.1039/C0CC02751K

115.He, M.; Chernov, A. I.; Fedotov, P. V.; Obraztsova, E. D.; Sainio, J.; Rikkinen, E.; Jiang, H.; Zhu, Z.; Tian, Y.; Kauppinen, E. I.; Niemelä, M.; Krauset, A. O. I. J. Am. Chem. Soc. 2010, 132, 13994-13996. doi:10.1021/ja106609y

116. Ghorannevis, Z.; Kato, T.; Kaneko, T.; Hatakeyama, R. J. Am. Chem. Soc. 2010, 132, 9570-9572. doi:10.1021/ja103362j

117.Loebick, C. Z.; Podila, R.; Reppert, J.; Chudow, J.; Ren, F.; Haller, G. L.; Rao, A. M.; Pfefferle, L. D. J. Am. Chem. Soc. 2010, 132, 11125-11131. doi:10.1021/ja102011h

118.He, M. S. A.; Chernov, A. I.; Obraztsova, E. D.; Sainio, J.; Rikkinen, E.; Jiang, H.; Zhu, Z.; Kaskela, A.; Nasibulin, A. G.; Kauppinen, E. I.; Niemelä, M.; Krause, O. Nano Res. 2011, 4, 334-342. doi:10.1007/s12274-010-0088-3

119.Zhu, Z.; Jiang, H.; Susi, T.; Nasibulin, A. G.; Kauppinen, E. I. J. Am. Chem. Soc. 2011, 133, 1224-1227. doi:10.1021/ja1087634

120.Zhao, Q. C.; Xu, Z. W.; Hu, Y.; Ding, F.; Zhang, J. Sci. Adv. 2016, 2 No. e1501729. doi:10.1126/sciadv.1501729

121.Liu, B. L.; Ren, W. C.; Li, S. S.; Liu, C.; Cheng, H.-M. Chem. Commun. 2012, 48, 2409-2411. doi:10.1039/c2cc16491d

122. He, M. S.; Jiang, H.; Liu, B. L.; Fedotov, P. V.; Chernov, A. I.; Obraztsova, E. D.; Cavalca, F.; Wagner, J. B.; Hansen, T. W.; Anoshkin, I. V.; Obraztsova, E. A.; Belkin, A. V.; Sairanen, E.; Nasibulin, A. G.; Lehtonen, J.; Kauppinen, E. I. Sci. Rep. 2013, 3, No. 1460. doi:10.1038/srep01460

123.Wang, H.; Wei, L.; Ren, F.; Wang, Q.; Pfefferle, L. D.; Haller, G. L.; Chen, Y. ACS Nano 2013, 7, 614-626. doi:10.1021/nn3047633
124.Yang, F.; Wang, X.; Zhang, D. Q.; Yang, J.; Luo, D.; Xu, Z. W.; Wei, J. K.; Wang, J. Q.; Xu, Z.; Peng, F.; Li, X. M.; Li, R. M.; Li, Y. L.; Li, M. H.; Bai, X. D.; Ding, F.; Li, Y. Nature 2014, 510, 522-524. doi:10.1038/nature13434

125. Yang, F.; Wang, X.; Zhang, D. Q.; Qi, K.; Yang, J.; Xu, Z.; Li, M. H.; Zhao, X. L.; Bai, X. D.; Li, Y. J. Am. Chem. Soc. 2015, 137, 8688-8691. doi:10.1021/jacs.5b04403

126.Zhang, S. C.; Tong, L. M.; Hu, Y.; Kang, L. X.; Zhang, J. J. Am. Chem. Soc. 2015, 137, 8904-8907. doi:10.1021/jacs.5b05384

127. Reich, S.; Li, L.; Robertson, J. Chem. Phys. Lett. 2006, 421, 469-472. doi:10.1016/j.cplett.2006.01.110

128.Ding, F.; Harutyunyan, A. R.; Yakobson, B. I. Proc. Natl. Acad. Sci. U. S. A. 2009, 106, 2506-2509. doi:10.1073/pnas.0811946106

129.Rao, R.; Liptak, D.; Cherukuri, T.; Yakobson, B. I.; Maruyama, B. Nat. Mater. 2012, 11, 213-216. doi:10.1038/nmat3231

130.Liu, B. L.; Liu, J.; Tu, X. M.; Zhang, J. L.; Zheng, M.; Zhou, C. W. Nano Lett. 2013, 13, 4416-4421. doi:10.1021/nl402259k

131. Artyukhov, V. I.; Penev, E. S.; Yakobson, B. I. Nat. Commun. 2014, 5, No. 4892. doi:10.1038/ncomms5892

132.Wang, H.; Yuan, Y.; Wei, L.; Goh, K.; Yu, D. S.; Chen, Y. Carbon 2015, 81, 1-19. doi:10.1016/j.carbon.2014.09.063

133.Bandow, S.; Takizawa, M.; Hirahara, K.; Yudasaka, M.; lijima, S. Chem. Phys. Lett. 2001, 337, 48-54. doi:10.1016/S0009-2614(01)00192-0

134.Bandow, S.; Hiraoka, T.; Yumura, T.; Hirahara, K.; Shinohara, H.; lijima, S. Chem. Phys. Lett. 2004, 384, 320-325. doi:10.1016/j.cplett.2003.12.032

135. Fujita, Y.; Niwa, N.; Bandow, S.; lijima, S. Appl. Phys. A 2006, 85, 307-310. doi:10.1007/s00339-006-3698-6

136. Fujita, Y.; Bandow, S.; lijima, S. Chem. Lett. 2007, 36, 94-95. doi:10.1246/cl.2007.94

137. Kramberger, C.; Waske, A.; Biedermann, K.; Pichler, T.; Gemming, T.; Büchner, B.; Kataura, H. Chem. Phys. Lett. 2005, 407, 254-259. doi:10.1016/j.cplett.2005.03.089

138.Pfeiffer, R.; Kuzmany, H.; Kramberger, C.; Schaman, C.; Pichler, T.; Kataura, H.; Achiba, Y.; Kürti, J.; Zólyomi, V. Phys. Rev. Lett. 2003, 90, No. 225501. doi:10.1103/physrevlett.90.225501

139. Pfeiffer, R.; Simon, F.; Kuzmany, H.; Popov, V. N. Phys. Rev. B 2005, 72, No. 161404. doi:10.1103/PhysRevB.72.161404

140.Pfeiffer, R.; Holzweber, M.; Peterlik, H.; Kuzmany, H.; Liu, Z.; Suenaga, K.; Kataura, H. Nano Lett. 2007, 7, 2428-2434. doi:10.1021/nl071107o

141.Simon, F.; Kramberger, C.; Pfeiffer, R.; Kuzmany, H.; Zólyomi, V.; Kurti, J.; Singer, P. M.; Alloul, H. Phys. Rev. Lett. 2005, 95, No. 017401. doi:10.1103/PhysRevLett.95.017401

142.Simon, F.; Kukovecz, Á.; Kramberger, C.; Pfeiffer, R.; Hasi, F.; Kuzmany, H.; Kataura, H. Phys. Rev. B 2005, 71, No. 165439. doi:10.1103/physrevb.71.165439

143. Shiozawa, H.; Pichler, T.; Grüneis, A.; Pfeiffer, R.; Kuzmany, H.; Liu, Z.; Suenaga, K.; Kataura, H. Adv. Mater. 2008, 20, 1443-1449. doi:10.1002/adma.200701466

144.Shiozawa, H.; Kramberger, C.; Pfeiffer, R.; Kuzmany, H.; Pichler, T.; Liu, Z.; Suenaga, K.; Kataura, H.; Silva, S. R. P. Adv. Mater. 2010, 22, 3685-3689. doi:10.1002/adma.201001211

145.Kharlamova, M. V.; Sauer, M.; Saito, T.; Sato, Y.; Suenaga, K.; Pichler, T.; Shiozawa, H. Nanoscale 2015, 7, 1383-1391. doi:10.1039/C4NR05586A 
146.Shiozawa, H.; Pichler, T.; Kramberger, C.; Rümmeli, M.; Batchelor, D.; Liu, Z.; Suenaga, K.; Kataura, H.; Silva, S. R. P. Phys. Rev. Lett. 2009, 102, No. 046804. doi:10.1103/physrevlett.102.046804

147.Kataura, H.; Maniwa, Y.; Abe, M.; Fujiwara, A.; Kodama, T.; Kikuchi, K.; Imahori, H.; Misaki, Y.; Suzuki, S.; Achiba, Y. Appl. Phys. A 2002, 74, 349-354. doi:10.1007/s003390201276

148. Kim, K. S.; Winograd, N. Surf. Sci. 1974, 43, 625-643. doi:10.1016/0039-6028(74)90281-7

149. Löchel, B. P.; Strehblow, H. H. J. Electrochem. Soc. 1984, 131, 713-723. doi:10.1149/1.2115678

150. Greenwood, N. N.; Earnshaw, A. Chemistry of the elements, 2nd ed.; Elsevier, 1997.

151.Leng, Y. G.; Shao, H. Y.; Wang, Y. T.; Suzuki, M.; Li, X. G. J. Nanosci. Nanotechnol. 2006, 6, 221-226.

152.Sinharoy, S.; Levenson, L. L. Thin Solid Films 1978, 53, 31-36. doi:10.1016/0040-6090(78)90367-X

153.Kovács, G. J.; Bertóti, I.; Radnóczi, G. Thin Solid Films 2008, 516, 7942-7946. doi:10.1016/j.tsf.2008.06.005

154.Einarsson, E.; Murakami, Y.; Kadowaki, M.; Maruyama, S. Carbon 2008, 46, 923-930. doi:10.1016/j.carbon.2008.02.021

155.Picher, M.; Anglaret, E.; Arenal, R.; Jourdain, V. Nano Lett. 2009, 9 , 542-547. doi:10.1021/nl802661z

156.Sharma, R.; Rez, P.; Brown, M.; Du, G. H.; Treacy, M. M. J. Nanotechnology 2007, 18, No. 125602. doi:10.1088/0957-4484/18/12/125602

157. Marchand, M.; Journet, C.; Guillot, D.; Benoit, J.-M.; Yakobson, B. I.; Purcell, S. T. Nano Lett. 2009, 9, 2961-2966. doi:10.1021/nl901380u

158. Finnie, P.; Li-Pook-Than, A.; Lefebvre, J. Nano Res. 2009, 2 , 783-792. doi:10.1007/s12274-009-9076-x

159.Futaba, D. N.; Hata, K.; Yamada, T.; Mizuno, K.; Yumura, M.; lijima, S. Phys. Rev. Lett. 2005, 95, No. 056104. doi:10.1103/PhysRevLett.95.056104

160.Puretzky, A. A.; Geohegan, D. B.; Jesse, S.; Ivanov, I. N.; Eres, G Appl. Phys. A 2005, 81, 223-240. doi:10.1007/s00339-005-3256-7

161. Wirth, C. T.; Zhang, C.; Zhong, G. F.; Hofmann, S.; Robertson, J. ACS Nano 2009, 3, 3560-3566. doi:10.1021/nn900613e

162.Meshot, E. R.; Plata, D. L.; Tawfick, S.; Zhang, Y. Y.; Verploegen, E. A.; Hart, A. J. ACS Nano 2009, 3, 2477-2486. doi:10.1021/nn900446a

163.Louchev, O. A.; Laude, T.; Sato, Y.; Kanda, H. J. Chem. Phys. 2003, 118, 7622-7634. doi:10.1063/1.1562195

164.Zhu, L. B.; Xu, J. W.; Xiao, F.; Jiang, H. J.; Hess, D. W.; Wong, C. P. Carbon 2007, 45, 344-348. doi:10.1016/j.carbon.2006.09.014

165.Wood, R. F.; Pannala, S.; Wells, J. C.; Puretzky, A. A.; Geohegan, D. B. Phys. Rev. B 2007, 75, No. 235446. doi:10.1103/physrevb.75.235446

166. Vinten, P.; Lefebvre, J.; Finnie, P. Chem. Phys. Lett. 2009, 469, 293-297. doi:10.1016/j.cplett.2008.12.095

167. Yasuda, S.; Futaba, D. N.; Yamada, T.; Yumura, M.; Hata, K. Nano Lett. 2011, 11, 3617-3623. doi:10.1021/nl201416c

168.Chen, G. H.; Davis, R. C.; Kimura, H.; Sakurai, S.; Yumura, M.; Futaba, D. N.; Hata, K. Nanoscale 2015, 7, 8873-8878. doi:10.1039/C5NR01125F

169.Zhang, C.; Pisana, S.; Wirth, C. T.; Parvez, A.; Ducati, C.; Hofmann, S.; Robertson, J. Diamond Relat. Mater. 2008, 17, 1447-1451. doi:10.1016/j.diamond.2008.01.094

170.Li-Pook-Than, A.; Lefebvre, J.; Finnie, P. J. Phys. Chem. C 2010, 114, 11018-11025. doi:10.1021/jp912056x
171.Rao, R.; Pierce, N.; Liptak, D.; Hooper, D.; Sargent, G.; Semiatin, S. L.; Curtarolo, S.; Harutyunyan, A. R.; Maruyama, B. ACS Nano 2013, 7, 1100-1107. doi:10.1021/nn304064u

172.Zhu, L. B.; Hess, D. W.; Wong, C.-P. J. Phys. Chem. B 2006, 110, 5445-5449. doi:10.1021/jp060027q

173. Meshot, E. R.; Hart, A. J. Appl. Phys. Lett. 2008, 92, No. 113107. doi:10.1063/1.2889497

174.Pal, S. K.; Talapatra, S.; Kar, S.; Ci, L.; Vajtai, R.; Borca-Tasciuc, T.; Schadler, L. S.; Ajayan, P. M. Nanotechnology 2008, 19, No. 045610. doi:10.1088/0957-4484/19/04/045610

175.In, J. B.; Grigoropoulos, C. P.; Chernov, A. A.; Noy, A. ACS Nano 2011, 5, 9602-9610. doi:10.1021/nn2028715

176.Pirard, S. L.; Douven, S.; Bossuot, C.; Heyen, G.; Pirard, J.-P. Carbon 2007, 45, 1167-1175. doi:10.1016/j.carbon.2007.02.021

177.van de Burgt, Y.; Bellouard, Y.; Mandamparambil, R. Phys. Chem. Chem. Phys. 2014, 16, 5162-5173. doi:10.1039/c4cp00061g

178.Liu, K.; Jiang, K. L.; Feng, C.; Chen, Z.; Fan, S. S. Carbon 2005, 43, 2850-2856. doi:10.1016/j.carbon.2005.06.002

179.Hsieh, C.-T.; Lin, Y.-T.; Lin, J.-Y.; Wei, J.-L. Mater. Chem. Phys. 2009 114, 702-708. doi:10.1016/j.matchemphys.2008.10.034

180.Ni, L.; Kuroda, K.; Zhou, L.-P.; Kizuka, T.; Ohta, K.; Matsuishi, K.; Nakamura, J. Carbon 2006, 44, 2265-2272. doi:10.1016/j.carbon.2006.02.031

181.Baker, R. T. K. Carbon 1989, 27, 315-323. doi:10.1016/0008-6223(89)90062-6

182.Choi, Y. C.; Shin, Y. M.; Lee, Y. H.; Lee, B. S.; Park, G.-S.; Choi, W. B.; Lee, N. S.; Kim, J. M. Appl. Phys. Lett. 2000, 76, 2367-2369. doi:10.1063/1.126348

183.Chiang, W.-H.; Sankaran, R. M. Diamond Relat. Mater. 2009, 18, 946-952. doi:10.1016/j.diamond.2009.01.010

184.Patole, S. P.; Kim, H.; Choi, J.; Kim, Y.; Baik, S.; Yoo, J. B. Appl. Phys. Lett. 2010, 96, No. 094101. doi:10.1063/1.3330848

185. Cervantes-Sodi, F.; McNicholas, T. P.; Simmons, J. G., Jr.; Liu, J.; Csányi, G.; Ferrari, A. C.; Curtarolo, S. ACS Nano 2010, 4, 6950-6956. doi:10.1021/nn101883s

186. Huang, Z. P.; Wang, D. Z.; Wen, J. G.; Sennett, M.; Gibson, H.; Ren, Z. F. Appl. Phys. A 2002, 74, 387-391. doi:10.1007/s003390101186

187.Kim, N. S.; Lee, Y. T.; Park, J.; Han, J. B.; Choi, Y. S.; Choi, S. Y.; Choo, J.; Lee, G. H. J. Phys. Chem. B 2003, 107, 9249-9255. doi:10.1021/jp034895o

188.Kim, N. S.; Lee, Y. T.; Park, J. H.; Ryu, H.; Lee, H. J.; Choi, S. Y.; Choo, J. B. J. Phys. Chem. B 2002, 106, 9286-9290. doi:10.1021/jp021018u

189. Gorbunov, A.; Jost, O.; Pompe, W.; Graff, A. Carbon 2002, 40, 113-118. doi:10.1016/S0008-6223(01)00080-X

190. Hofmann, S.; Ducati, C.; Robertson, J.; Kleinsorge, B. Appl. Phys. Lett. 2003, 83, 135-137. doi:10.1063/1.1589187

191.Lee, Y. T.; Kim, N. S.; Park, J.; Han, J. B.; Choi, Y. S.; Ryu, H.; Lee, H. J. Chem. Phys. Lett. 2003, 372, 853-859. doi:10.1016/S0009-2614(03)00529-3

192.Bartsch, K.; Biedermann, K.; Gemming, T.; Leonhardt, A. J. Appl. Phys. 2005, 97, No. 114301. doi:10.1063/1.1922067

193.Kim, K.-E.; Kim, K.-J.; Jung, W. S.; Bae, S. Y.; Park, J.; Choi, J.; Choo, J. Chem. Phys. Lett. 2005, 401, 459-464. doi:10.1016/j.cplett.2004.11.113

194. Kim, S. H.; Zachariah, M. R. J. Phys. Chem. B 2006, 110, 4555-4562. doi:10.1021/jp0541718 
195. Bronikowski, M. J. J. Phys. Chem. C 2007, 111, 17705-17712. doi:10.1021/jp071079y

196. Chiang, W.-H.; Sankaran, R. M. Appl. Phys. Lett. 2007, 91 , No. 121503. doi:10.1063/1.2786835

197.Nessim, G. D.; Seita, M.; O'Brien, K. P.; Hart, A. J.; Bonaparte, R. K.; Mitchell, R. R.; Thompson, C. V. Nano Lett. 2009, 9, 3398-3405. doi:10.1021/nl900675d

198. Hsieh, C.-T.; Lin, Y.-T.; Chen, W.-Y.; Wei, J.-L. Powder Technol. 2009, 192, 16-22. doi:10.1016/j.powtec.2008.11.004

199. Voelskow, K.; Becker, M. J.; Xia, W.; Muhler, M.; Turek, T. Chem. Eng. J. 2014, 244, 68-74. doi:10.1016/j.cej.2014.01.024

200.Lee, Y. T.; Park, J.; Choi, Y. S.; Ryu, H.; Lee, H. J. J. Phys. Chem. B 2002, 106, 7614-7618. doi:10.1021/jp020488I

201.Lee, Y. T.; Kim, N. S.; Bae, S. Y.; Park, J.; Yu, S.-C.; Ryu, H.; Lee, H. J. J. Phys. Chem. B 2003, 107, 12958-12963. doi:10.1021/jp0274536

202.Chen, M.; Chen, C.-M.; Shi, S.-C.; Chen, C.-F. Jpn. J. Appl. Phys. 2003, 42, 614-619. doi:10.1143/JJAP.42.614

203. Chhowalla, M.; Teo, K. B. K.; Ducati, C.; Rupesinghe, N. L.; Amaratunga, G. A. J.; Ferrari, A. C.; Roy, D.; Robertson, J.; Milne, W. I. J. Appl. Phys. 2001, 90, 5308-5317. doi:10.1063/1.1410322

204.Ducati, C.; Alexandrou, I.; Chhowalla, M.; Amaratunga, G. A. J.; Robertson, J. J. Appl. Phys. 2002, 92, 3299-3303. doi:10.1063/1.1499746

205.Ma, H.; Pan, L. J.; Nakayama, Y. Carbon 2011, 49, 854-861. doi:10.1016/j.carbon.2010.10.029

206. Somorjai, G. A. Introduction to surface chemistry and catalysis; Wiley: New York, USA, 1994

207. Haruta, M.; Yamada, N.; Kobayashi, T.; lijima, S. J. Catal. 1989, 115, 301-309. doi:10.1016/0021-9517(89)90034-1

208. Tsunoyama, H.; Sakurai, H.; Tsukuda, T. Chem. Phys. Lett. 2006, 429, 528-532. doi:10.1016/j.cplett.2006.08.066

209. Henry, C. R. Surf. Sci. Rep. 1998, 31, 235-325. doi:10.1016/S0167-5729(98)00002-8

210.Kataura, H.; Kumazawa, Y.; Maniwa, Y.; Ohtsuka, Y.; Sen, R.; Suzuki, S.; Achiba, Y. Carbon 2000, 38, 1691-1697. doi:10.1016/S0008-6223(00)00090-7

211.Page, A. J.; Minami, S.; Ohta, Y.; Irle, S.; Morokuma, K. Carbon 2010, 48, 3014-3026. doi:10.1016/j.carbon.2010.04.001

212.Baker, R. T. K.; Chludzinski, J. J., Jr.; Dudash, N. S.; Simoens, A. J. Carbon 1983, 21, 463-468. doi:10.1016/0008-6223(83)90138-0

213.Baker, R. T. K.; Chludzinski, J. J., Jr.; Lund, C. R. F. Carbon 1987, 25 , 295-303. doi:10.1016/0008-6223(87)90129-1

214.Chorkendorff, I.; Niemantsverdriet, J. W. Concepts of Modern Catalysis and Kinetics, 2nd ed.; Wiley-VCH: Weinheim, Germany, 2007. doi: $10.1002 / 3527602658$

215.Diamond, S.; Wert, C. Trans. Metall. Soc. AIME 1967, 239, 705.

216. Morgan, D. W.; Kitchener, J. A. Trans. Faraday Soc. 1954, 50, 51-60. doi:10.1039/TF9545000051

217. Grace, R. E.; Derge, G. Trans. Am. Inst. Min., Metall. Pet. Eng. 1958, 212, 331-337.

218.Kovenskiy, I. I. Phys. Met. Metallogr. 1963, 16, 107.

219.Schmidt, F. A.; Warner, J. C. J. Less-Common Met. 1972, 26 , 325-326. doi:10.1016/0022-5088(72)90055-0

220.Rudman, P. S. Trans. Metall. Soc. AIME 1967, 239, 1949.

221.Wells, C.; Batz, W.; Mehl, R. F.

Trans. Am. Inst. Min., Metall. Pet. Eng. 1950, 188, 553-560.

222.Smith, R. P. Trans. Metall. Soc. AIME 1964, 230, 476.
223. Mojica, J. F.; Levenson, L. L. Surf. Sci. 1976, 59, 447-460. doi:10.1016/0039-6028(76)90028-5

224.Brandes, E. A.; Brook, G. B., Eds. Smithells' Metals Reference Book, 7th ed.; Butterworth-Heinemann Ltd: London, UK, 1992. doi:10.1016/c2009-0-25363-3

225. Silcocks, C. G. Proc. R. Soc. London, Ser. A 1957, 242, 411-429. doi:10.1098/rspa.1957.0185

226.Palmer, H. B.; Dormish, F. L. J. Phys. Chem. 1964, 68, 1553-1560. doi:10.1021/j100788a049

227.Zhang, Y.; Smith, K. J. Catal. Today 2002, 77, 257-268. doi:10.1016/S0920-5861(02)00251-1

228. Li, J.; Kazakov, A.; Dryer, F. L. J. Phys. Chem. A 2004, 108 , 7671-7680. doi:10.1021/jp0480302

229.Zhong, G. F.; Iwasaki, T.; Robertson, J.; Kawarada, H. J. Phys. Chem. B 2007, 111, 1907-1910. doi:10.1021/jp067776s

230.Amama, P. B.; Pint, C. L.; McJilton, L.; Kim, S. M.; Stach, E. A.; Murray, P. T.; Hauge, R. H.; Maruyama, B. Nano Lett. 2009, 9, 44-49. doi:10.1021/nl801876h

231.Ding, F.; Xu, Z. W.; Yakobson, B. I.; Young, R. J.; Kinloch, I. A.; Cui, S. A.; Deng, L. B.; Puech, P.; Monthioux, M. Phys. Rev. B 2010, 82, No. 041403. doi:10.1103/physrevb.82.041403

232.Liu, X. J.; Kuzmany, H.; Saito, T.; Pichler, T. Phys. Status Solidi B 2011, 248, 2492-2495. doi:10.1002/pssb.201100116

233.Briones, A.; Liu, X. J.; Kramberger, C.; Saito, T.; Pichler, T. Phys. Status Solidi B 2011, 248, 2488-2491. doi:10.1002/pssb.201100114

234. Kharlamova, M. V.; Sauer, M.; Saito, T.; Krause, S.; Liu, X.; Yanagi, K.; Pichler, T.; Shiozawa, H. Phys. Status Solidi B 2013, 250 , 2575-2580. doi:10.1002/pssb.201300089

235.Kharlamova, M. V.; Sauer, M.; Egorov, A.; Kramberger, C.; Saito, T.; Pichler, T.; Shiozawa, H. Phys. Status Solidi B 2015, 252, 2485-2490. doi:10.1002/pssb.201552206

\section{License and Terms}

This is an Open Access article under the terms of the Creative Commons Attribution License (http://creativecommons.org/licenses/by/4.0), which permits unrestricted use, distribution, and reproduction in any medium, provided the original work is properly cited.

The license is subject to the Beilstein Journal of Nanotechnology terms and conditions: (http://www.beilstein-journals.org/bjnano)

The definitive version of this article is the electronic one which can be found at: doi:10.3762/bjnano.8.85 